\title{
Household size and composition in the developing world [Arabic]
}

John Bongaarts

Population Council

Follow this and additional works at: https://knowledgecommons.popcouncil.org/departments_sbsr-pgy

Part of the Demography, Population, and Ecology Commons, Family, Life Course, and Society Commons, and the International Public Health Commons How does access to this work benefit you? Let us know!

\section{Recommended Citation}

Bongaarts, John. 2001. "Household size and composition in the developing world," Policy Research Division Working Paper no. 144 [Arabic]. New York: Population Council. Version of record: https://doi.org/ $10.1080 / 00324720127697$ 


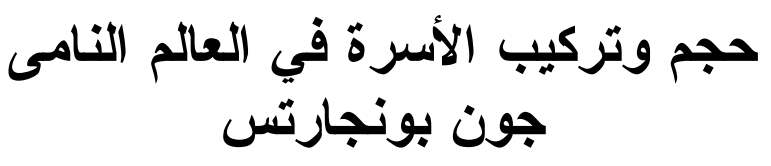

جون بونجارتس هو نائب رئيس قسم بحوث السياسات بمجلس السكان.

يتقدم المؤلف بالثكر والتقدير لكل من توماس ك. بورش (Thomas K. Burch) وسينثيا

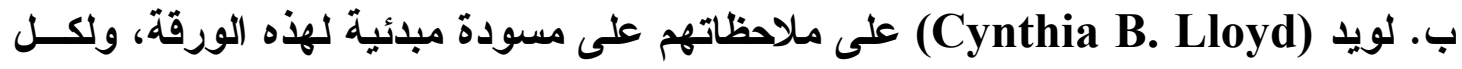

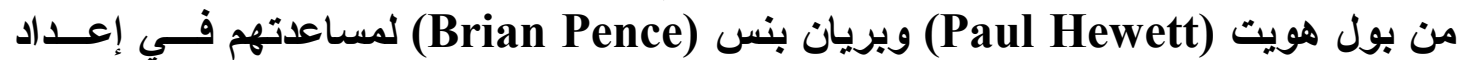

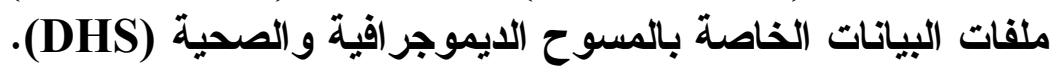




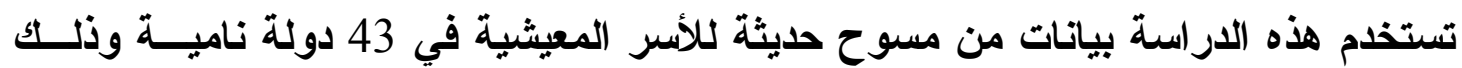

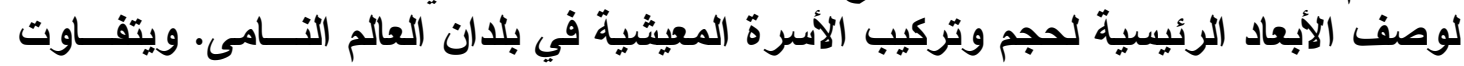

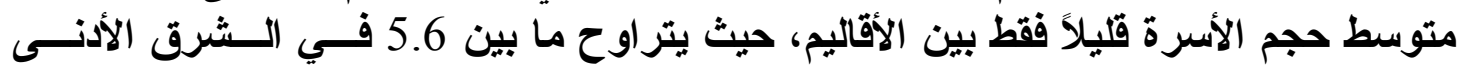

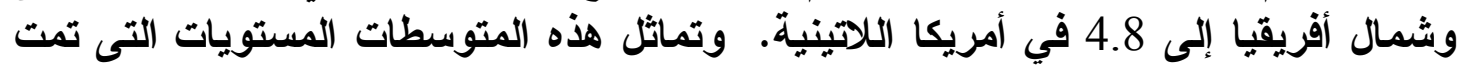

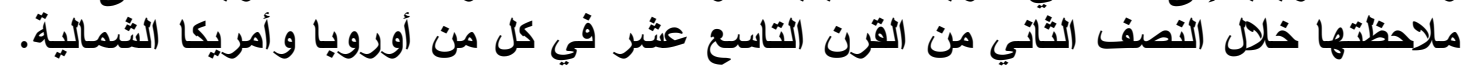

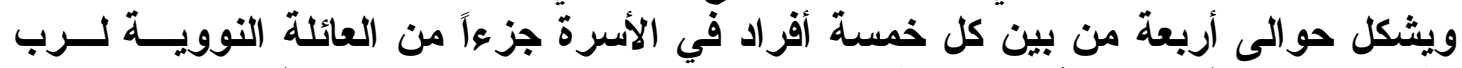

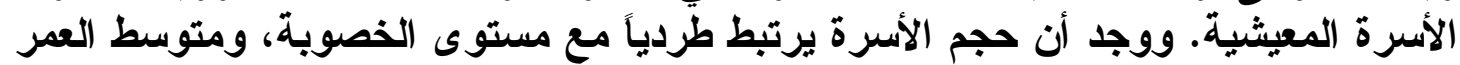

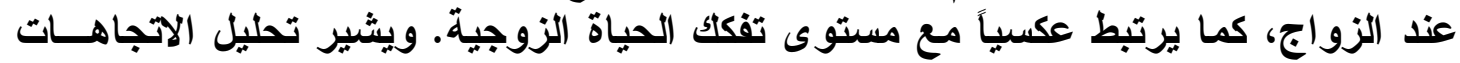

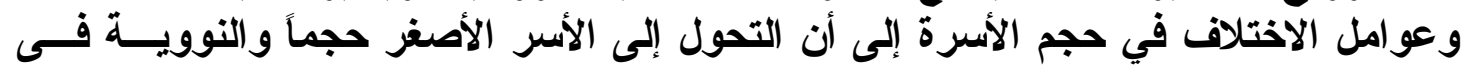
الغالب يسير بيطء في الاول النامية المعاصرة.

غير مسموح بإعادة طبع أو نسخ هذه المادة إلا بعد الحصول علـى موافقــة كتابيــة مـنـ المؤلف. 
العائلة والأسرة هما أكثر المؤسسات الاجتماعية والاقتصادية أولية في المجتمع الإحسـساني.

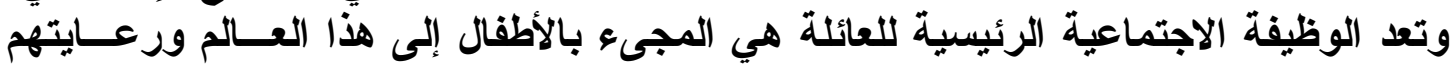

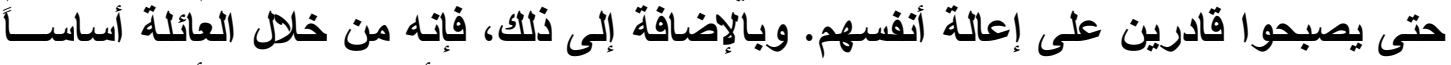

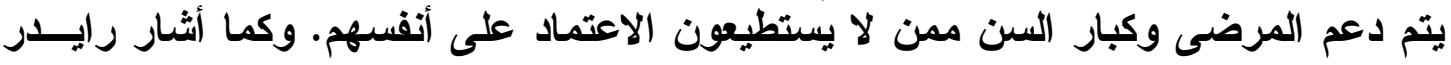
1977 (Ryder) 197

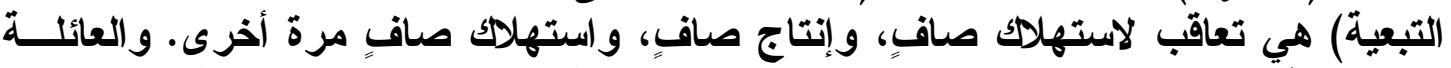

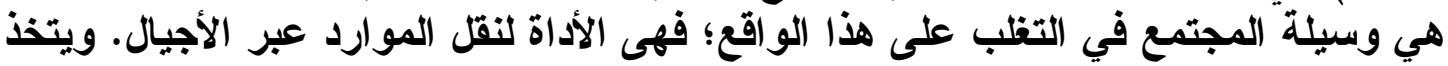

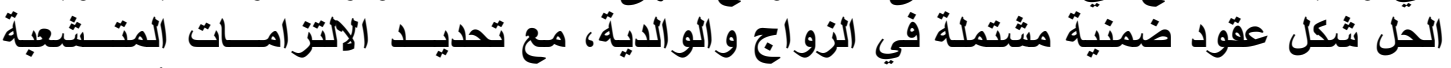

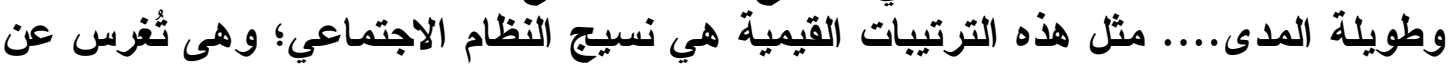

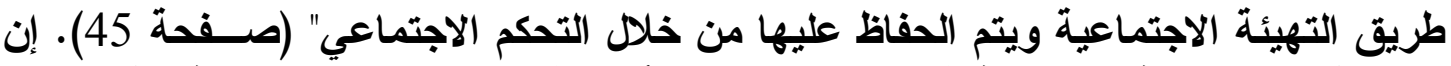

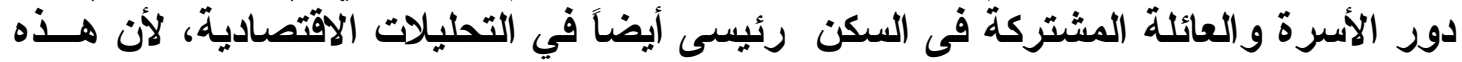

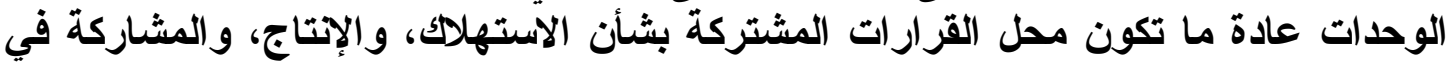

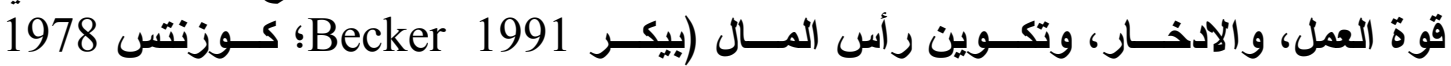
.(Kuznets

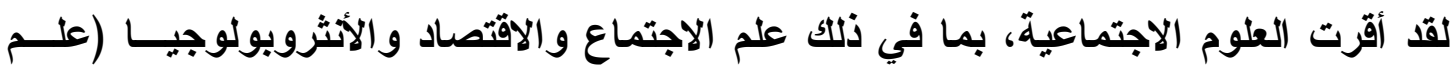

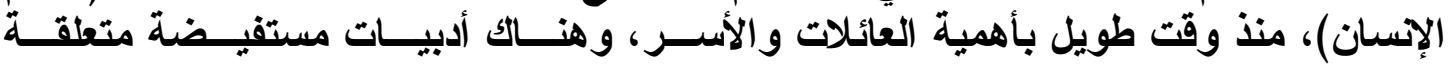

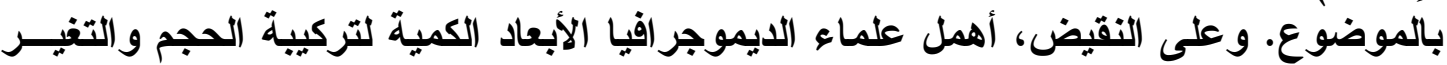

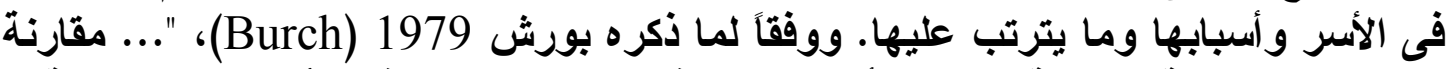

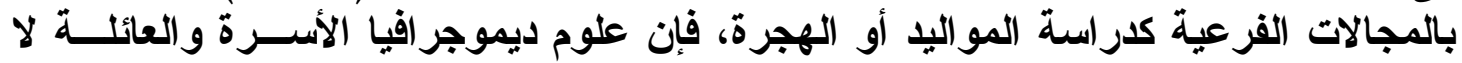

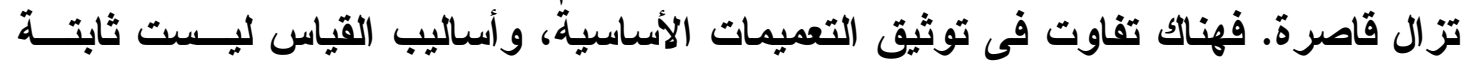

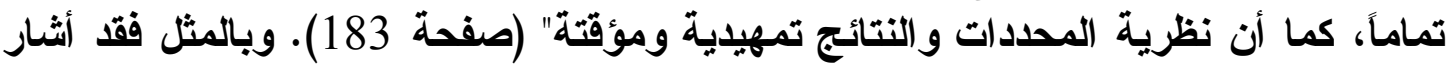

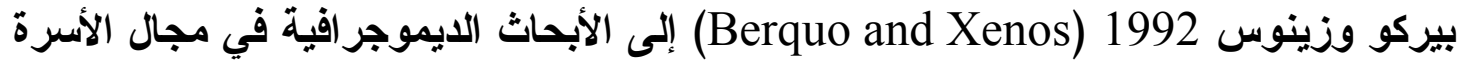

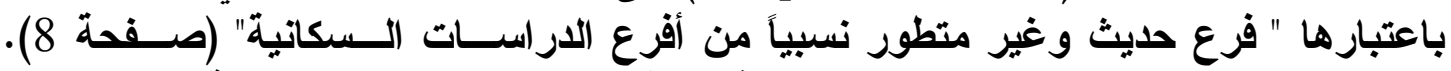

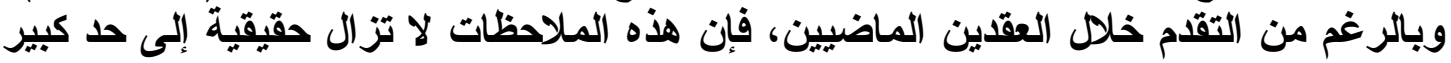

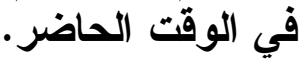

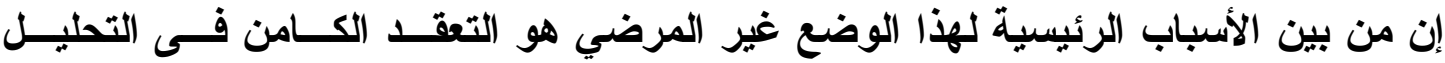

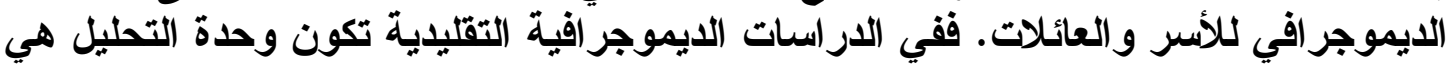

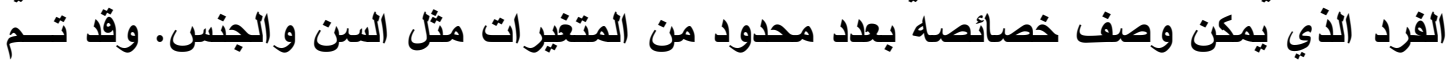

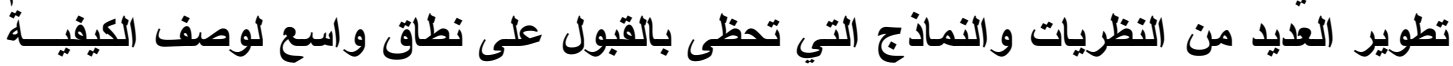

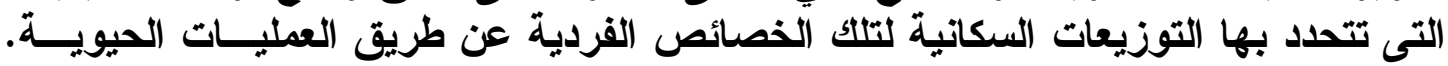

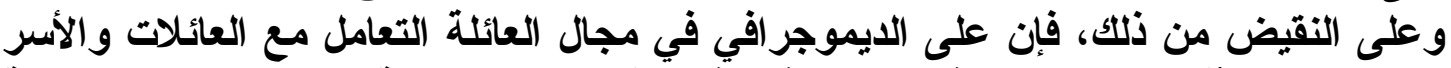

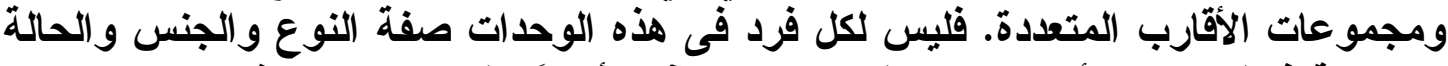

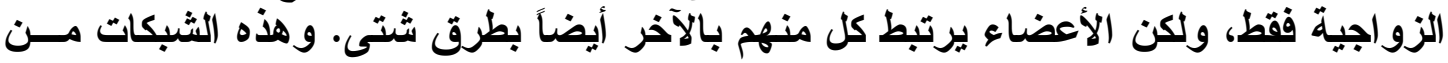

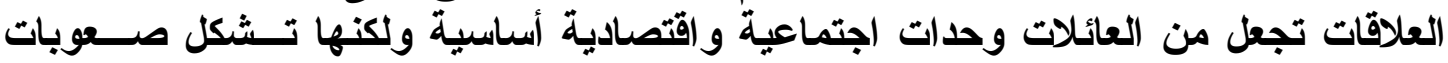




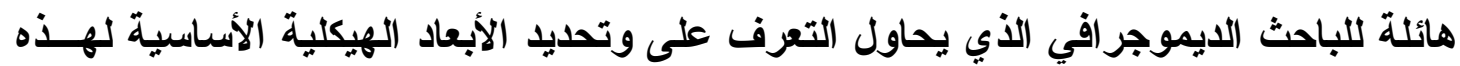

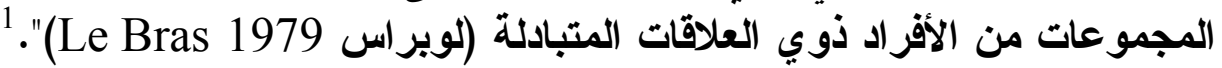

إن مصطلحي الأسرة (Household) و العائلة (Family) لا يستخدمان باتساق في الأدبيات.

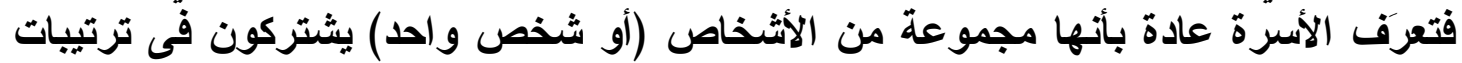

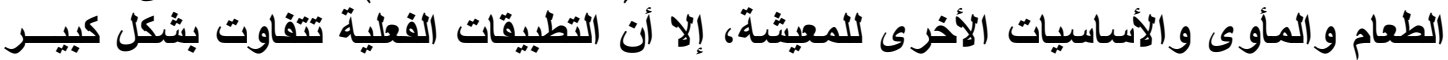

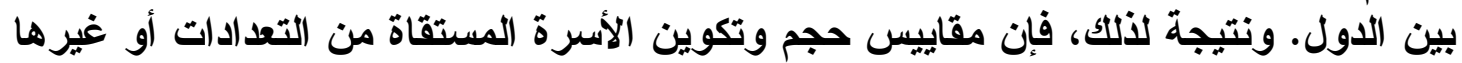

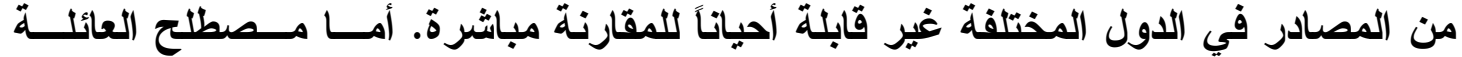

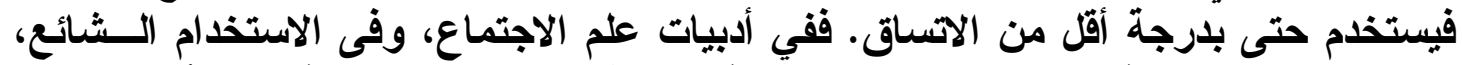

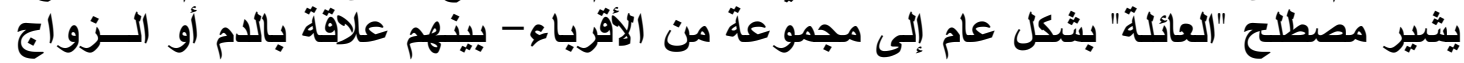

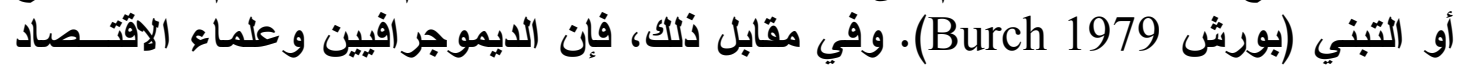

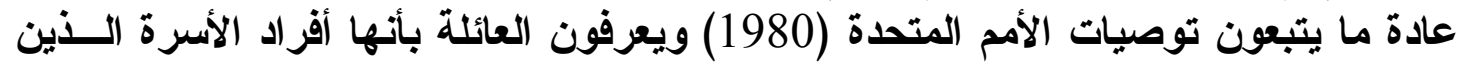

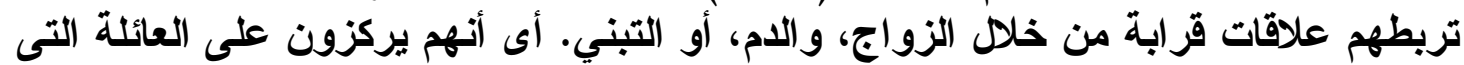

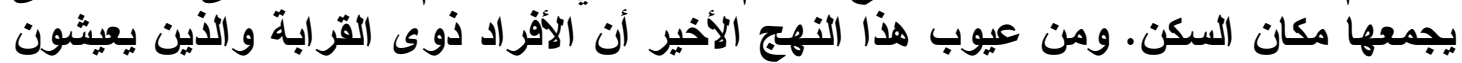

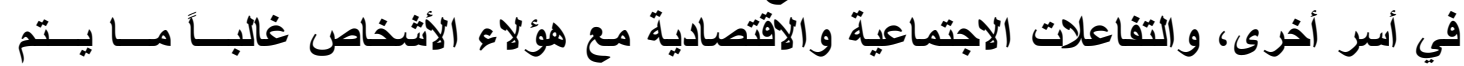

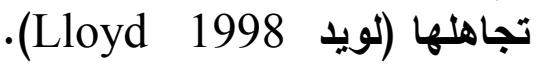

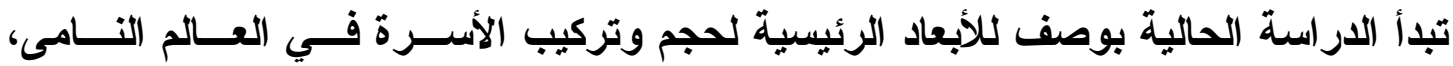

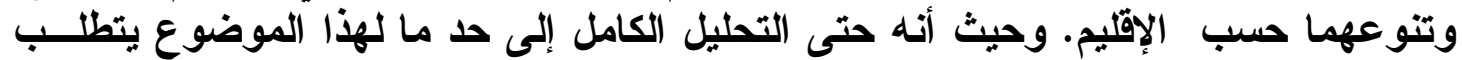

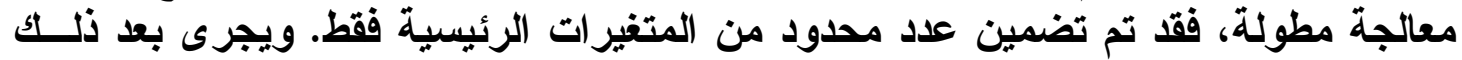

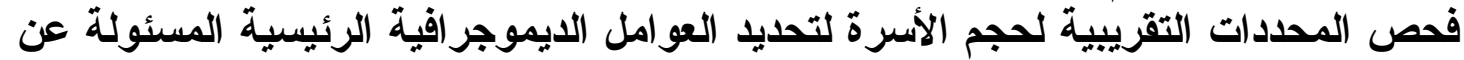

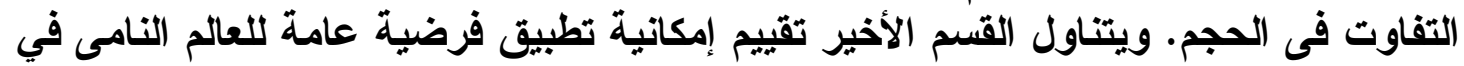

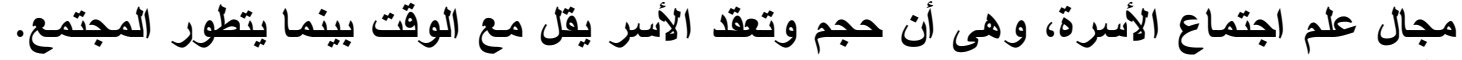

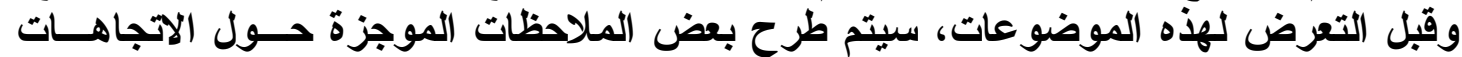

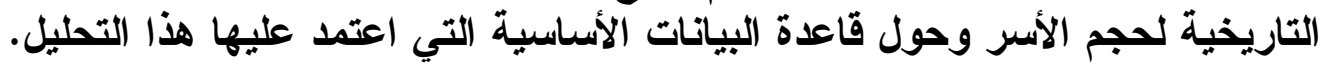

\section{الاتجاهات التاريخية في حجم الأسرة:}

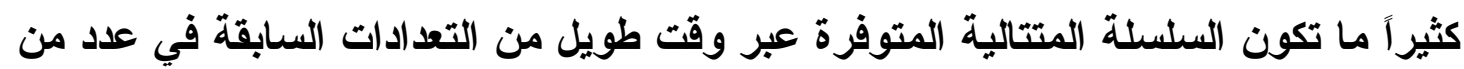

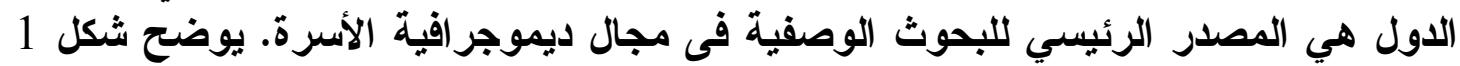

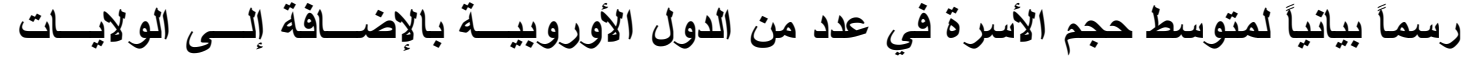

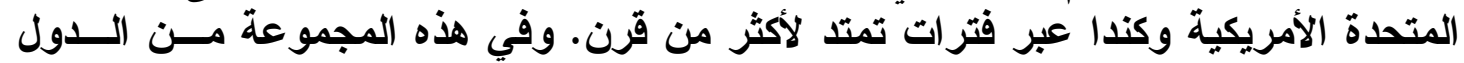

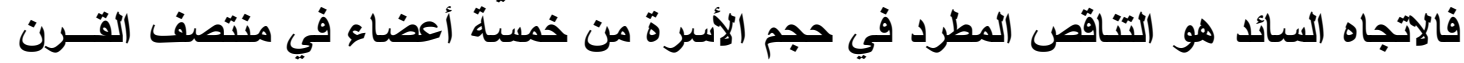

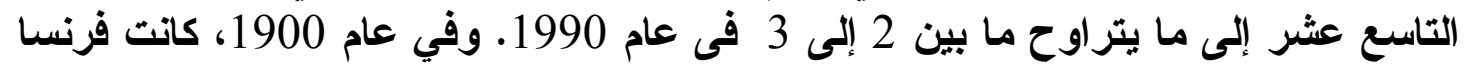

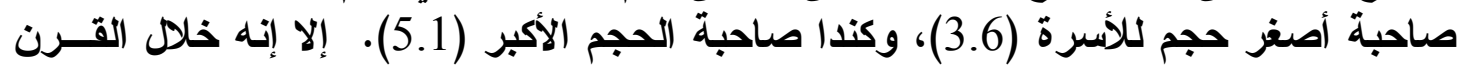

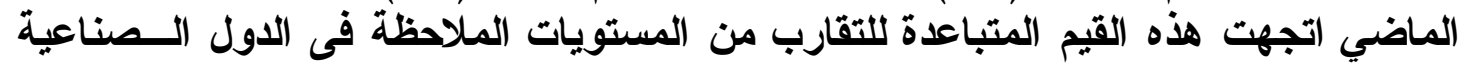

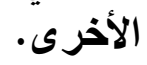




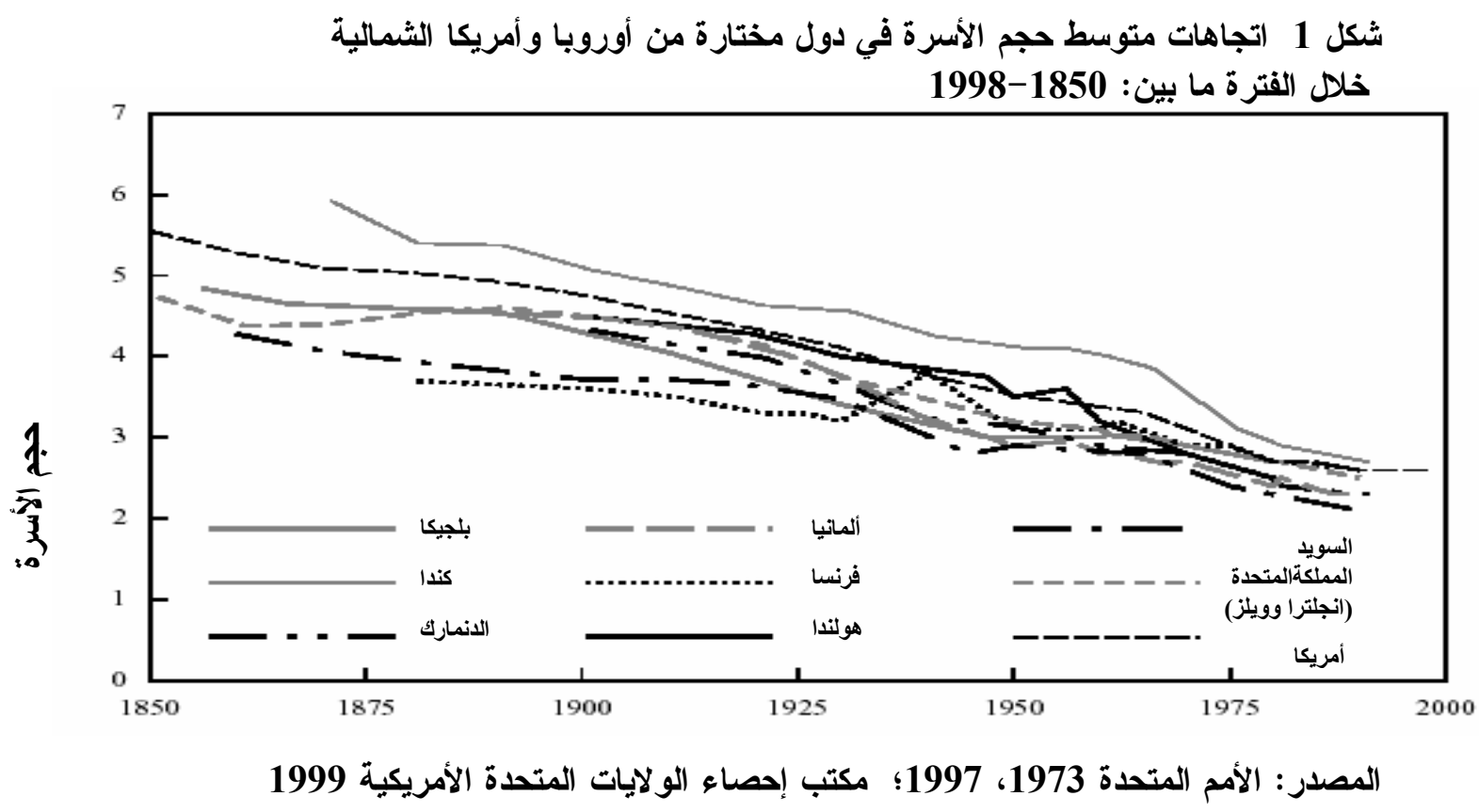

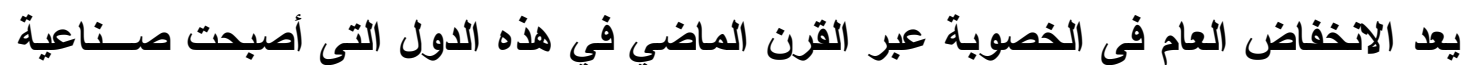

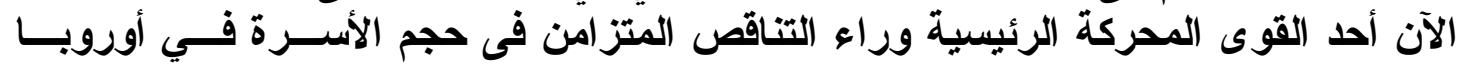

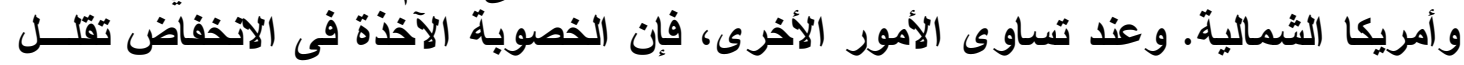

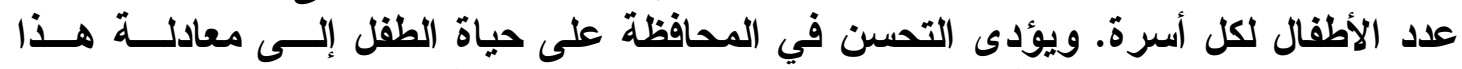

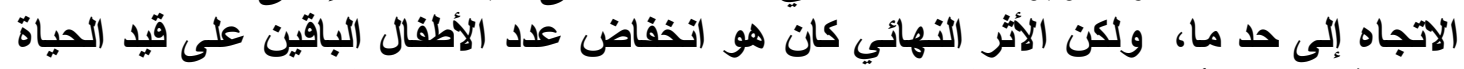

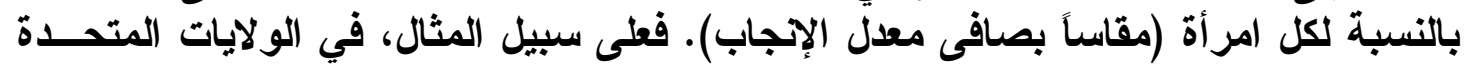

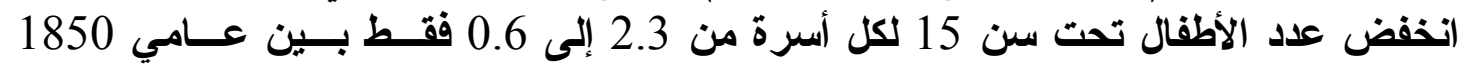

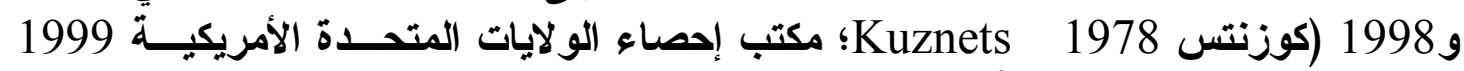
2.(U.S. Census Bureau

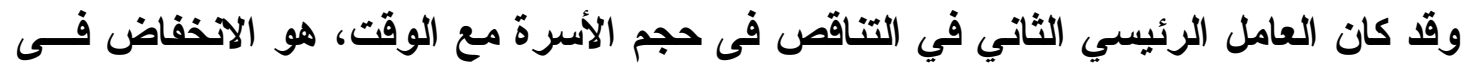

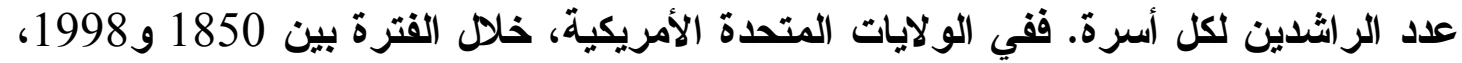

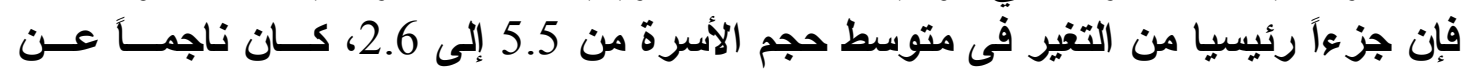

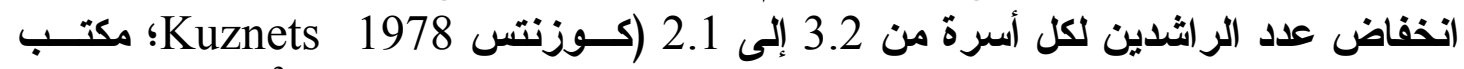

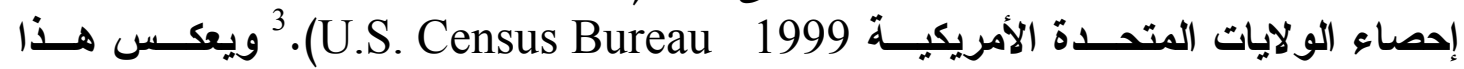

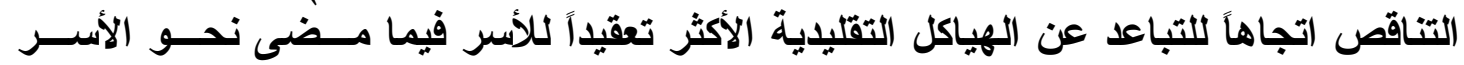

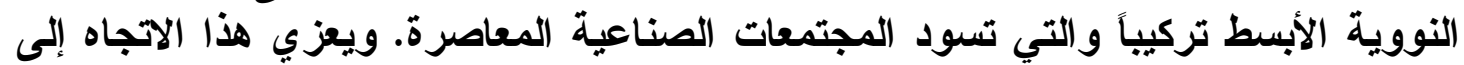

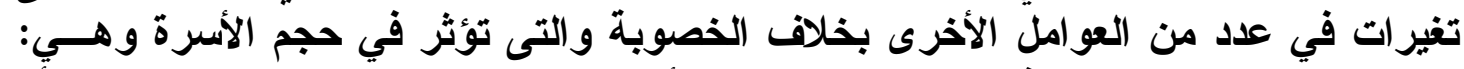

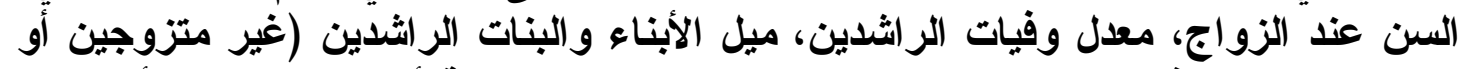

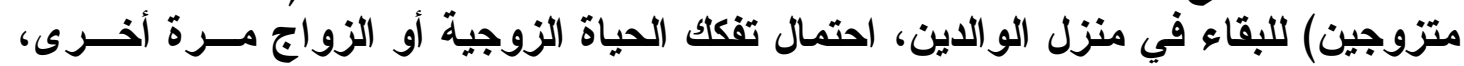

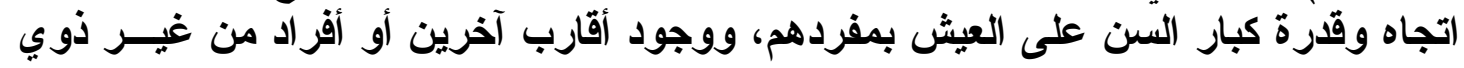




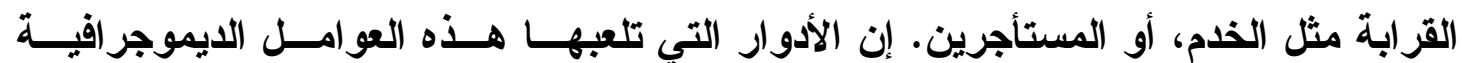

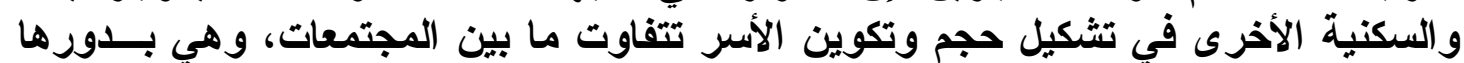

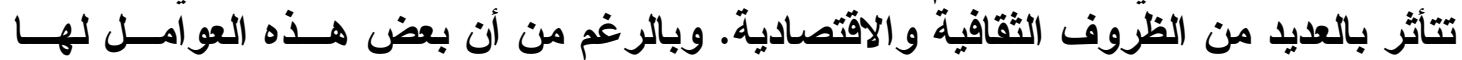

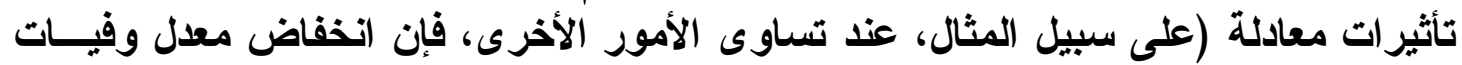

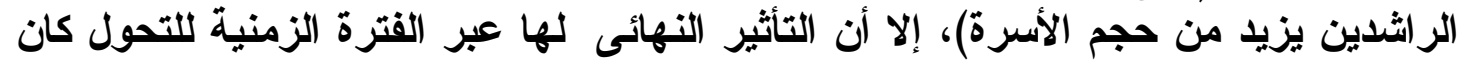

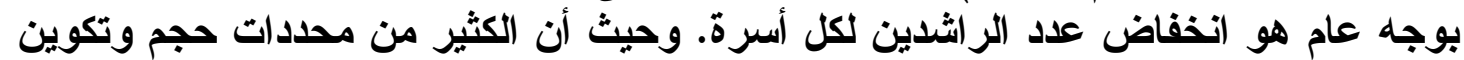

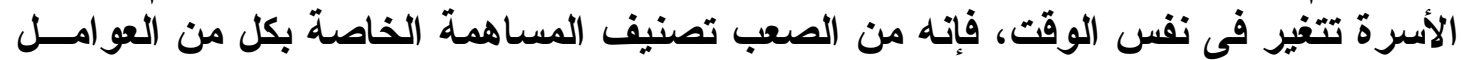

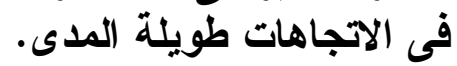

(البيانات

تستخدم هذه الاراسة بيانات من مسوح الأسر التى أجريت في 43 دولة شاركت في برنامج

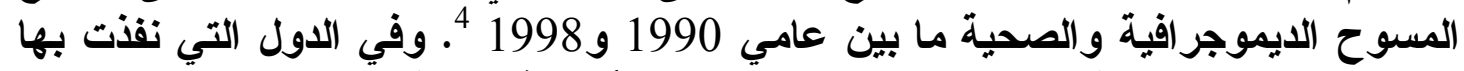

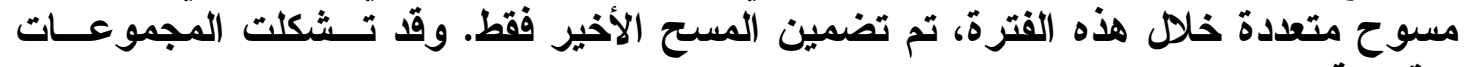
الإقليمية للاول على النحو التالي:

آسيا: بنجلاديش، الهند، إندونيسيا، كازاخستان، قيرجستان، نيبـال، باكسـتان، الفلبـين، أوزبكستان أمريكا اللاتينية: بوليفيا، البرازيل، كولومبيا، جمهورية الــدومينكان، جواتيمسـالا، هـايتي،

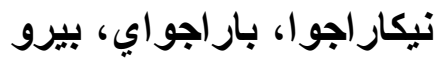

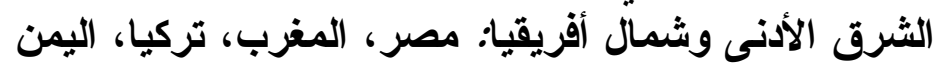

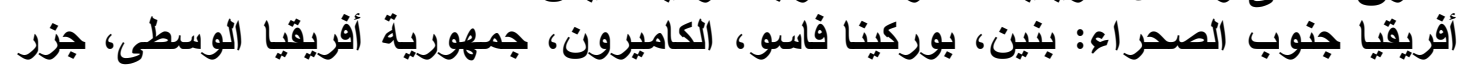

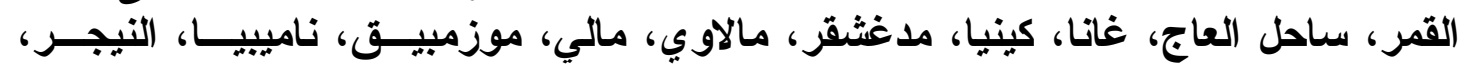

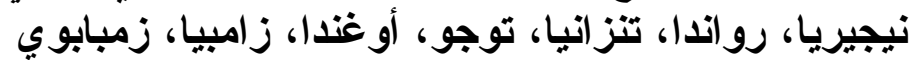

يتمثل الهدف الرئيسي من المستح الايموجرافي والصحي للأسر في تحديد النساء في ســن

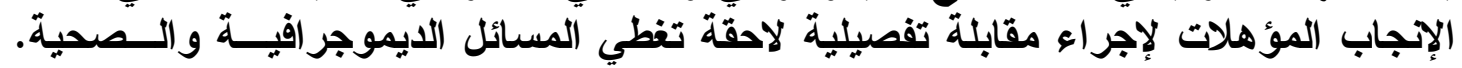

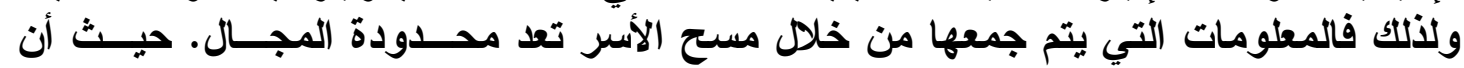

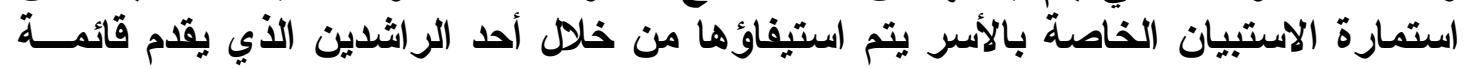

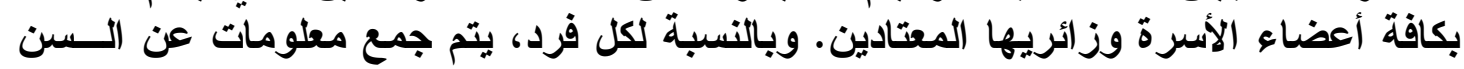

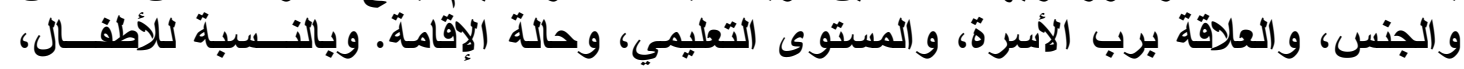

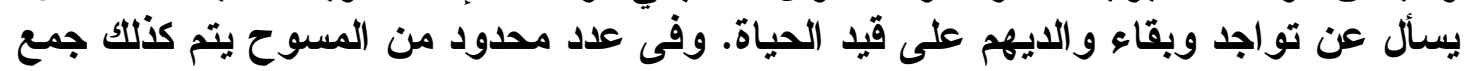

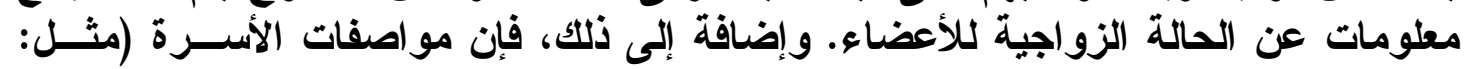

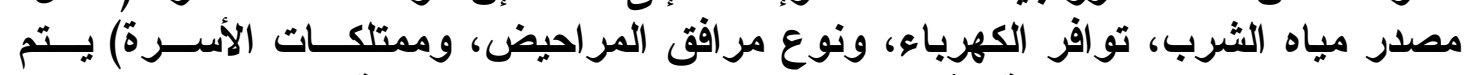

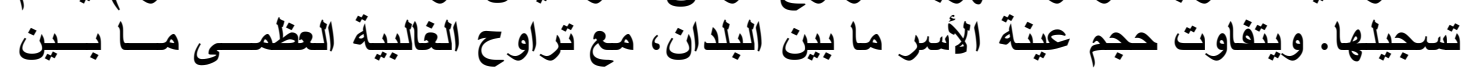

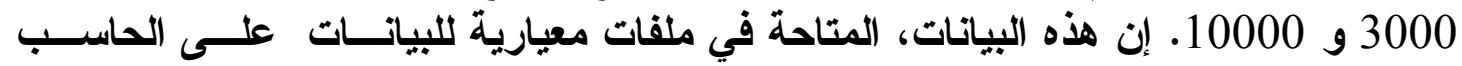

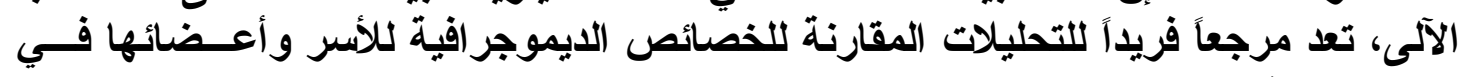

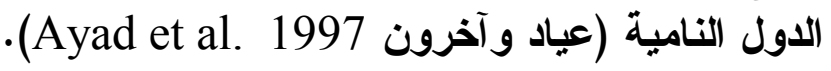

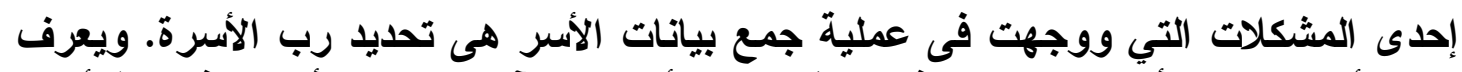

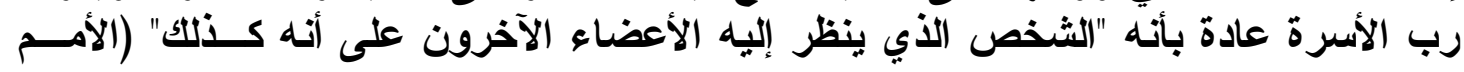

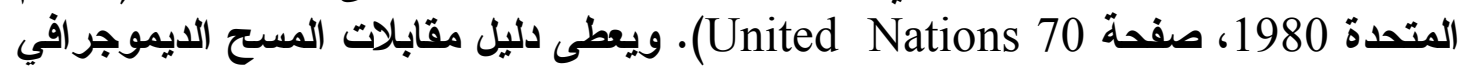




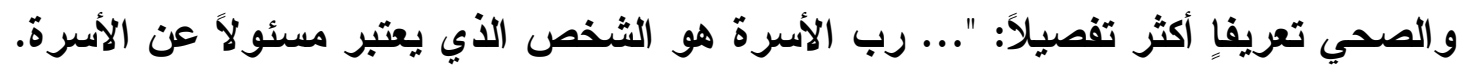

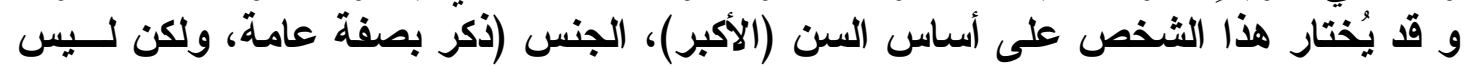

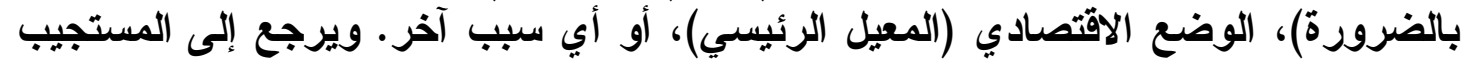

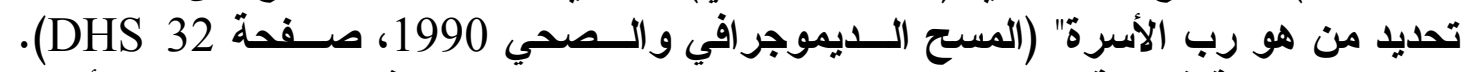

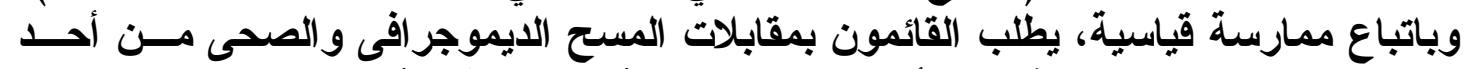

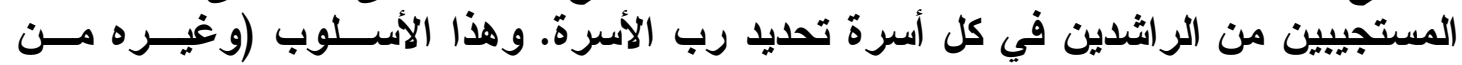

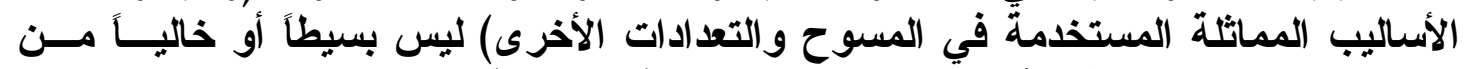

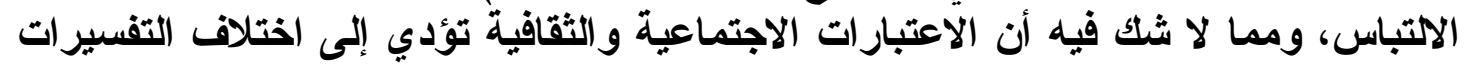

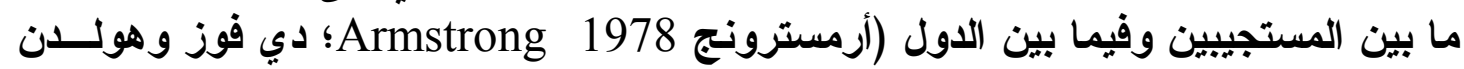

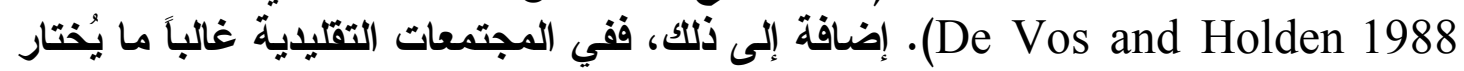

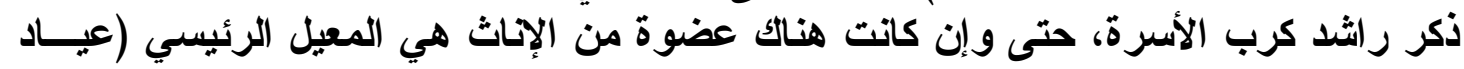

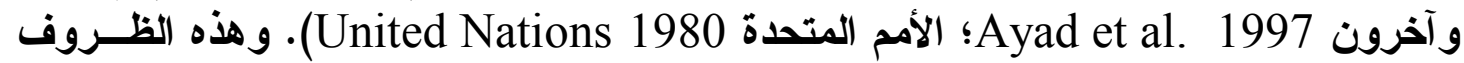

من المحتم أن تعقد عملية تحليل التركيبة الأسرية.

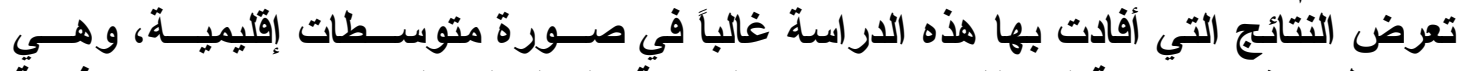

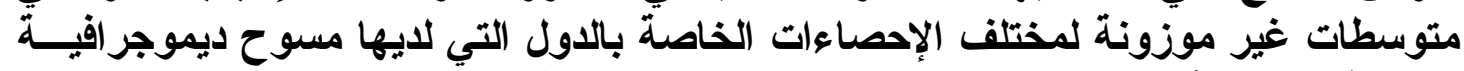

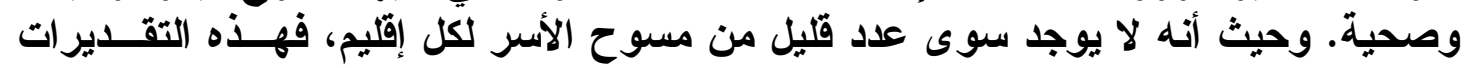

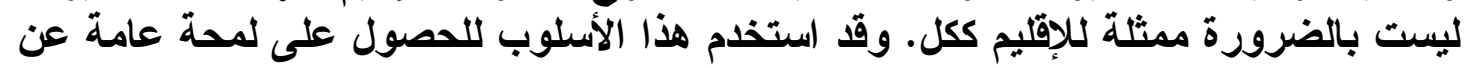

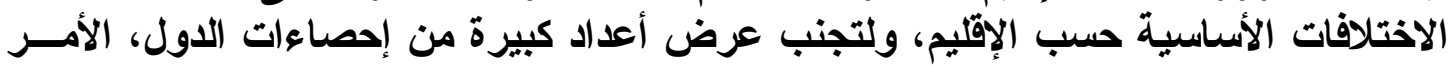
الأي قد يجعل من الصعب تحديد الأماط العامة ذات الأب الأهمية.

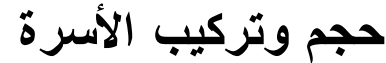

الحجم الجمبر

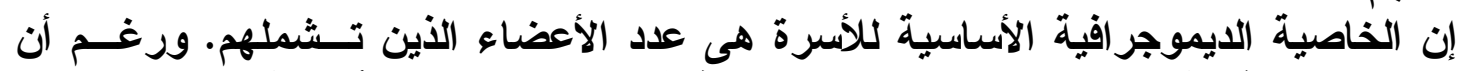

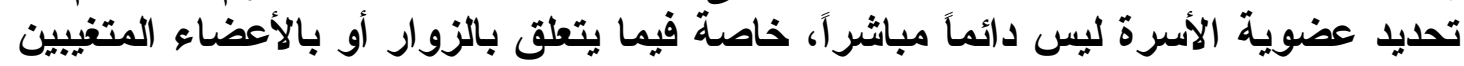

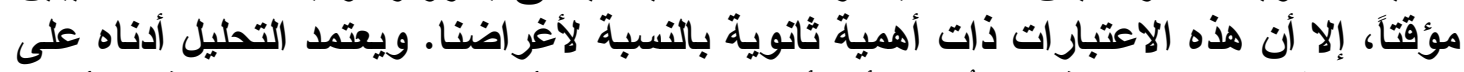

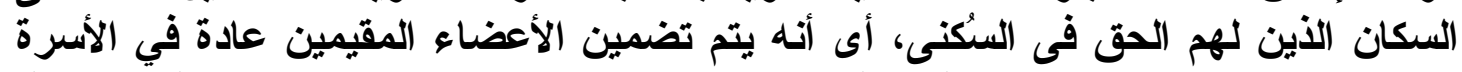

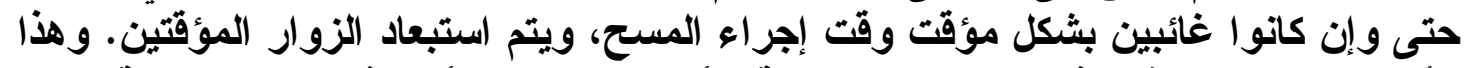

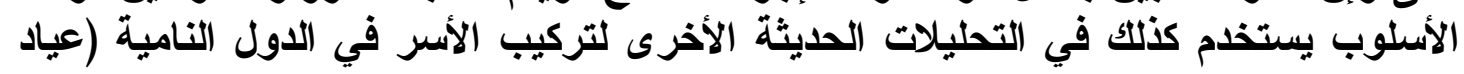

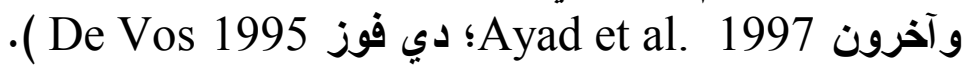

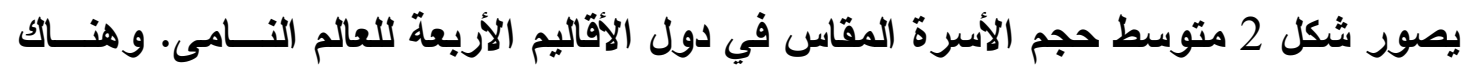

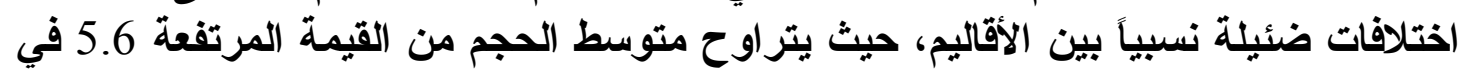

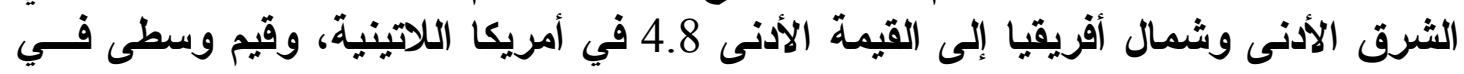

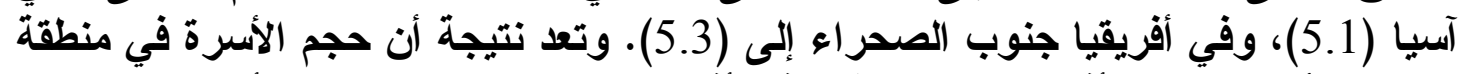

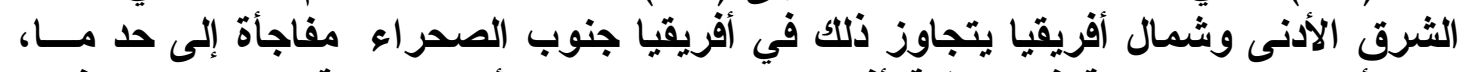

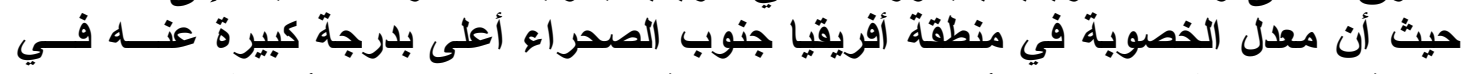

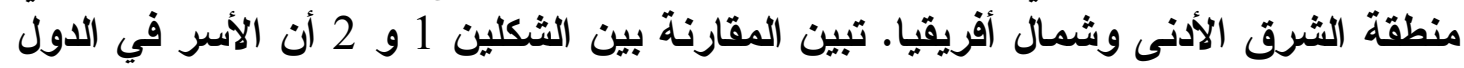

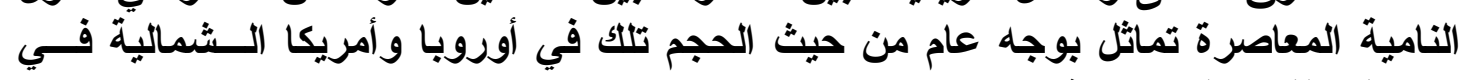
منتصف القرن التاسع عشر. 


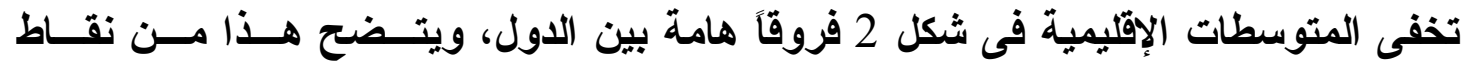

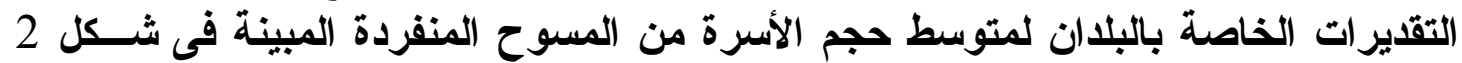

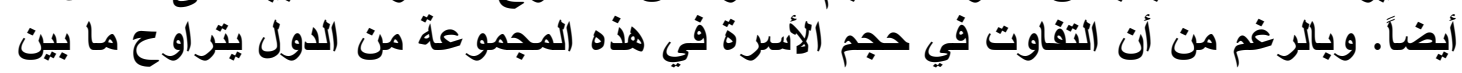

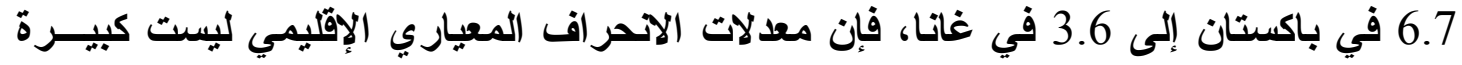

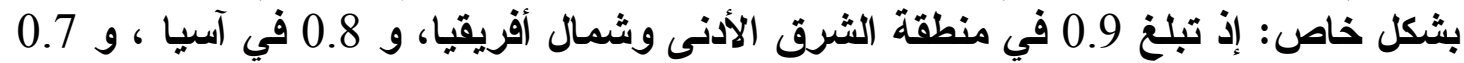

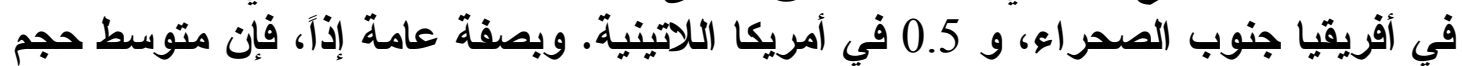

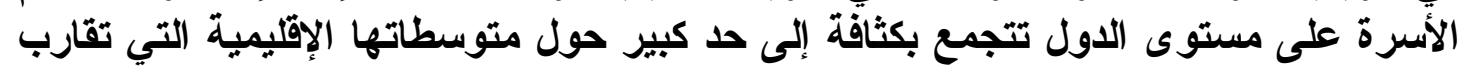

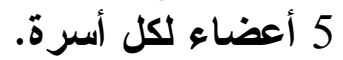

شكل 2 متوسط حجم الأسرة حسب الإقليم والدول داخل الإقليم

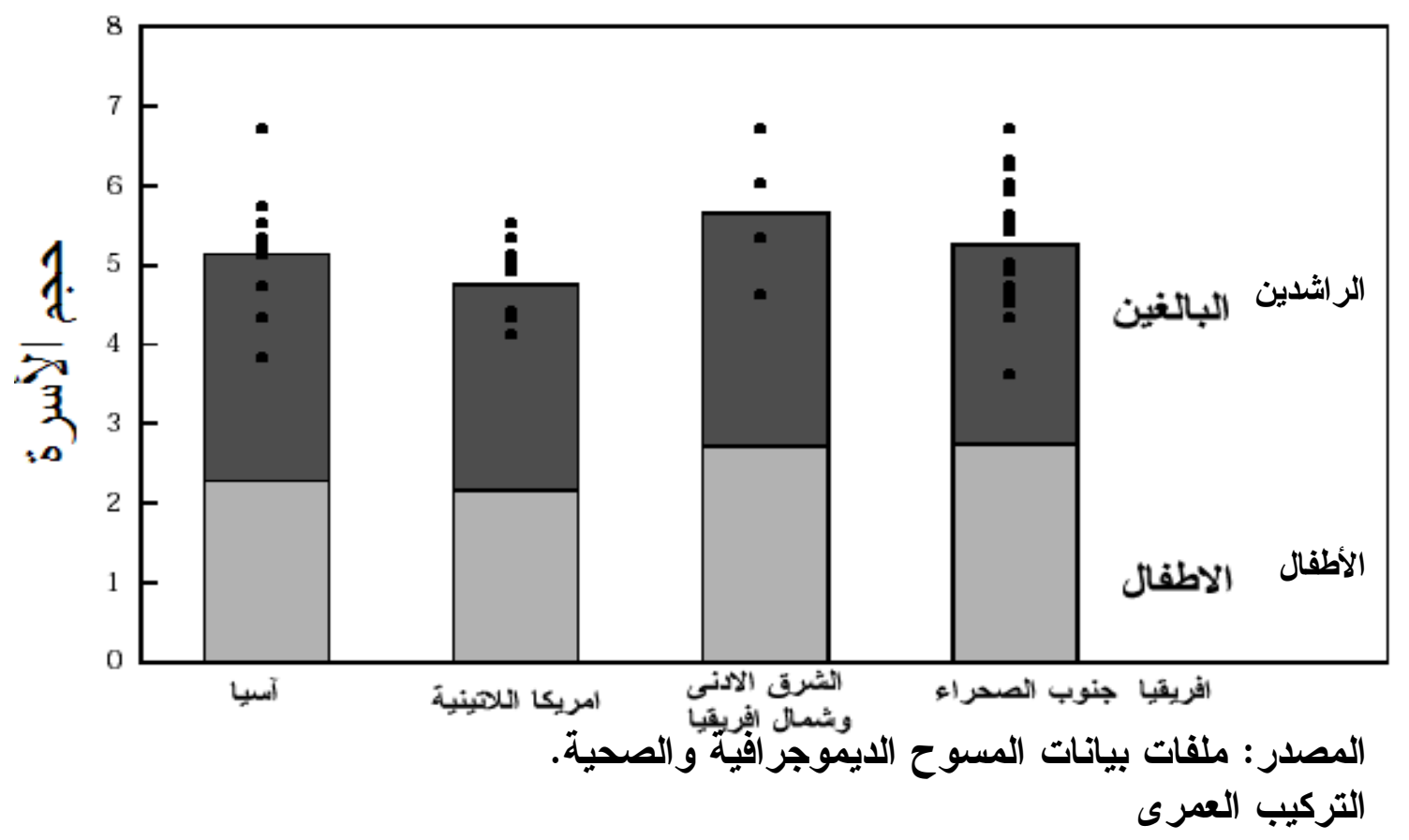

كخطوة أولى فى تحليل تركيب الأسر نقوم بحساب متوسط عدد الراشدين (18 سنة فــأكثر)

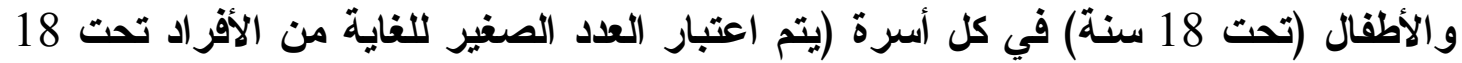

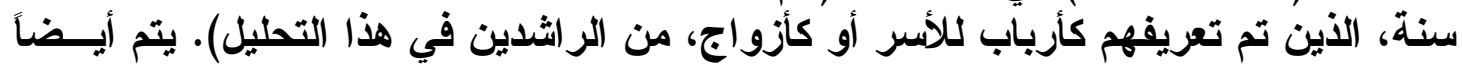

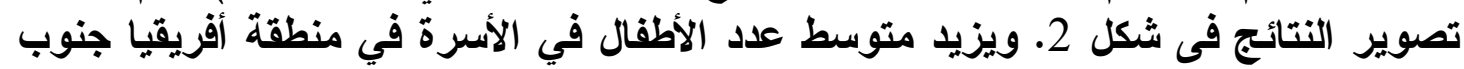

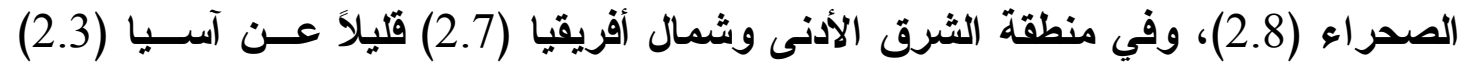

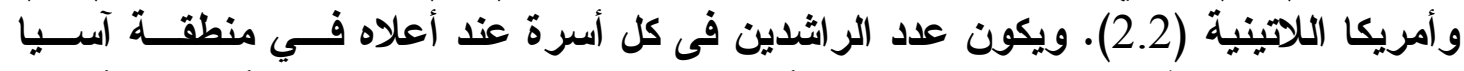

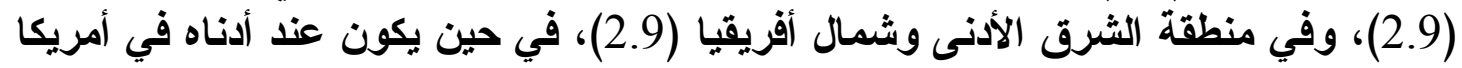

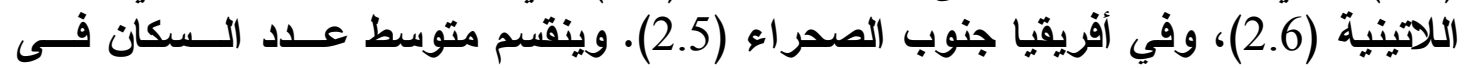

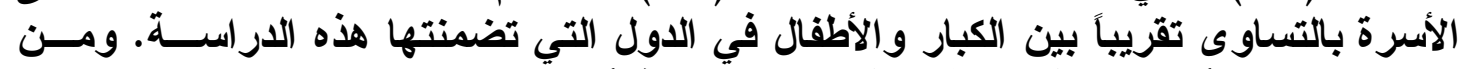

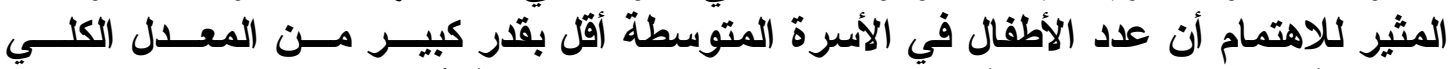

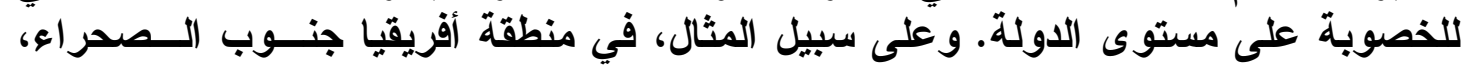

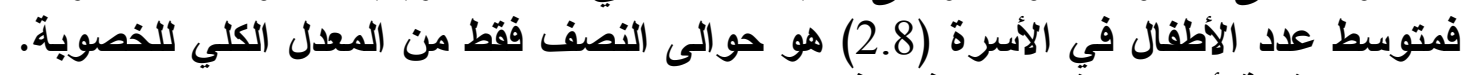
وستتم مناقشة أسباب هذْه الاختلافات فيما يلي. 


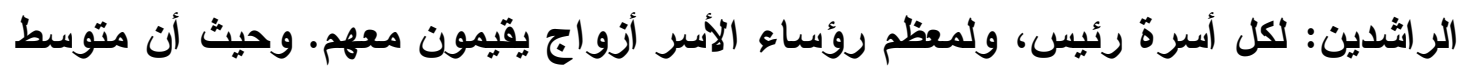

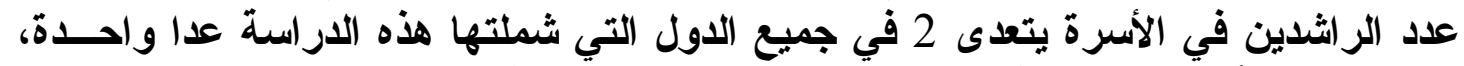

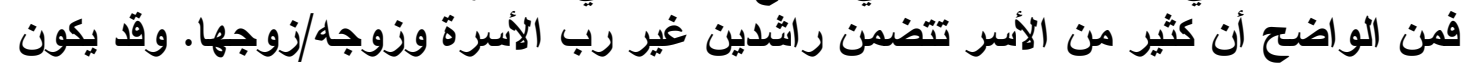

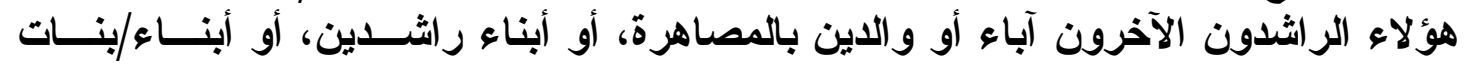

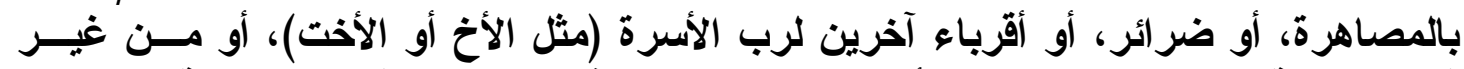

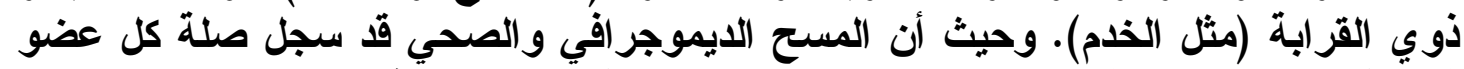

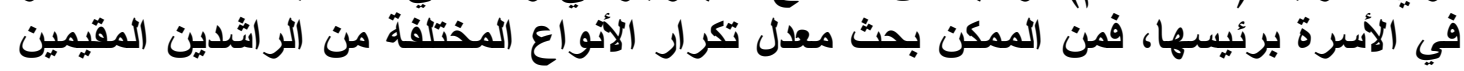

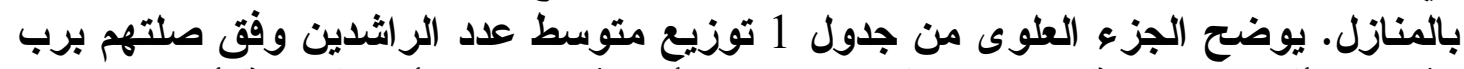

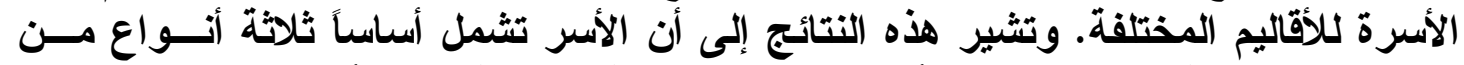

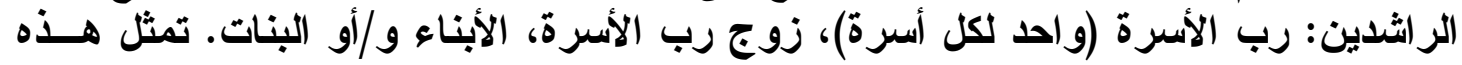

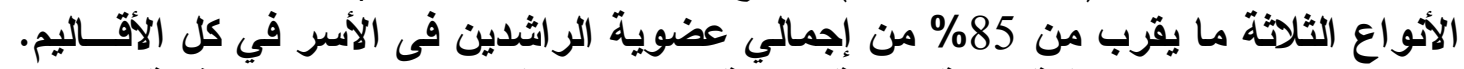

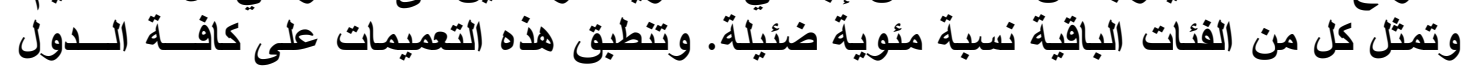

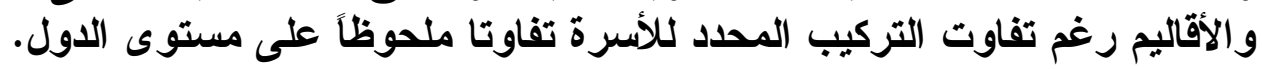

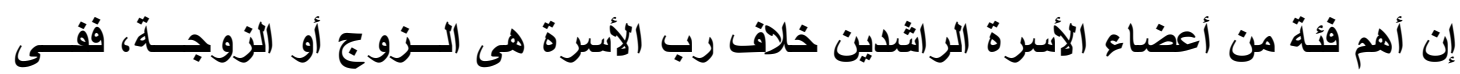

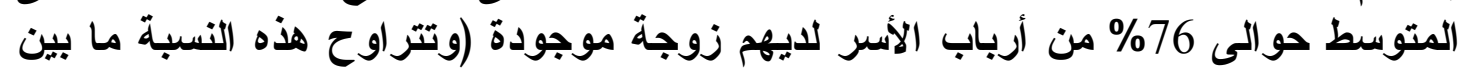

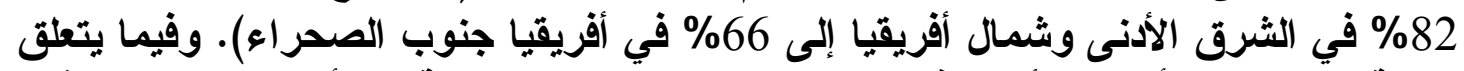

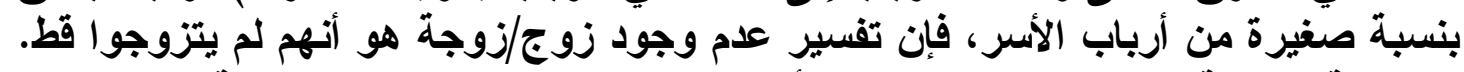

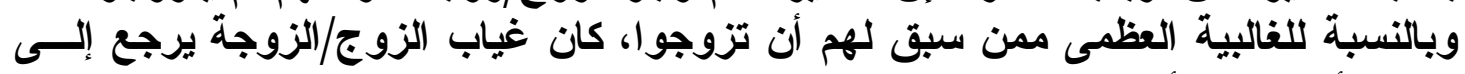
الموت أو الطلاق أو الافقصال.

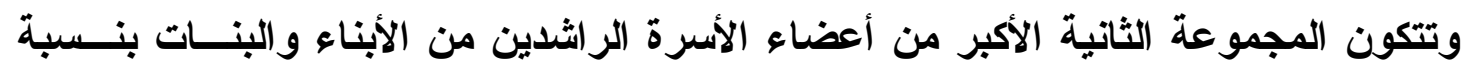

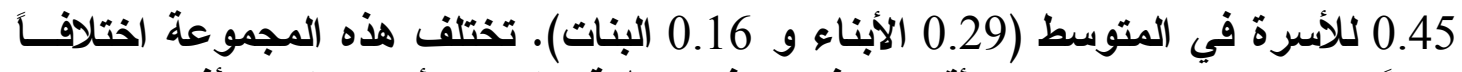

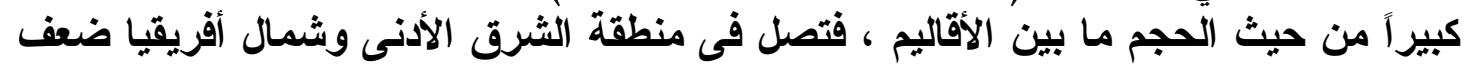

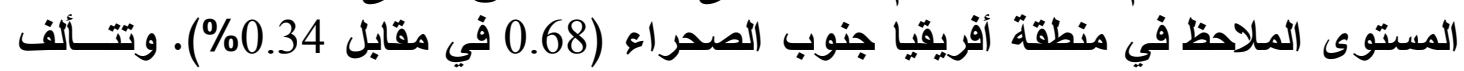

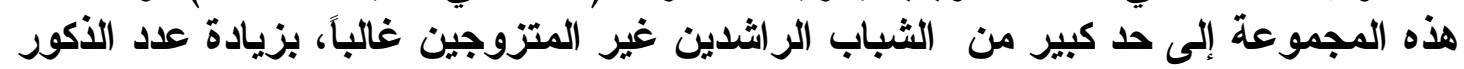

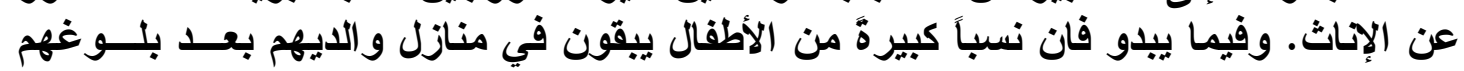

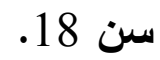

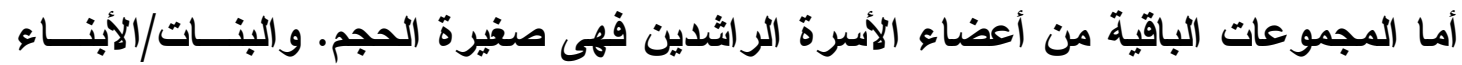

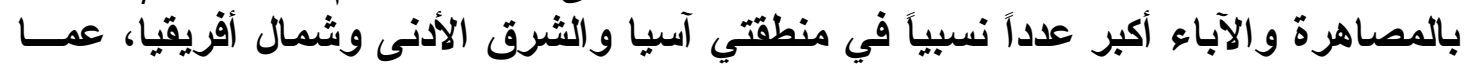

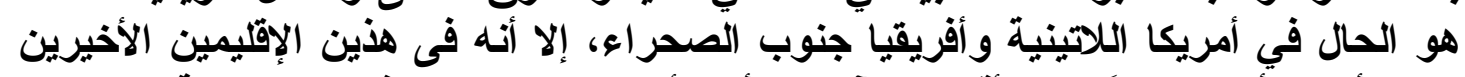

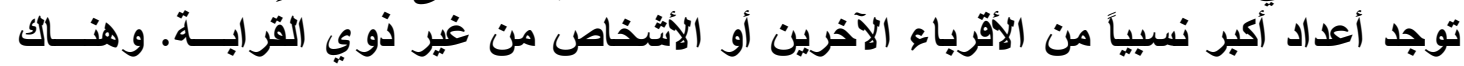

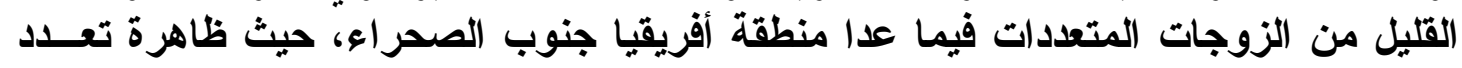

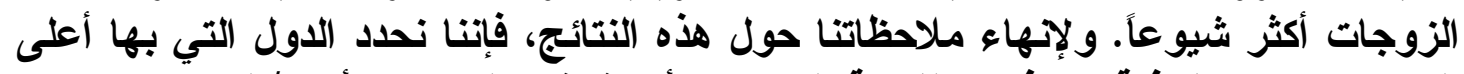

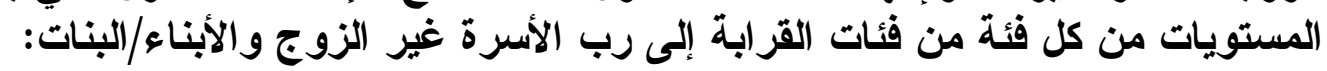
• أبناء/بنات بالمصاهرة: نيبال (0.30)، الهند (0.29)، أوزبكستان (0.28).

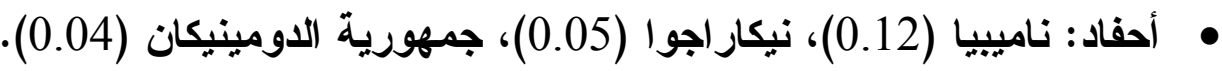

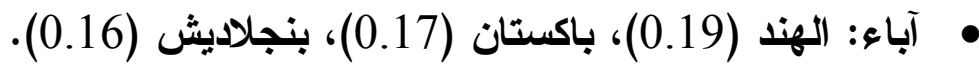 • آباء بالمصاهرة: جزر القمر (0.11)، إندونيسيا (0.05)، الفلبين (0.05)، (0.03). 


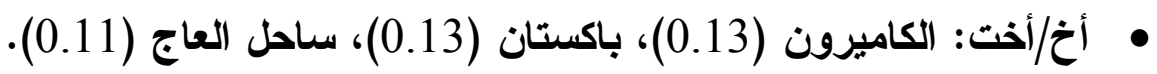

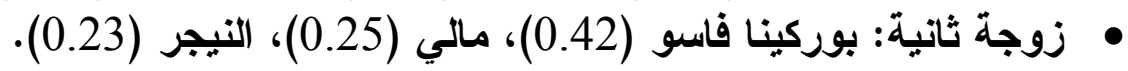

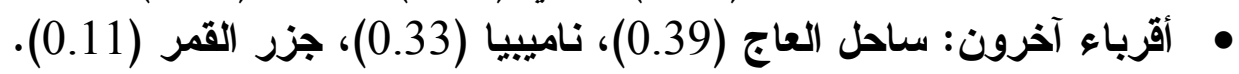

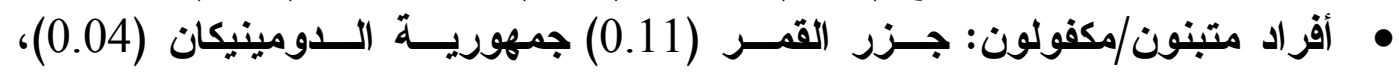
نيكار اجوا (0.03).

• أفراد من غير ذوي القربى: ناميبيا (0.20)، ساحل العاج (0.13)، هايتي (0.12). تجدر الإثارة إلى أن تفسير النتائج الخاصة بالدول السابقة يخرج عن نطاق هذه الدراسة. جدول 1 متوسط عدد الأعضاء فى الأسرة حسب قرابتهم لرب الأسرة وتبعاً للإقليم

\begin{tabular}{|c|c|c|c|c|}
\hline أفريقيا جنوب & وشمال أفريقيا & أمريكا اللاتينية & آسيا & العلاقة برب الأسرة \\
\hline 1.00 & 1.00 & 1.00 & 1.00 & رب الأسرن \\
\hline 0.66 & 0.82 & 0.69 & 0.79 & زوج/ زوجة \\
\hline 0.34 & 0.68 & 0.54 & 0.58 & ابن/ابنة \\
\hline 0.04 & 0.14 & 0.05 & 0.20 & ابن/ابنة بالمصاهرة \\
\hline 0.03 & 0.01 & 0.02 & 0.02 & أحفاد \\
\hline 0.05 & 0.11 & 0.04 & 0.10 & آباء \\
\hline 0.01 & 0.01 & 0.02 & 0.02 & آباء بالمصاهرة \\
\hline 0.08 & 0.08 & 0.06 & 0.06 & أخخ/أختت \\
\hline 0.10 & 0.01 & 0.00 & 0.00 & زوجة ثاتية \\
\hline 0.13 & 0.06 & 0.09 & 0.06 & أققارب آخرون \\
\hline 0.01 & 0.00 & 0.02 & 0.00 & متبنون/مكفولون \\
\hline 0.05 & 0.01 & 0.06 & 0.03 & من غير الأقارب \\
\hline 2.50 & 2.93 & 2.60 & 2.86 & ألابن/ابنة \\
\hline 2.02 & 2.28 & 1.62 & 1.78 & أخ/أخت \\
\hline 0.34 & 0.31 & 0.32 & 0.38 & أقارب آخرون \\
\hline 0.04 & 0.04 & 0.02 & 0.03 & متبنون/مكفولون \\
\hline 0.25 & 0.08 & 0.09 & 0.07 & من غير الأقارب \\
\hline 0.05 & 0.01 & 0.06 & 0.01 & \\
\hline 0.04 & 0.01 & 0.05 & 0.01 & المجموع \\
\hline 2.75 & 2.71 & 2.16 & 2.28 & حجم الأسرة \\
\hline 5.25 & 5.65 & 4.76 & 5.14 & \\
\hline
\end{tabular}


المصدر: تم حسابها من ملفات بيانات المسوح الايموجرافية و الصحية.

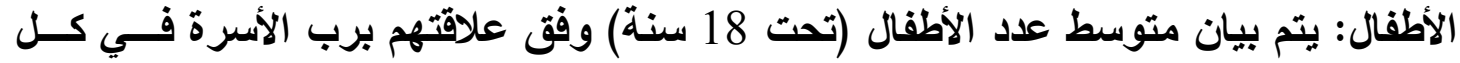

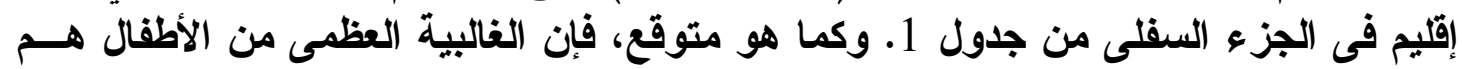

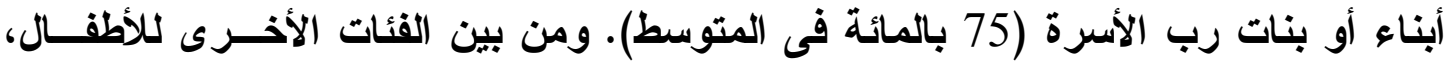

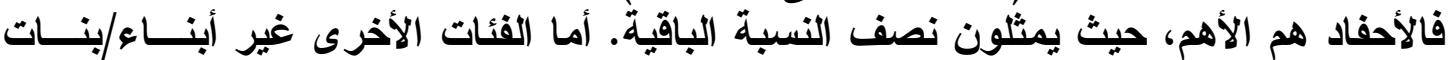

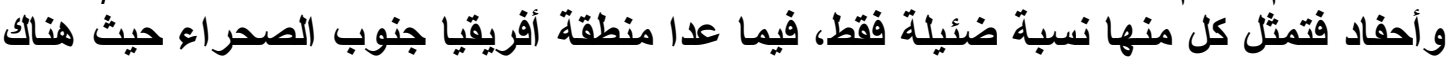

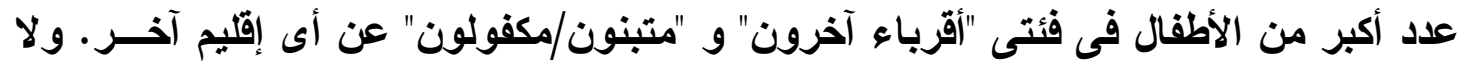

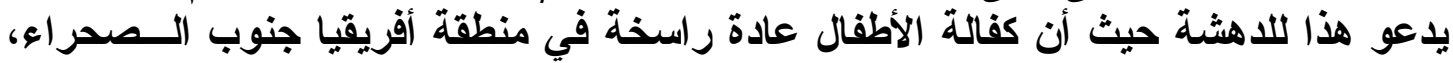
ولكن حتى في هذا الإقليم فإن هذه الفئات مجتمعة تمثل 12 بالمائة فقط من الأطفال.

\section{تعقد تزكيب الأسرة}

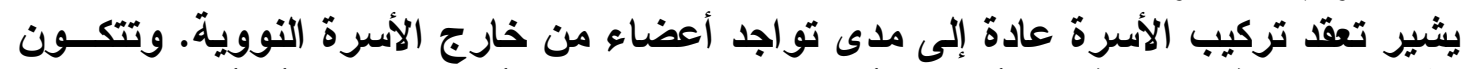

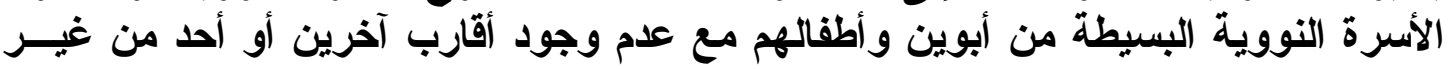

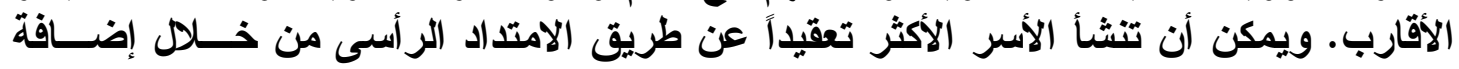

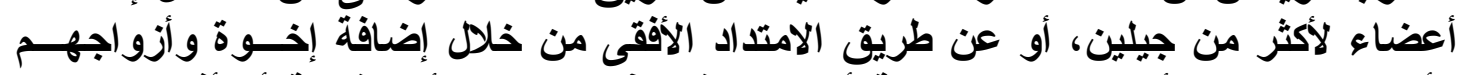

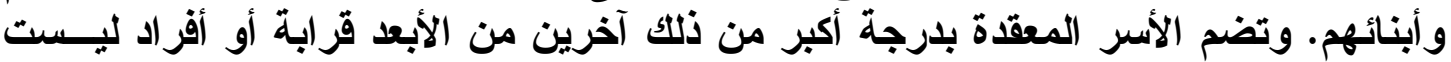

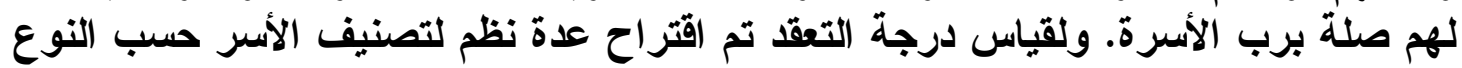

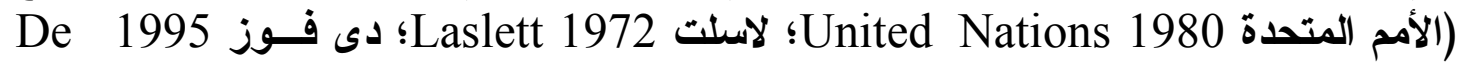
Vos

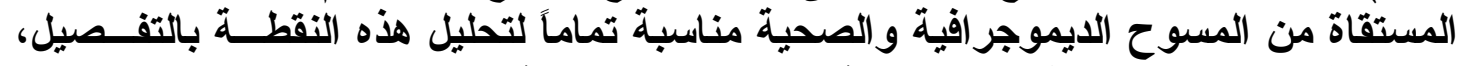

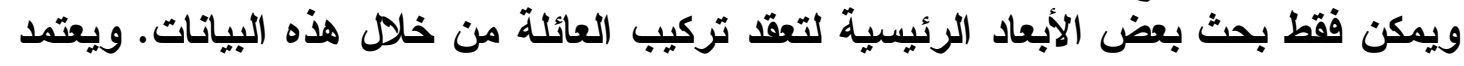

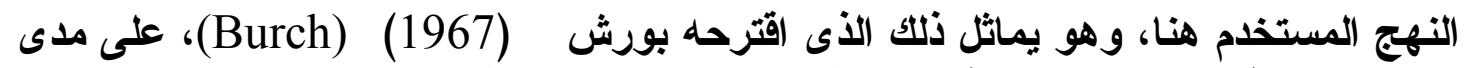

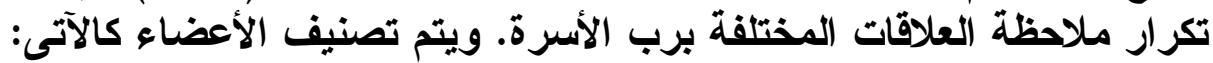

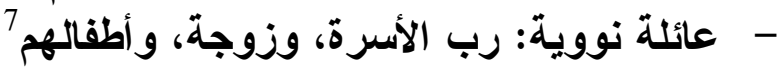

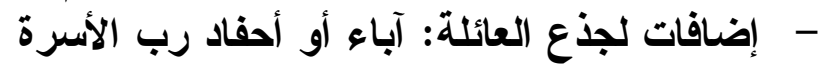

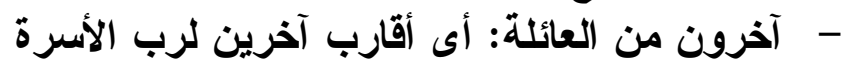

$$
\text { - }
$$

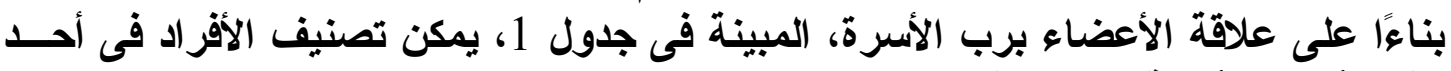

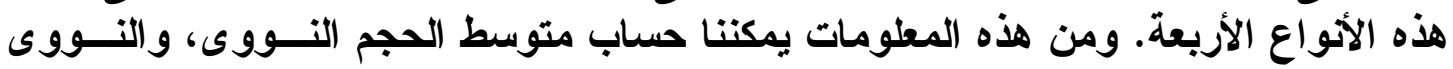

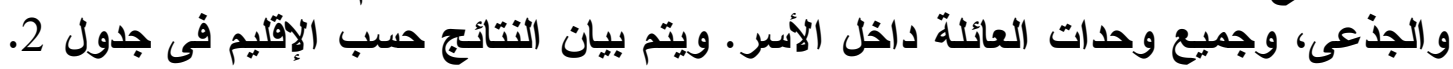

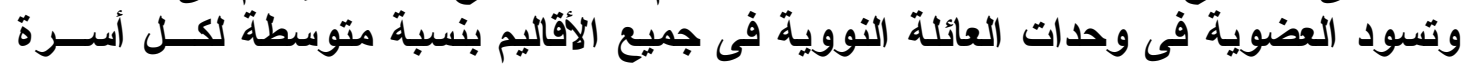

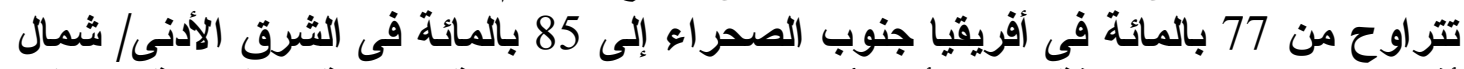

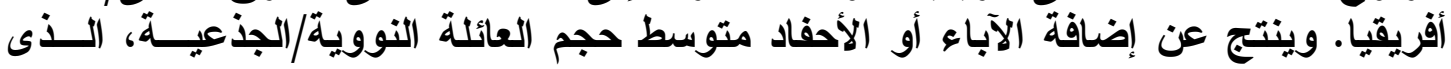

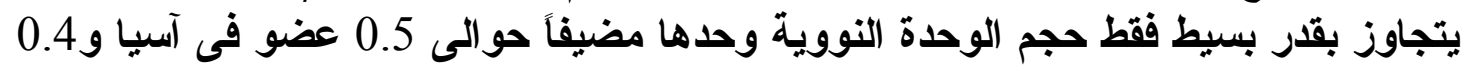

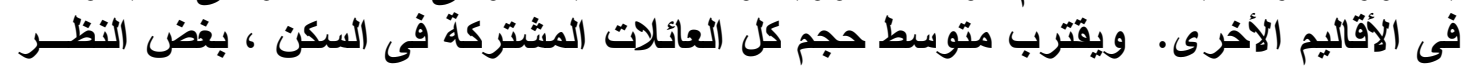

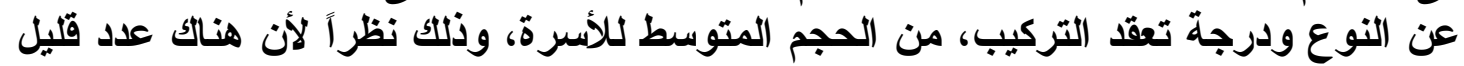

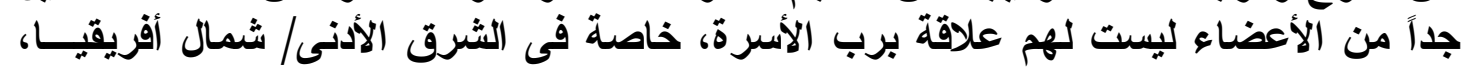




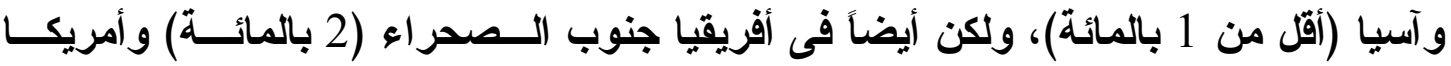

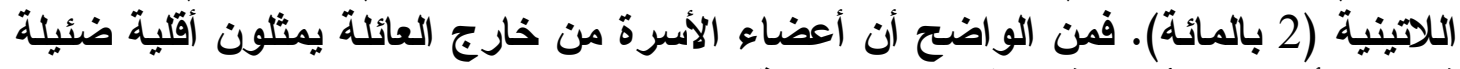
فقط من أعضاء الأسرة في هذه الدول الناع ان النامية.

جدول 2 متوسط حجم وحدات العائلة المشتركة فى السكن تبعاً للإقليم

\begin{tabular}{|c|c|c|c|c|}
\hline أفريقيا جنوب الصحراء & الأدنى/شرقيال & أمريكا اللاتينية & آسيا & \\
\hline \multicolumn{5}{|r|}{ متوسط الحجم } \\
\hline 4.03 & 4.77 & 3.86 & 4.15 & العائلة النووية \\
\hline 4.44 & 5.20 & 4.25 & 4.65 & النويائلة/الجذعية \\
\hline 5.16 & 5.62 & 4.64 & 5.10 & جميع العائلات \\
\hline 5.25 & 5.65 & 4.76 & 5.14 & الأسرة \\
\hline \multicolumn{5}{|r|}{ النسبة لحجم الأسرة } \\
\hline 0.77 & 0.85 & 0.81 & 0.81 & العائلة النووية \\
\hline 0.85 & 0.92 & 0.89 & 0.90 & النووية/الجذعية \\
\hline 0.98 & 1.00 & 0.98 & 0.99 & جميع العائلات \\
\hline 1.00 & 1.00 & 1.00 & 1.00 & الأسرة \\
\hline
\end{tabular}

المصدر: تم حسابها من ملفات بيانات المسوح الايموجرافية و الصحية. 


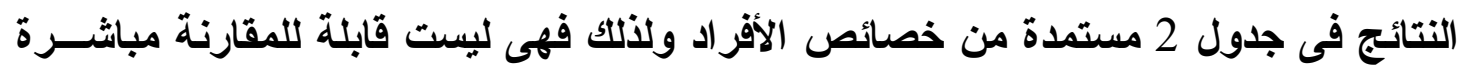

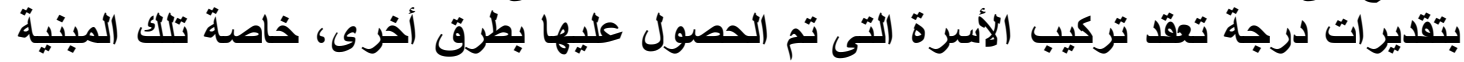

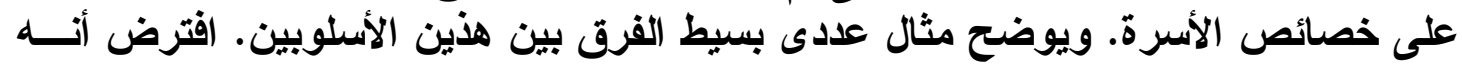

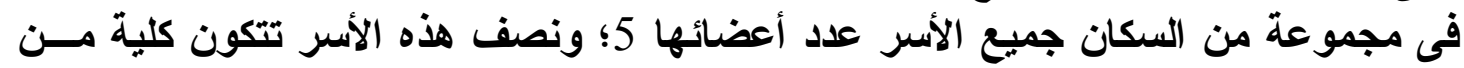

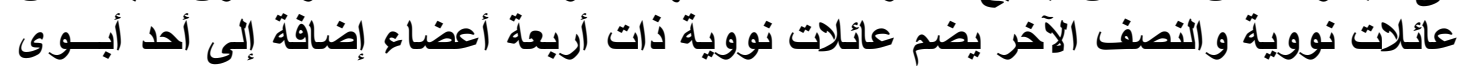

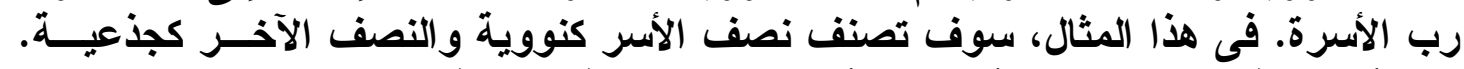

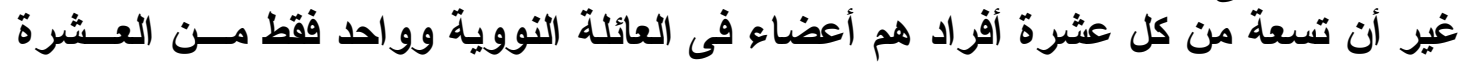

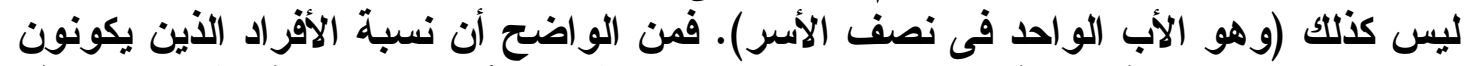

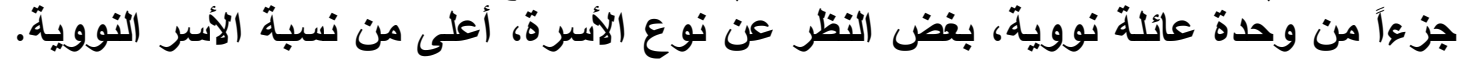

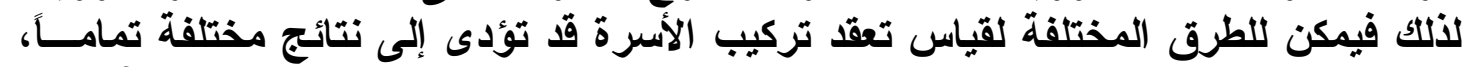

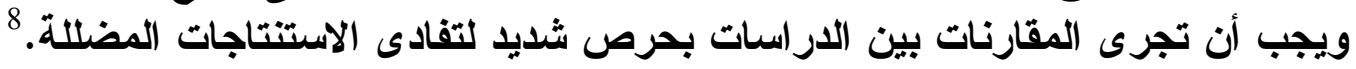

النوع الاجتماعى لرب الأسرة والتركيب الأسرى

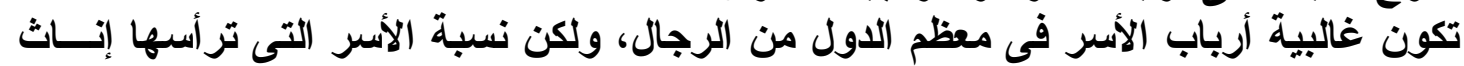

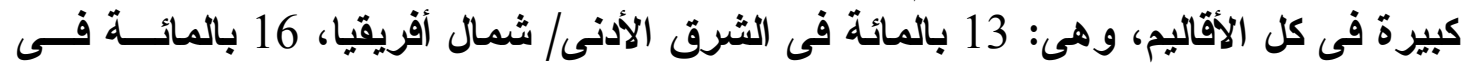

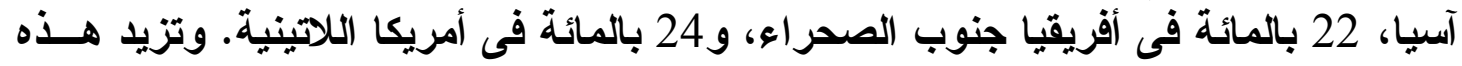

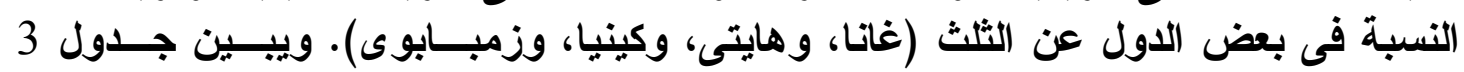

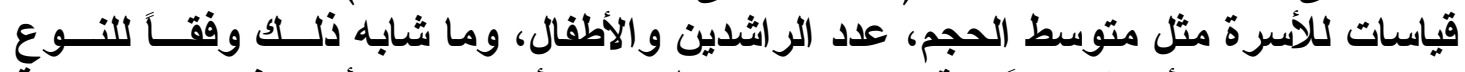

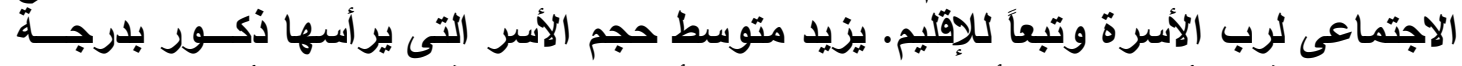

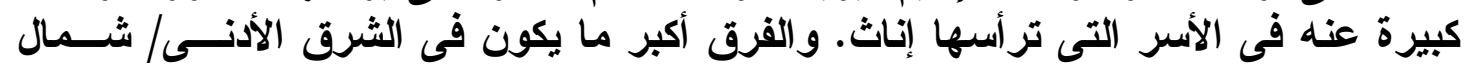

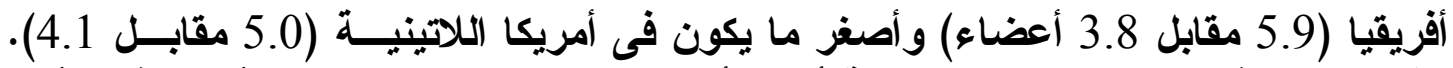

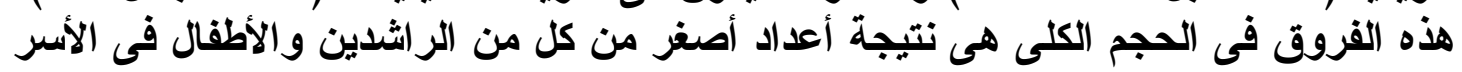

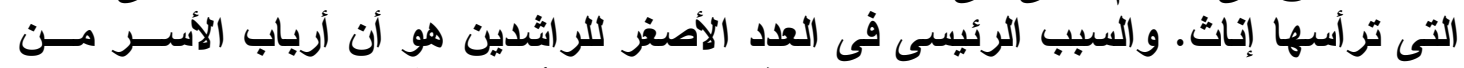

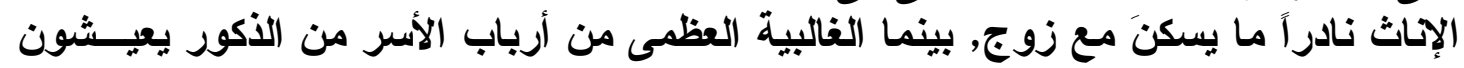

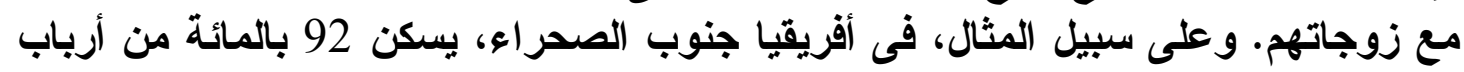

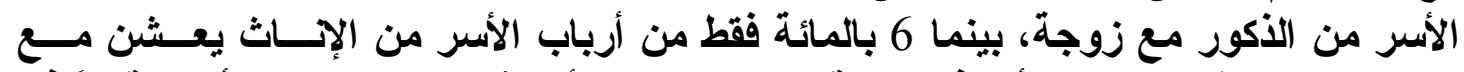

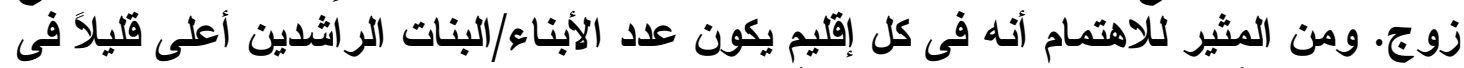
الأسر التى ترأسها الإناث عن تلكت التى يرأسها الذكور.

جدول 3 متوسط حجم مكونات الأسرة وفقاً للنوع الاجتماعى لرب الأسرة

\begin{tabular}{|c|c|c|c|}
\hline إجمالى & أنثى & ذكر & \\
\hline & & & حجم الأسرة \\
\hline $\begin{array}{l}5.1 \\
4.8\end{array}$ & $\begin{array}{l}3.8 \\
4.1\end{array}$ & $\begin{array}{l}5.4 \\
5.0\end{array}$ & أمريكا اللاتينية \\
\hline 5.7 & 3.8 & 5.9 & الشرق الأدنى وشمال أفريقيا \\
\hline 5.3 & 4.2 & 5.5 & أفريقيا جنوب الصحر اء \\
\hline & & & عدد الأطفال \\
\hline 2.3 & 1.6 & 2.4 & آسيا \\
\hline 2.2 & 1.8 & 2.3 & \\
\hline
\end{tabular}




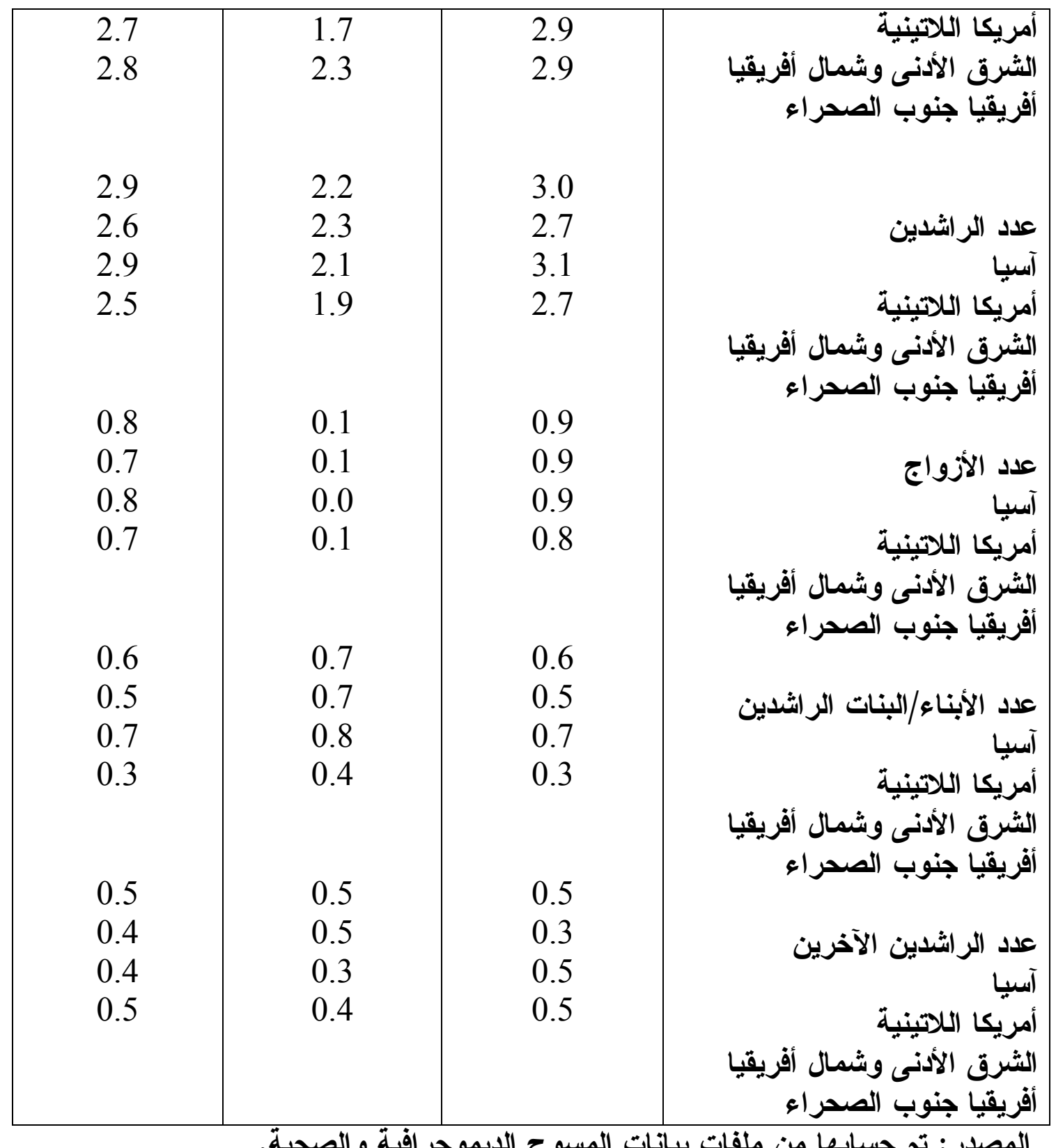

العلاقة بين حجم وتركيب الأسرة

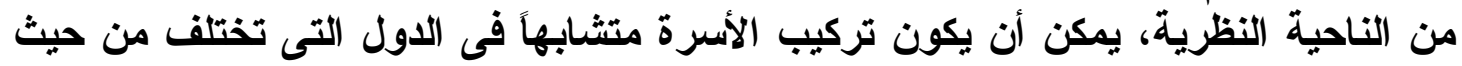

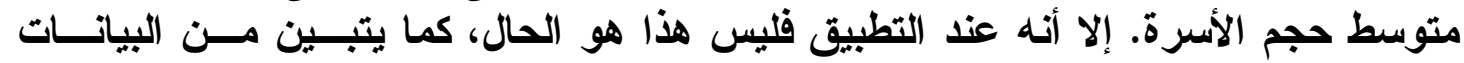

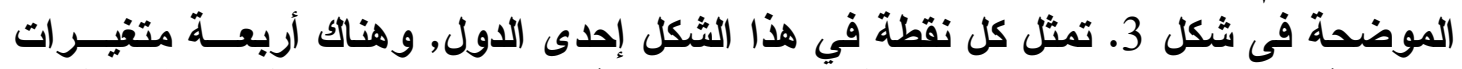

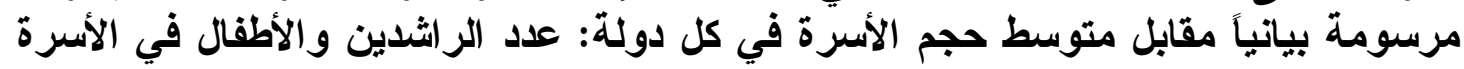

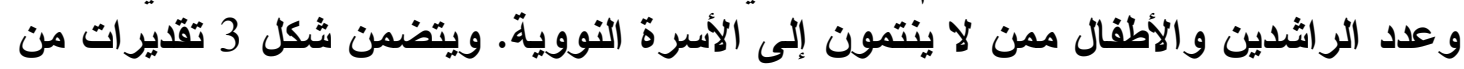

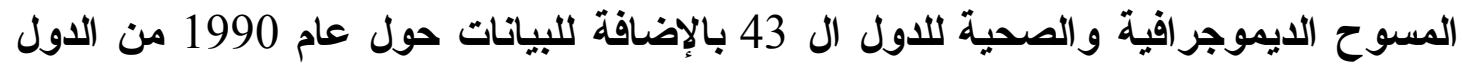

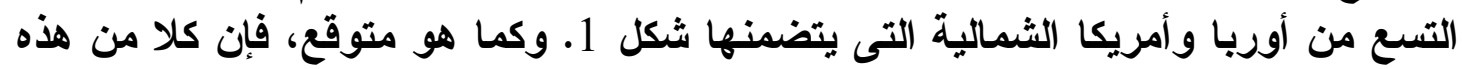

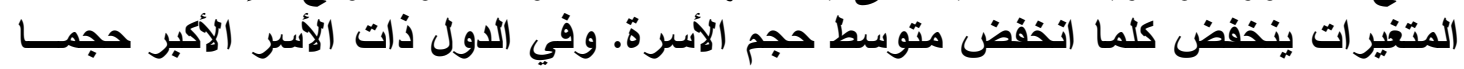

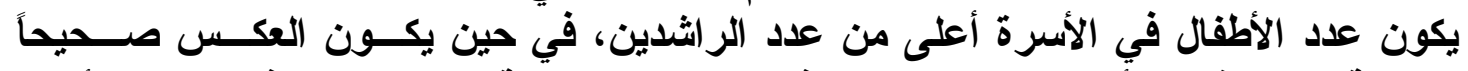

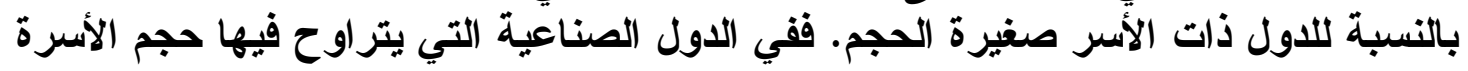


ما بين 2 و3 أفراد، فإن متوسط عدد الأطفال في الأسرة لا يمثل سوى ربع إجمالي عضوية الأنية

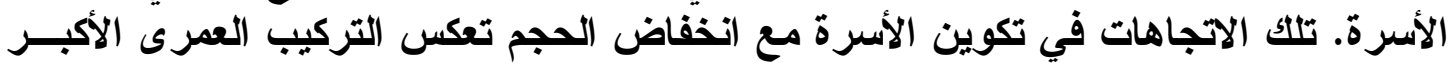

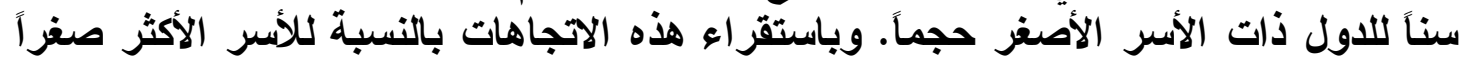

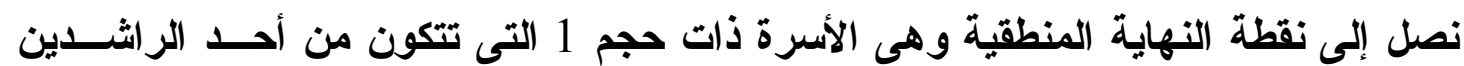

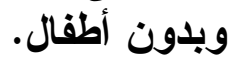

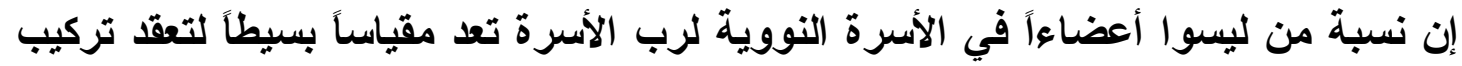

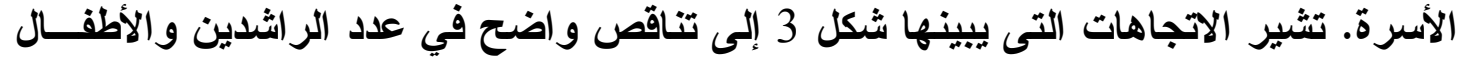

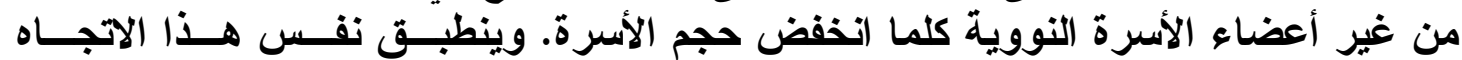

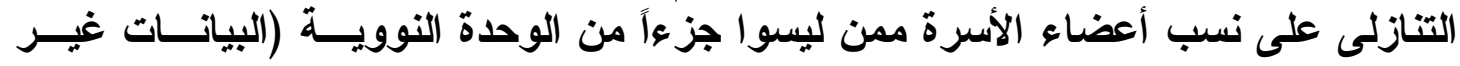

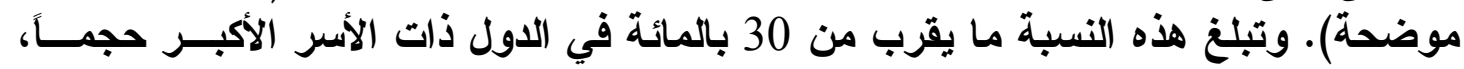

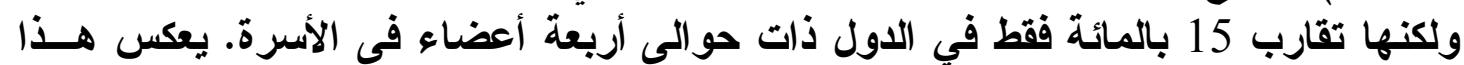

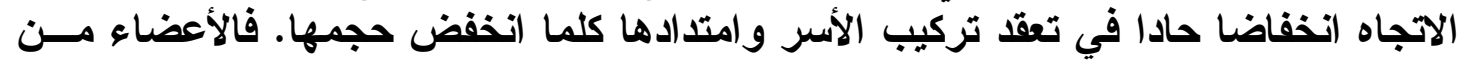

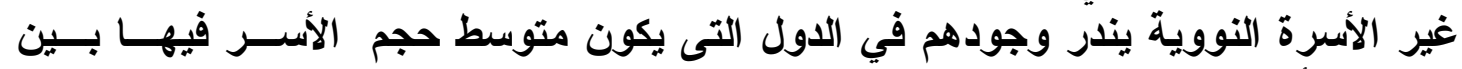
المتوسط أو الصغير الورية

شكل 3 العلاقة بين متوسط عدد الراثدين، والأطفال، والراشدين والأطفال من غير الأسرة النووية فى كل أسرة ومتوسط حجم الأسرة

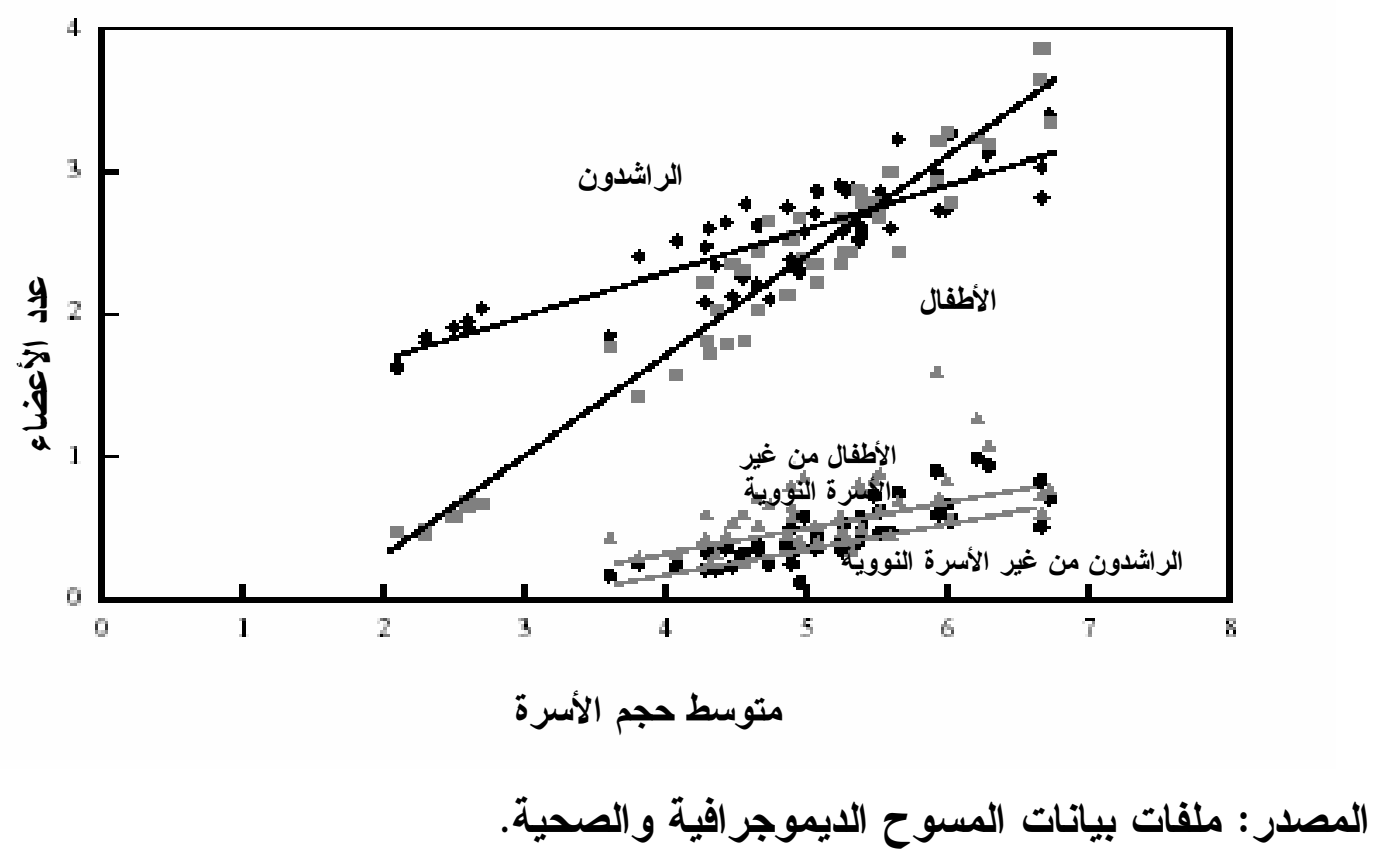

المحددات التقريبية لحجم الأسرة

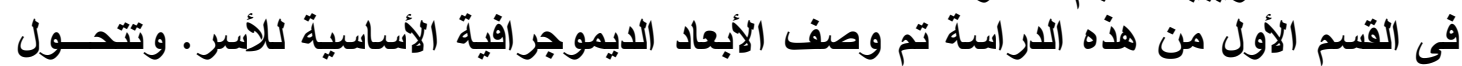

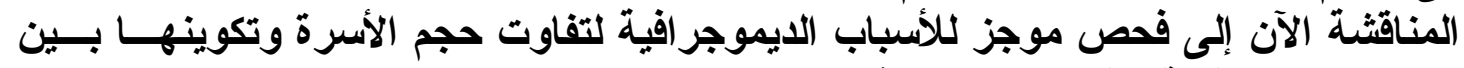

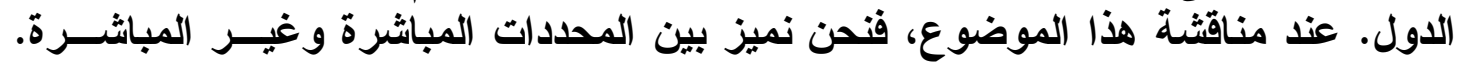

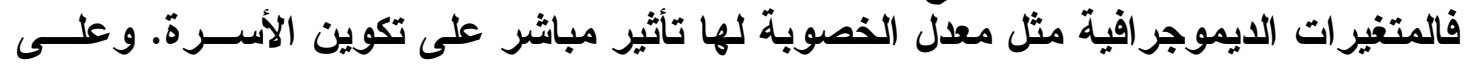


النقيض، فإن المتغيرات الاجتماعية والاقتصادية مثل الاخل لا تؤثر في تركيب الأسرة بشكل

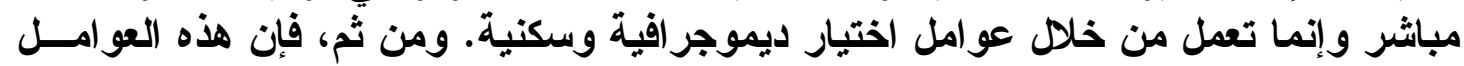

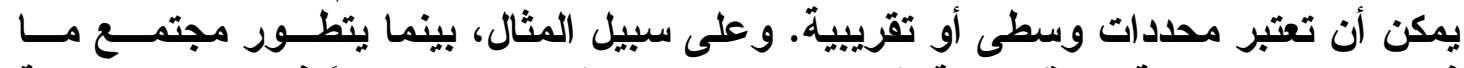

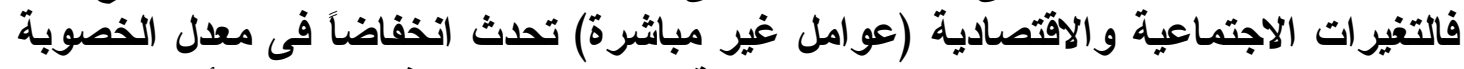
(محدد تقريبي)، ويؤدي انخفاض معدل الخصوية بدوره إلى تغير في تركيب الأسرة بخفض فئرل

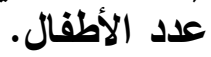

اقترح بونجارتس (1983) (Bongaarts) ست محددات ديموجرافية تقريبية لحجم الأســرة

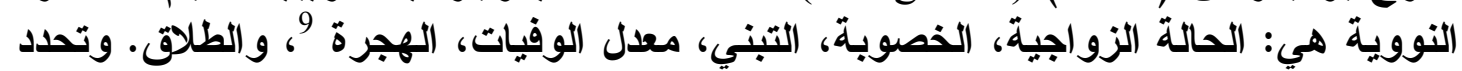

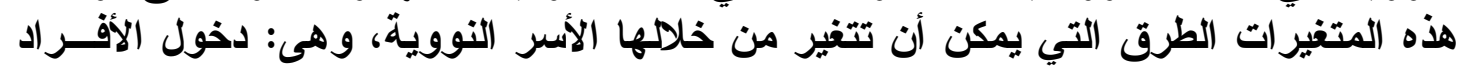

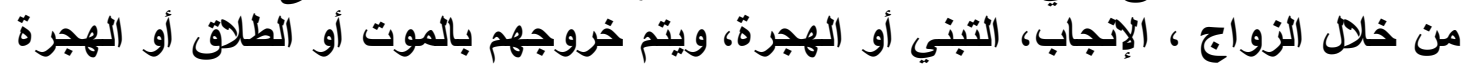

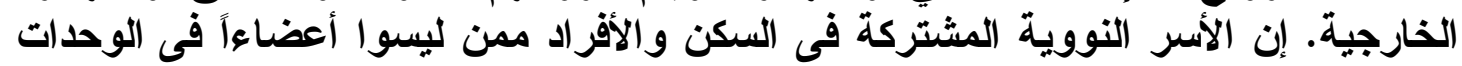

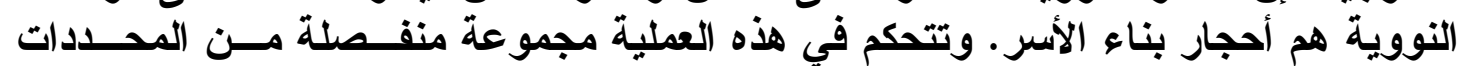

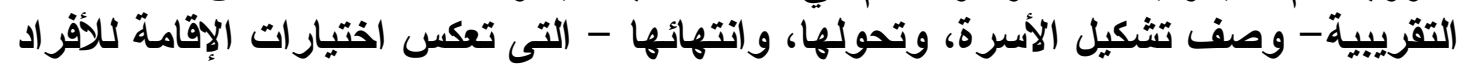

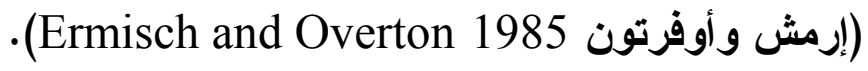

يوضح التحليل السابق أن الأسر تتكون بشكل أساسي من أرباب الأسر، و أزواجهم، والأبناء

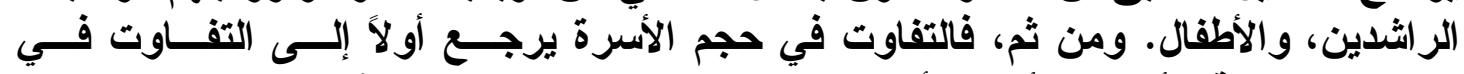

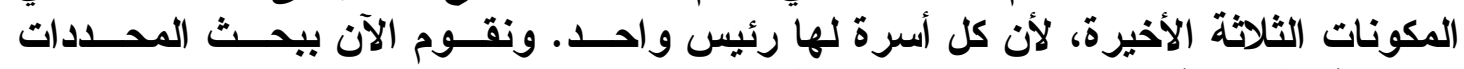

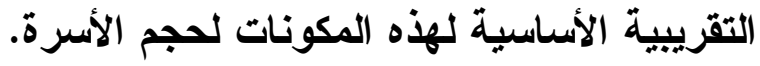

الخصوبة وعدد الأطفال في الأسرة:

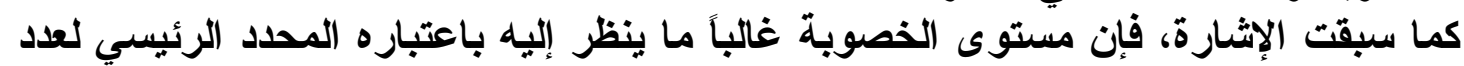

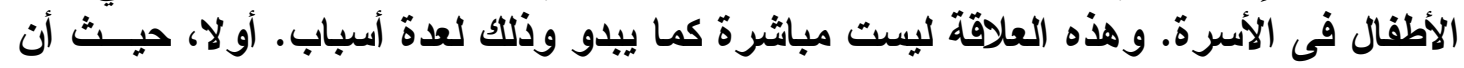

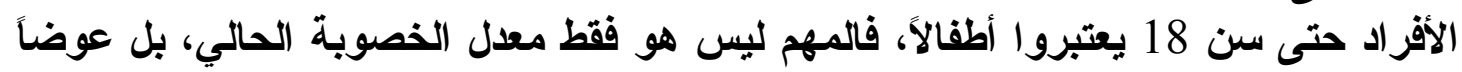

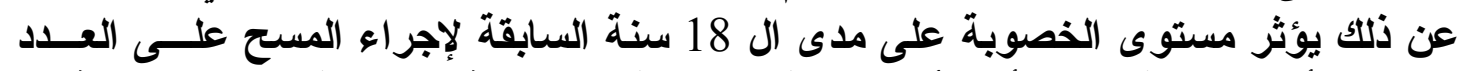

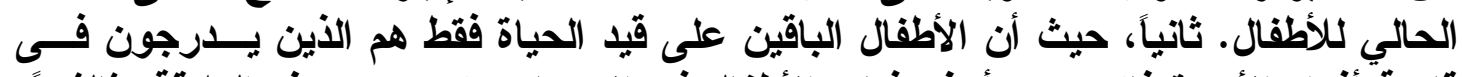

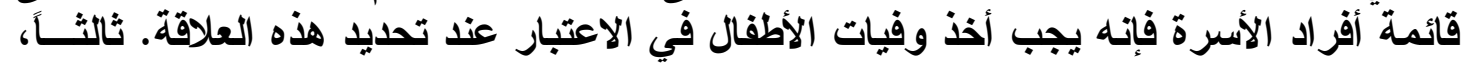

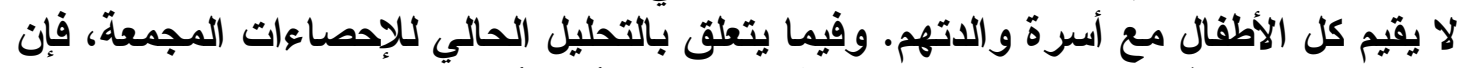

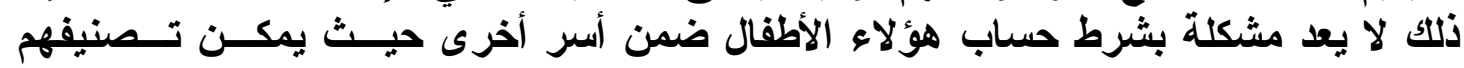

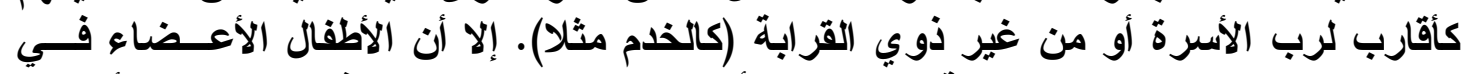

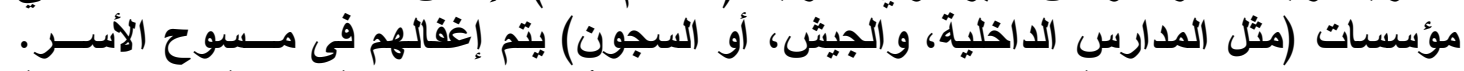

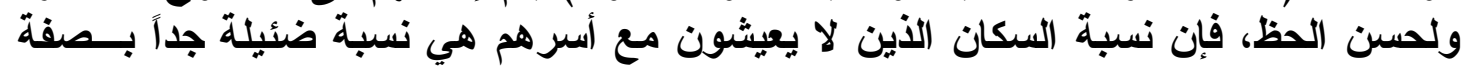

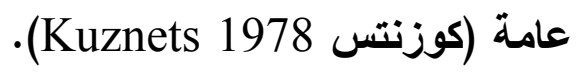

يوضح شكل 4 رسماً بيانياً للعلاقة بين متوسط عدد الأطفال فــي الأســرة (children per )

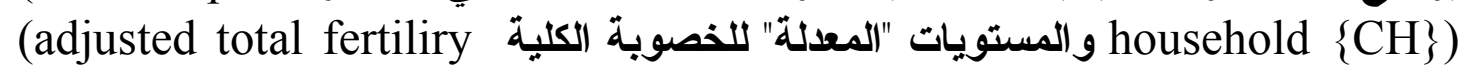
rates\{ATFR\})

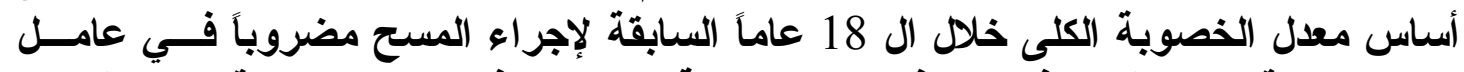

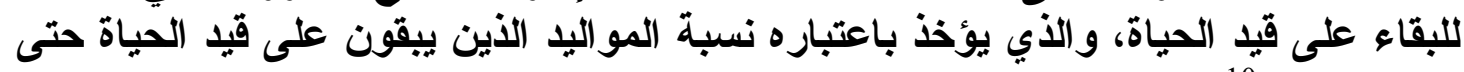

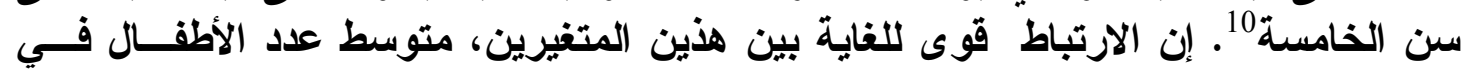




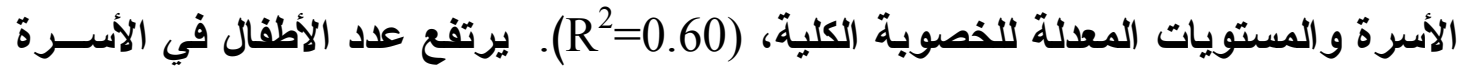

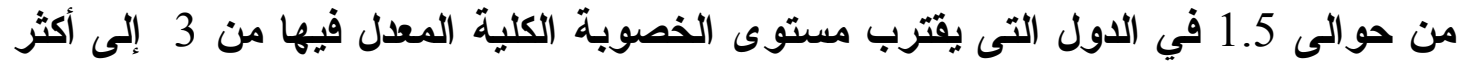

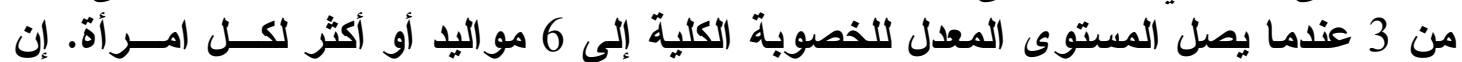

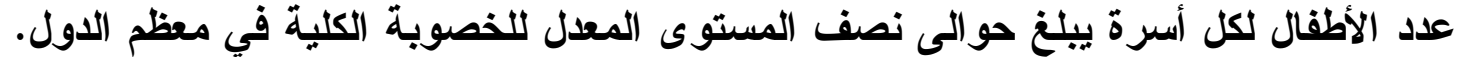

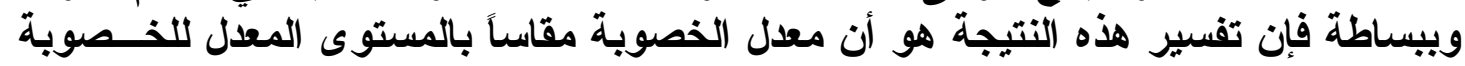

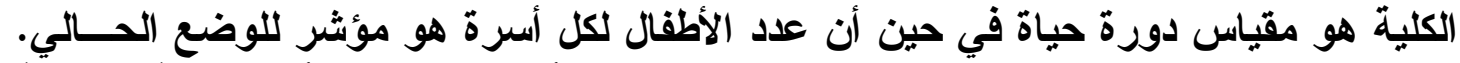

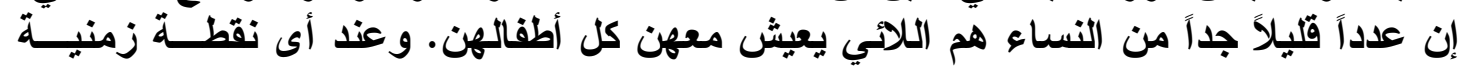

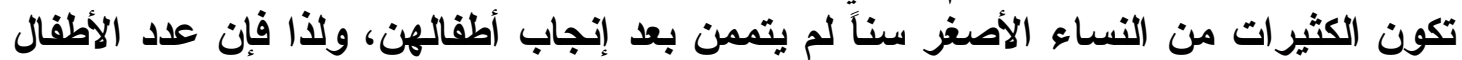

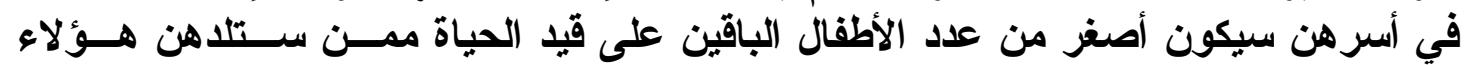

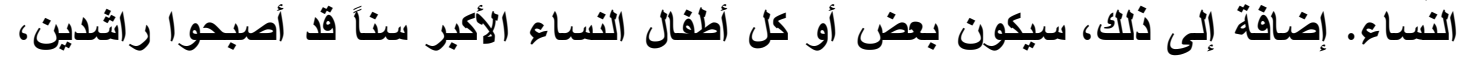

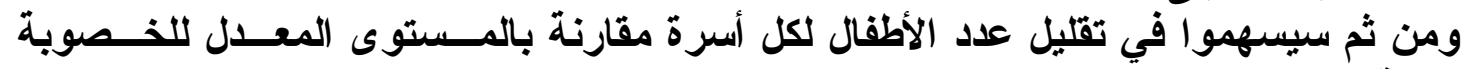
الكلية.

شكل 4 العلاقة بين متوسط عدد الأطفال للأسرة والمستوى المعدل للخصوبة الكلية في 43 دولة شملها المسح الايموجرافي والصحي

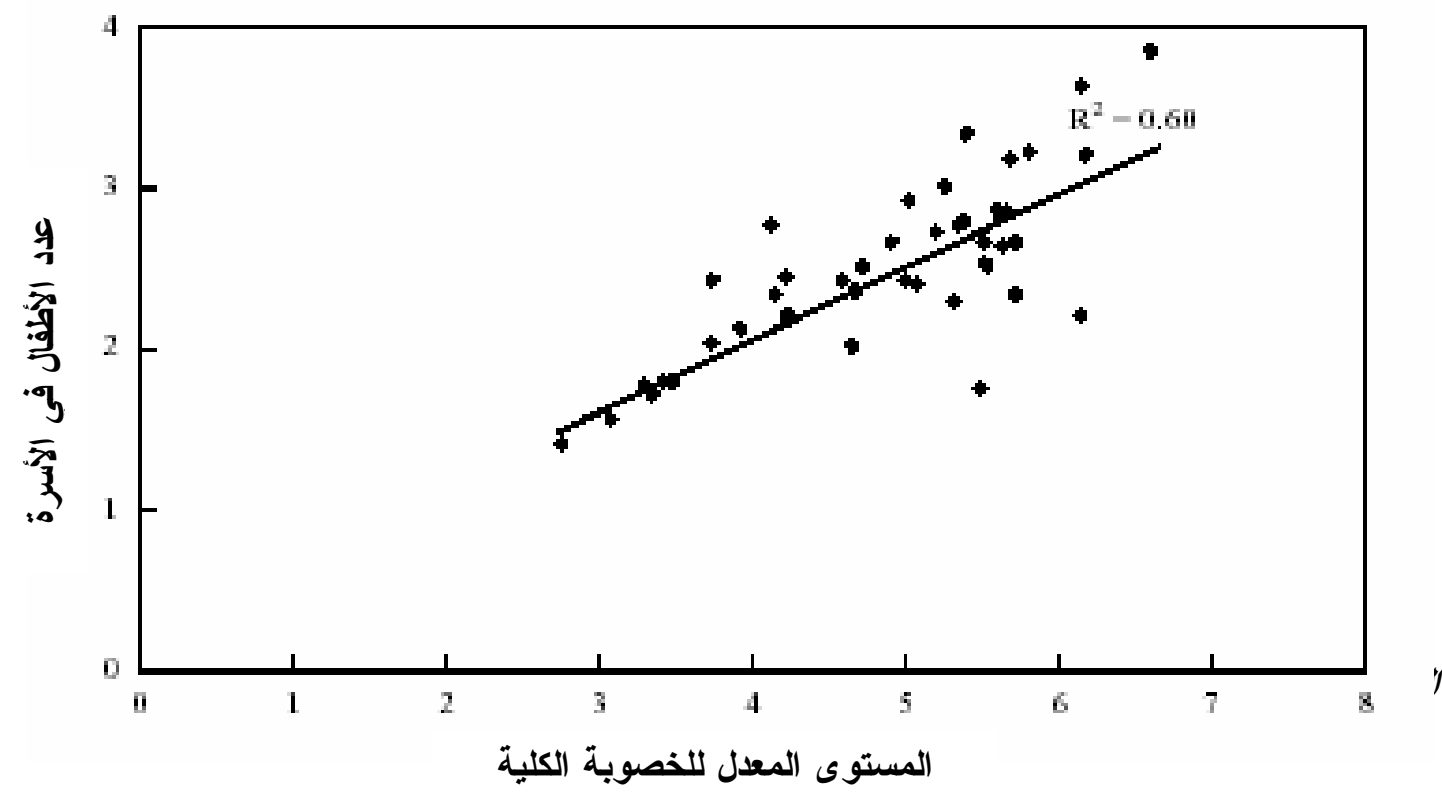

المصدر : ملفات بيانات المسوح الايموجرافية والصحية.

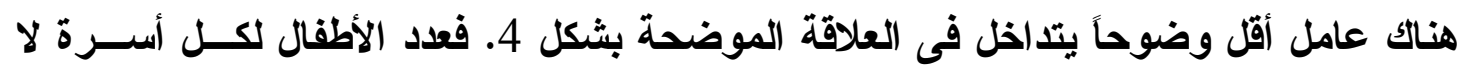

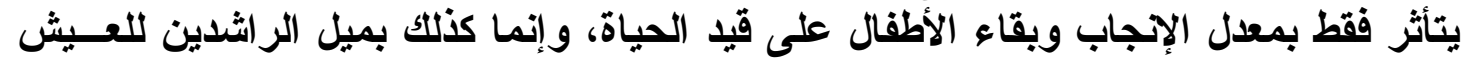

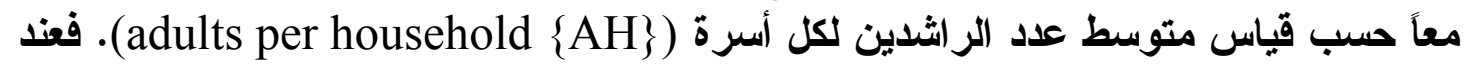

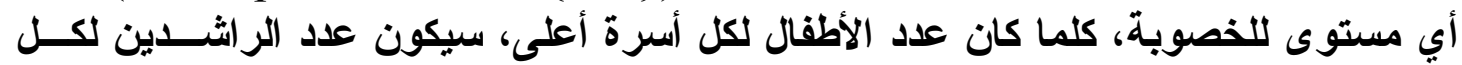

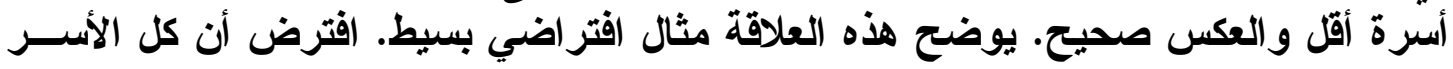


تتكون من عائلات نووية تضم كل منها 6 أعضاء: زوج، زوجة، و4 أطفال ( أي أن عـداد

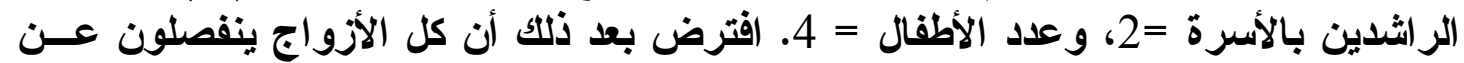

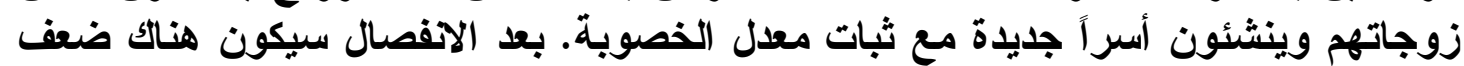

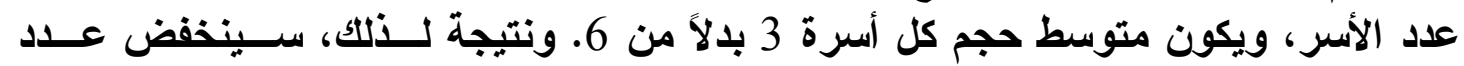

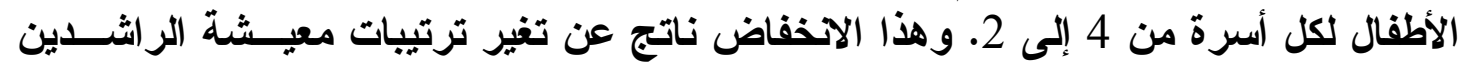

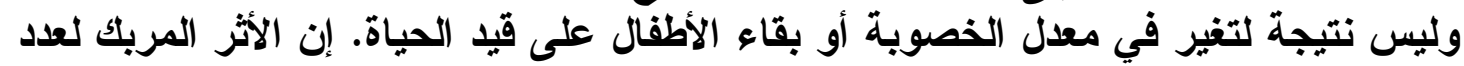

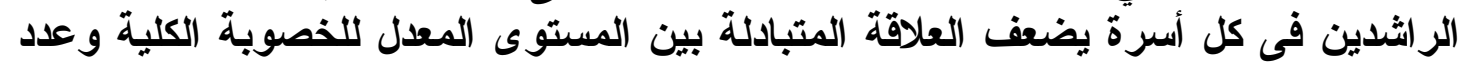

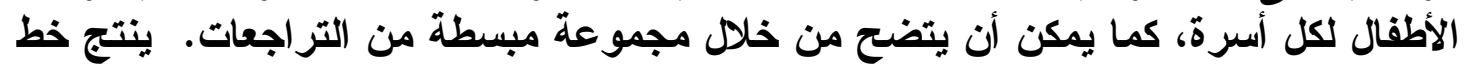
معامل التزاجع الخطى لأقل المربعات المطابق للبيانات في شكل شلئ 4 المعادلة التالية:

$$
\mathrm{CH}=0.34+0.45 \text { ATFR }\left(\mathrm{R}^{2}=0.60\right)
$$

وعند إضافة عدد الراشدين بالأسرة (AH) كمتغير تفسيرى فإن النتيجة تصبح:

$$
\mathrm{CH}=-2.15+0.49 \mathrm{ATFR}+0.87 \mathrm{AH}\left(\mathrm{R}^{2}=0.92\right)
$$

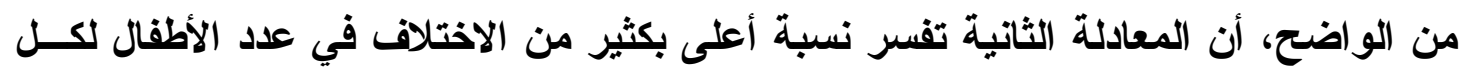

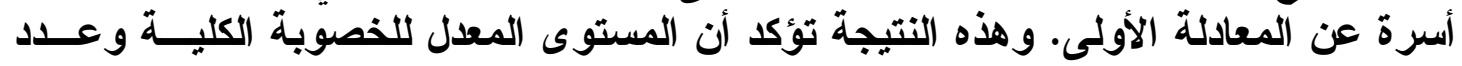

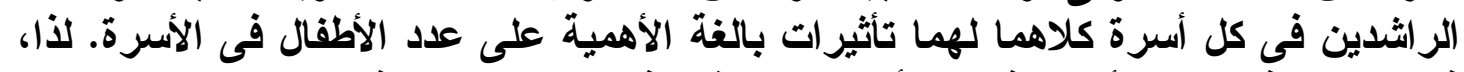

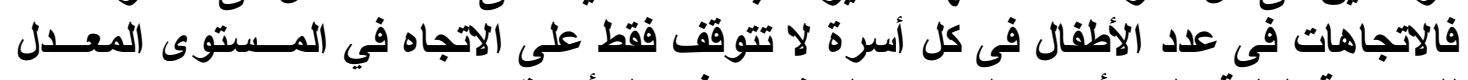

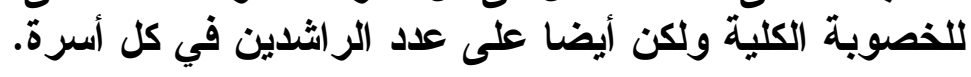

سن الزواج و عدد الأبناء والبنات الر اشداين لكل أسرة:

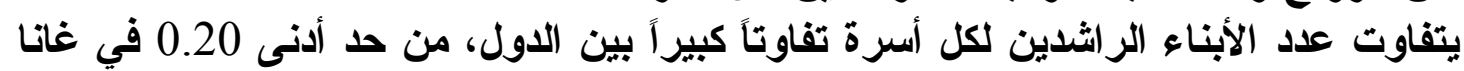

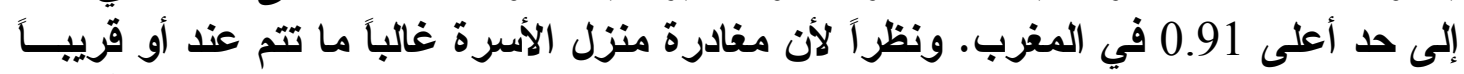

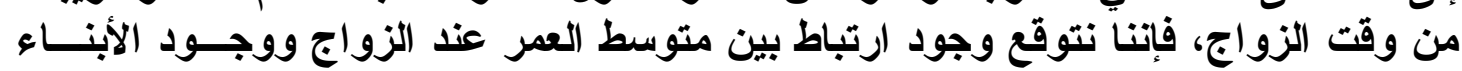

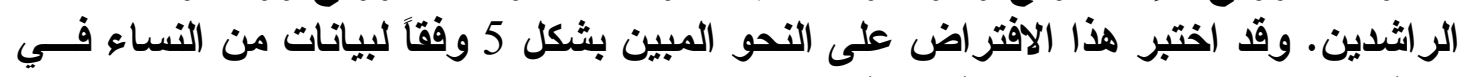

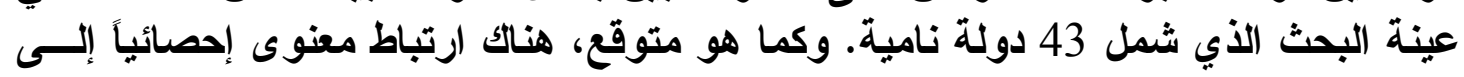

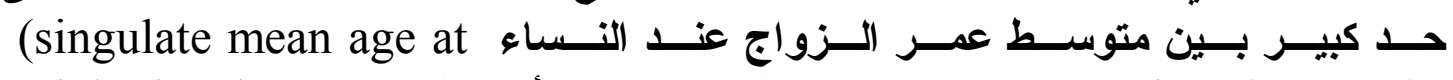

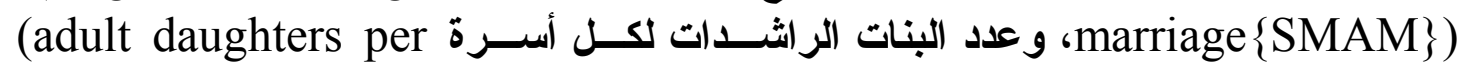
:household $\{\mathrm{AD}\})$

$$
\mathrm{AD}=-0.46+0.030 \mathrm{SMAM}\left(\mathrm{R}^{2}=0.68\right)
$$

شكل 5 العلاقة بين متوسط عدد البنات الراشدات لكل أسرة ومتوسط العمر عند الزواج 


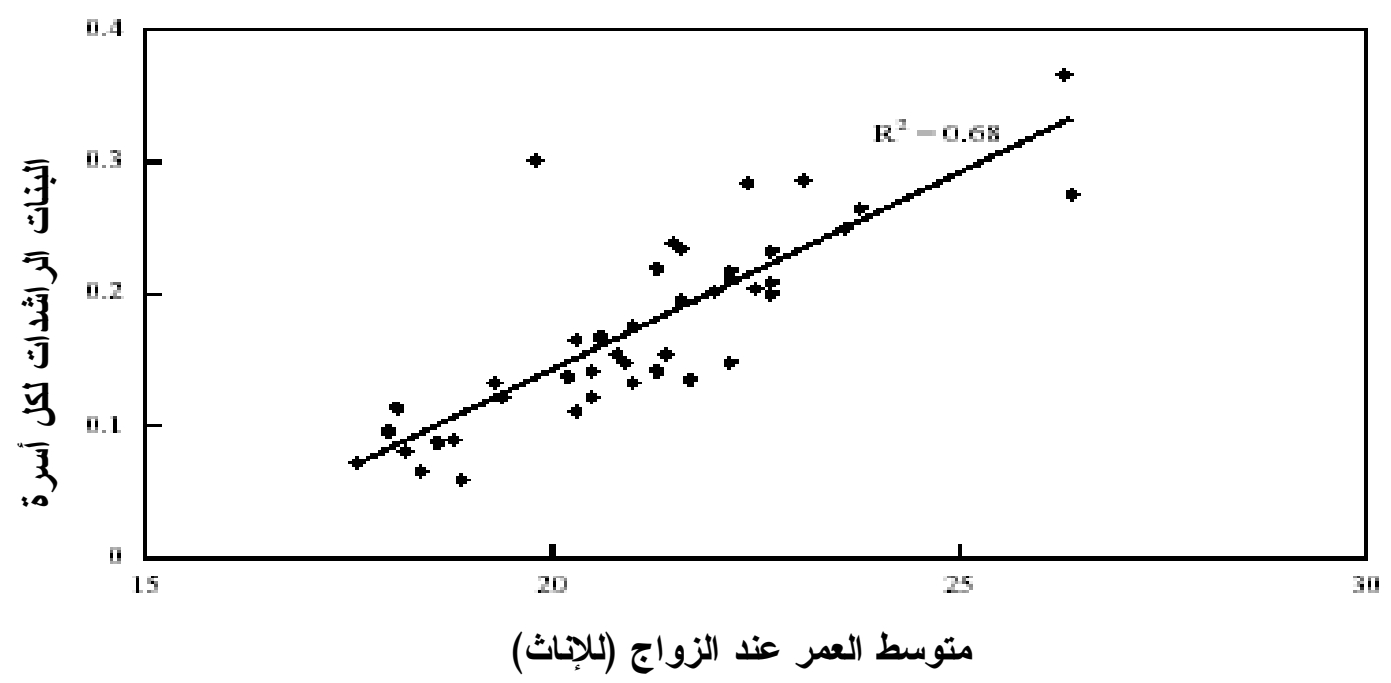

المصدر : ملفات بيانات المسوح الديموجراقيه والصحيه؛ الامم المتحدة 2000

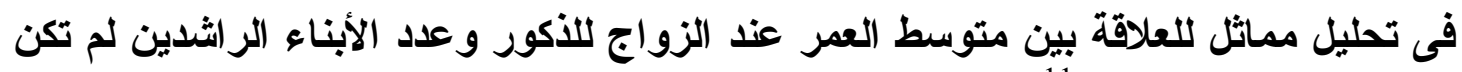

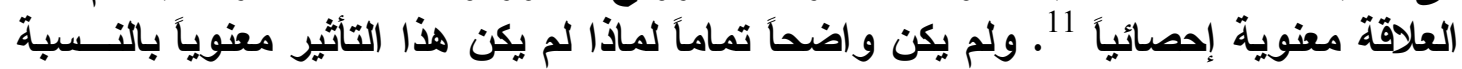

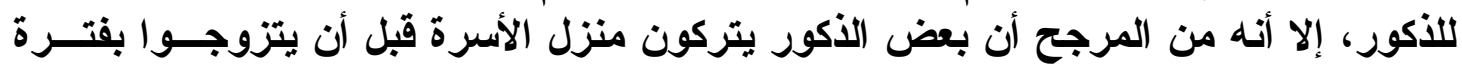

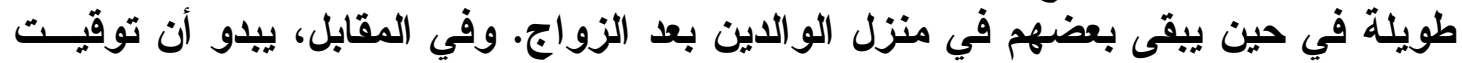

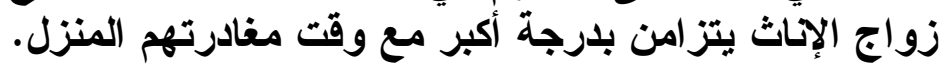

تفكك الحياة الزوجية ووجود الزوج

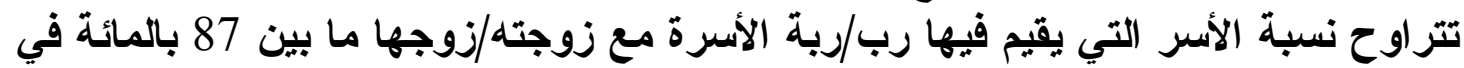

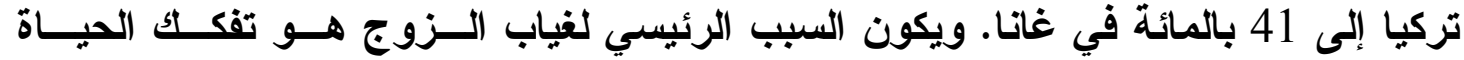

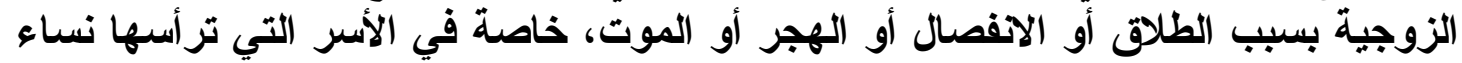

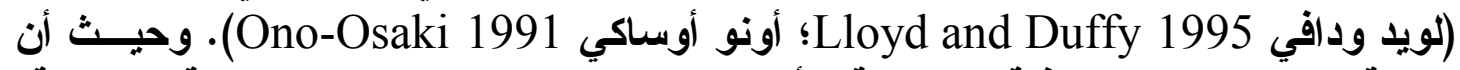

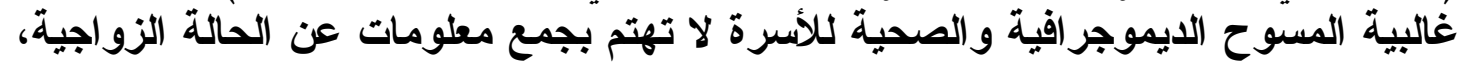

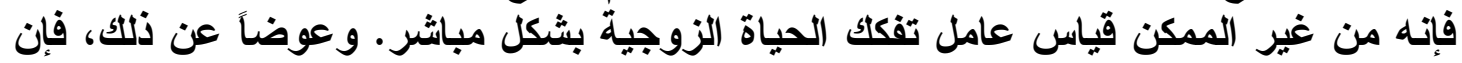

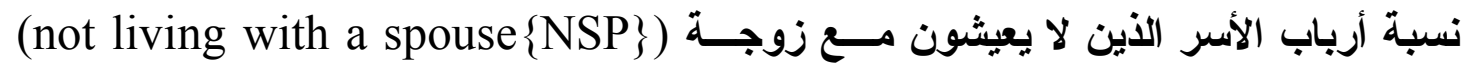
يمكن استخدامها كمؤشر غير مباشر لأنفر لتفك الحياة الزوجية.

التأثيرات المجتمعة للمحددات التقريبية

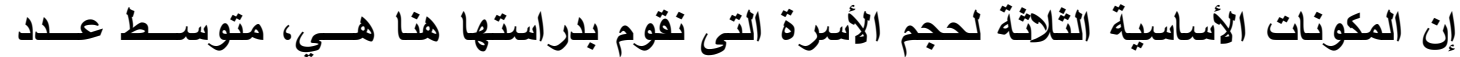

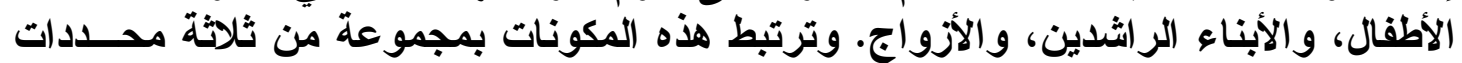

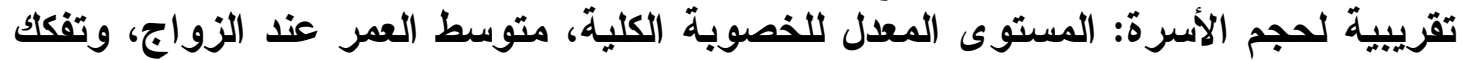

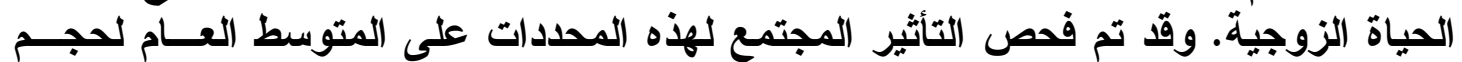

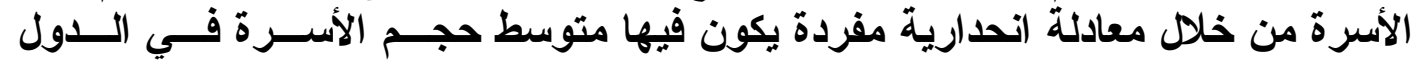

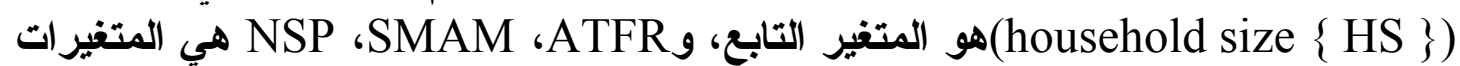

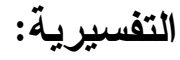




$$
\mathrm{HS}=0.65+0.60 \mathrm{ATFR}+0.13 \mathrm{SMAM}-4.19 \mathrm{NSP}\left(\mathrm{R}^{2}=0.59\right)
$$

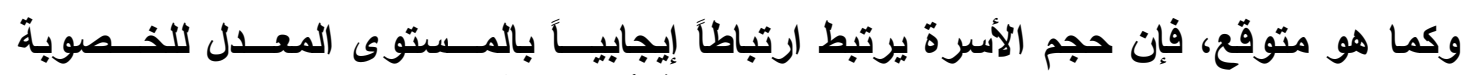

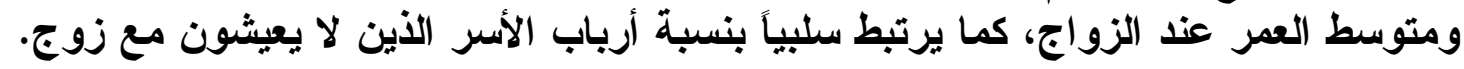

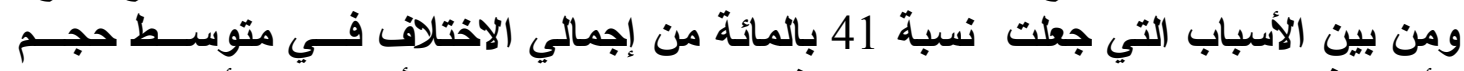

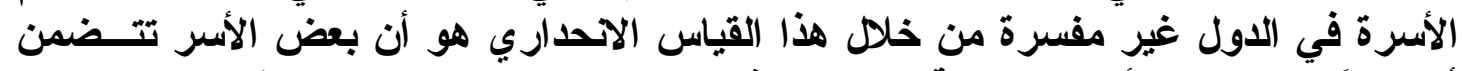

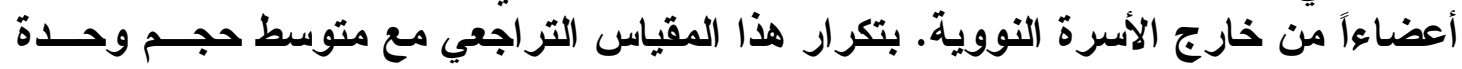

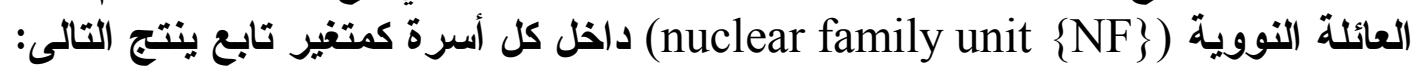

$$
\mathrm{NF}=1.9+0.37 \mathrm{ATFR}+0.07 \mathrm{SMAM}-4.18 \mathrm{NSP}\left(\mathrm{R}^{2}=0.81\right)
$$

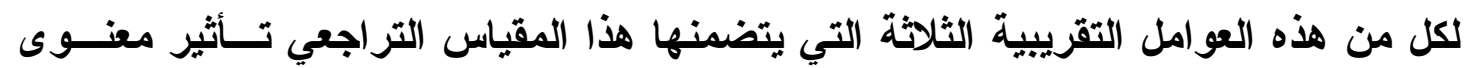

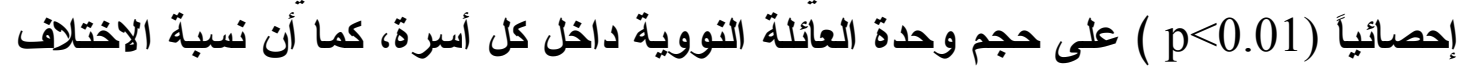
المفسرة على مستوى الدولة ترتفع إلى نسبة أكثر اعتباراً تبلغ 81 بالمائة.

التحول إلى الأسرة النووية؟

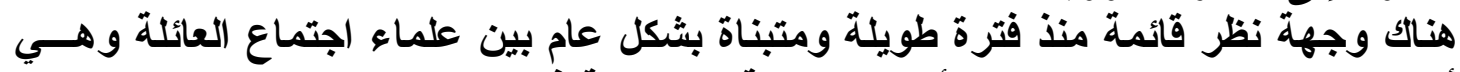

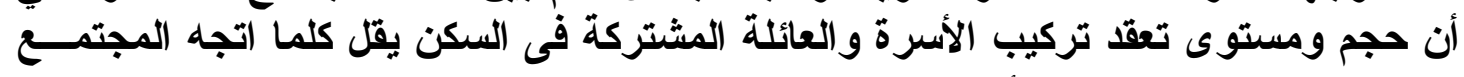

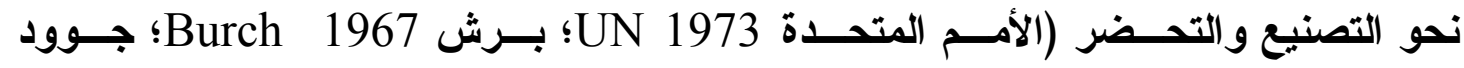

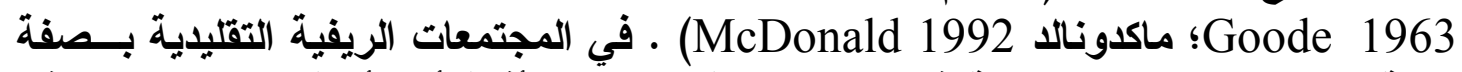

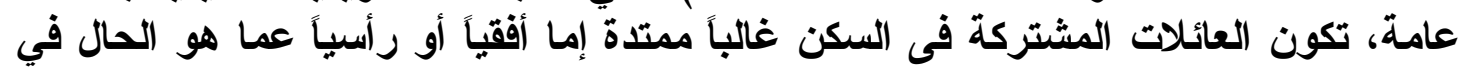

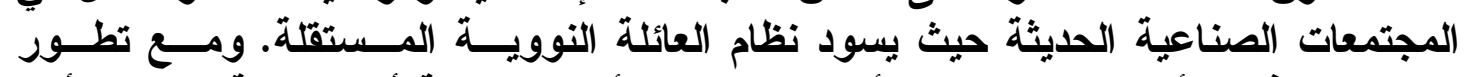

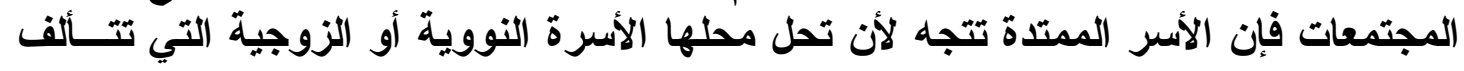

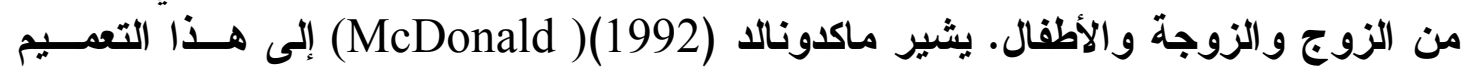

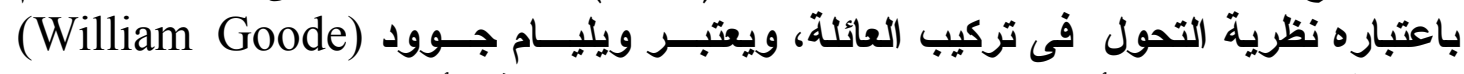

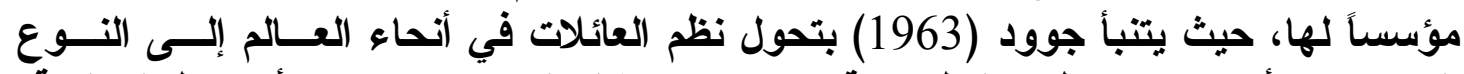

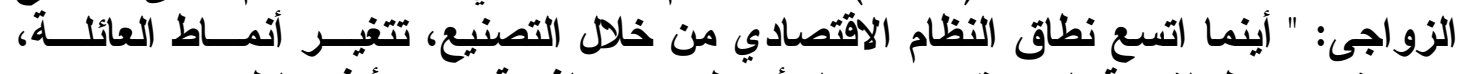

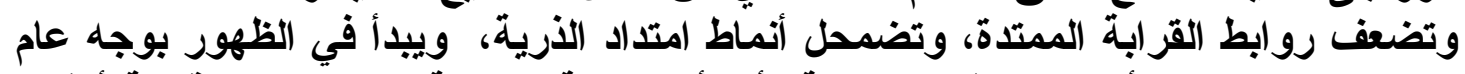

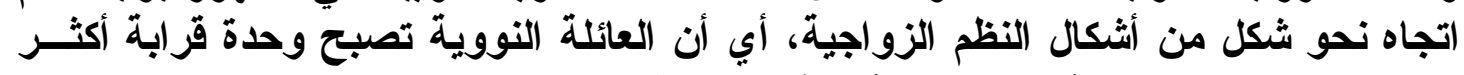

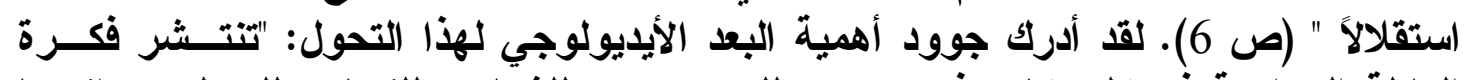

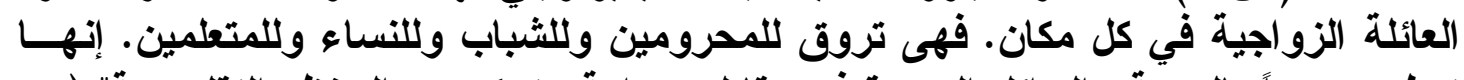

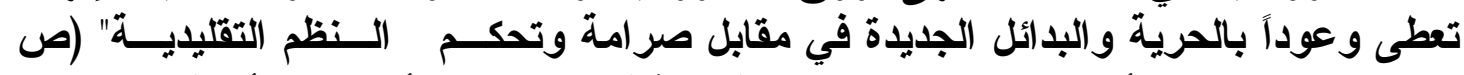

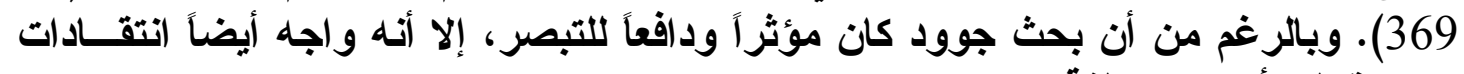
مستندة إلى أسس مختلفة.

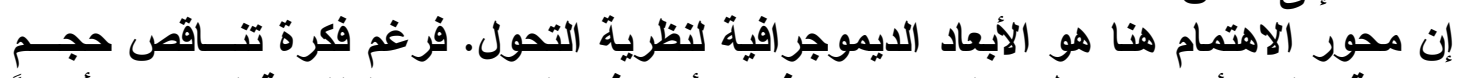

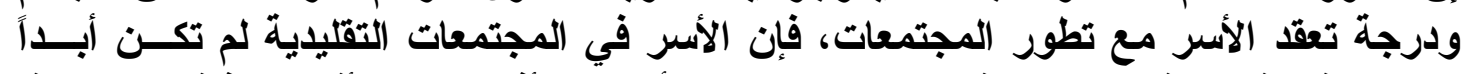

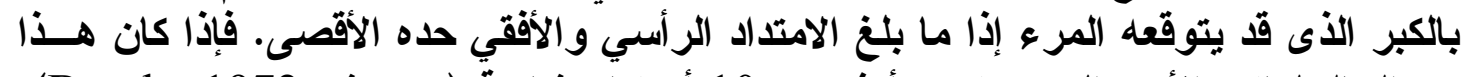

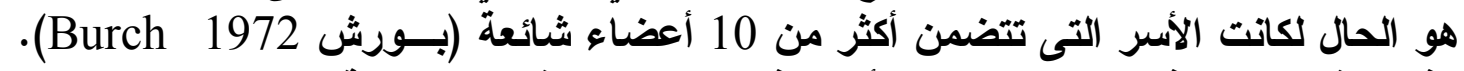

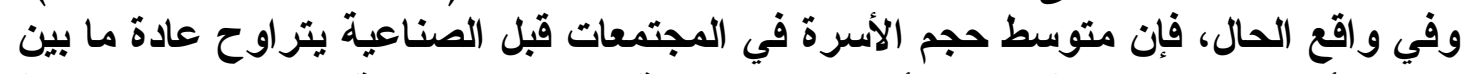

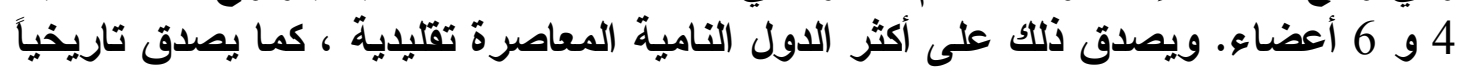


على المجتمعات الأوربية (لاسلت 1972). في حين يرى ليفي (1965) (Levy) أن قيــوداً

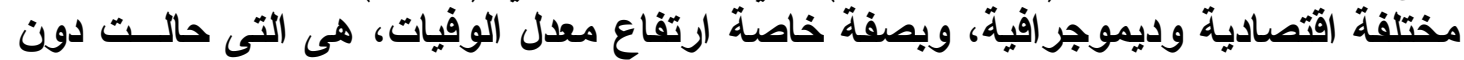

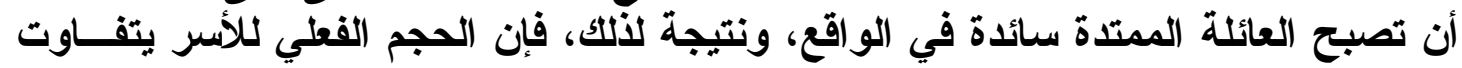
بلرجة أقلَ بكثير عن الأماط المثالية.

وبغض النظر عن القيود التي قد تكون حددت الأسر في الماضي، فهناك قليل من الثنك فــي التهي

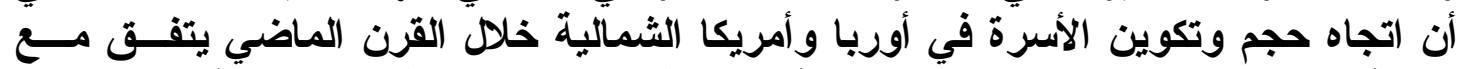

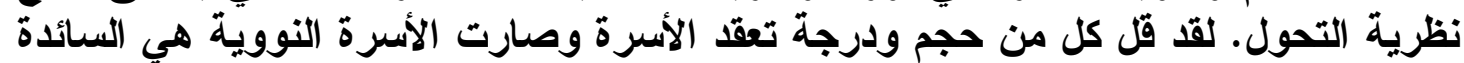

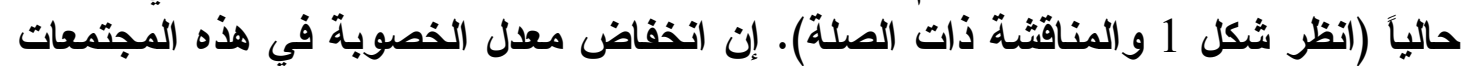

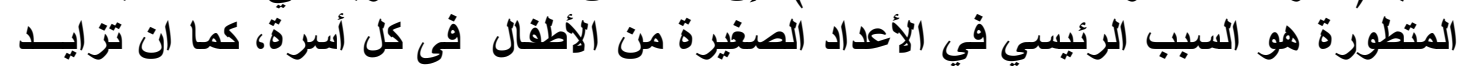

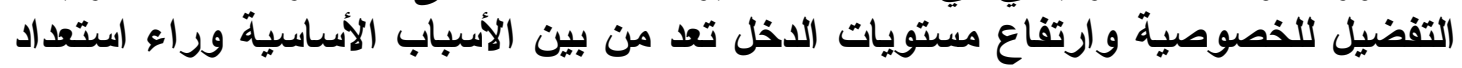

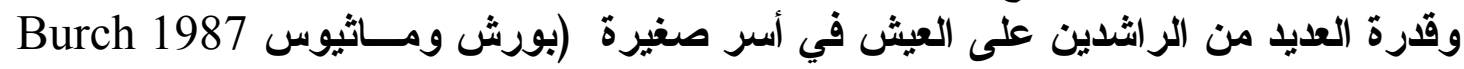
.(and Matthews

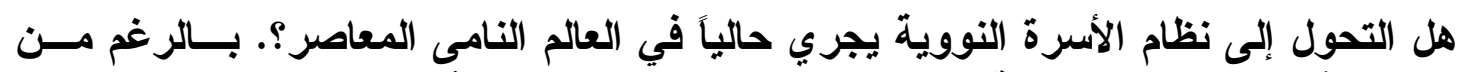

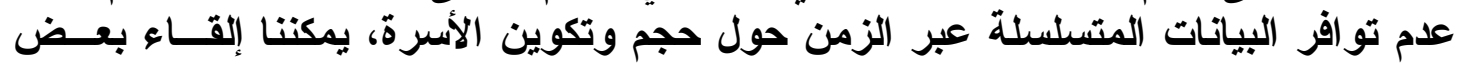

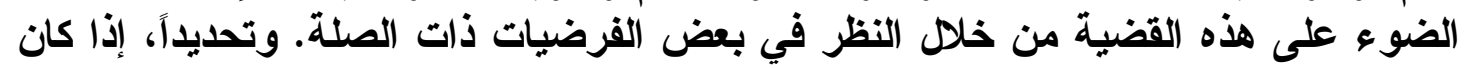

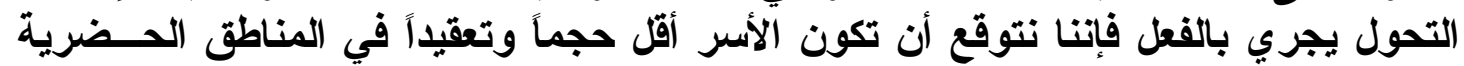

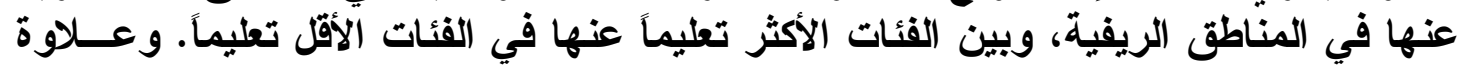

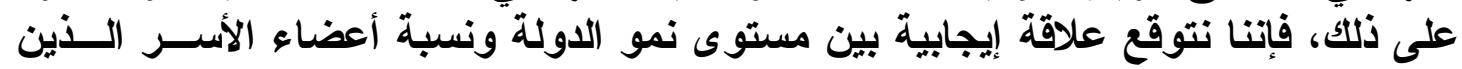

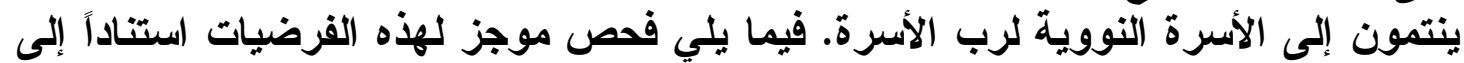
بيانات المسوح الايموجرافية والصحية.

التقاوت بين الدول

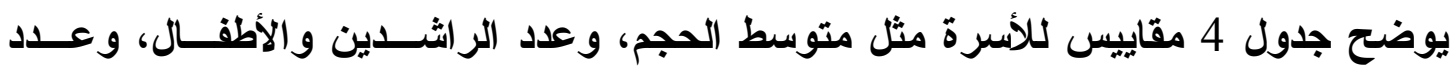

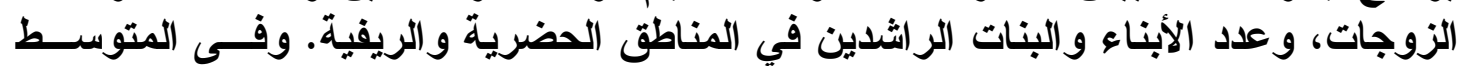

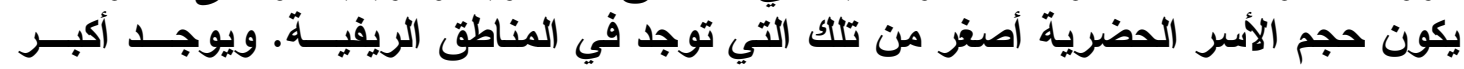

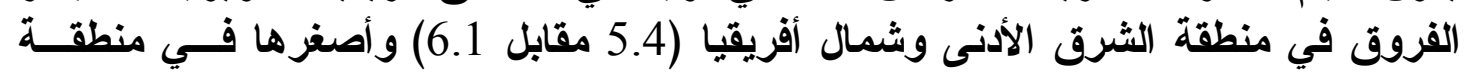

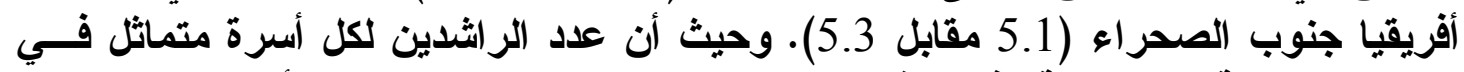

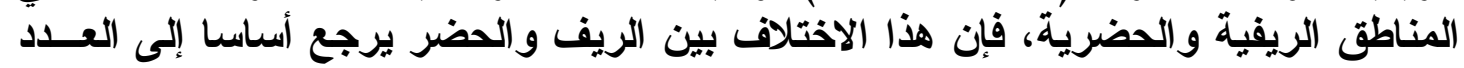

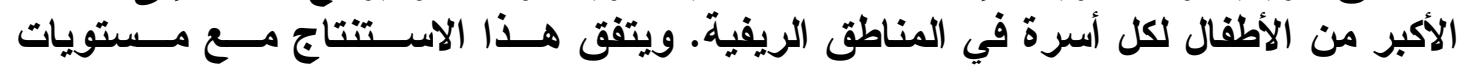

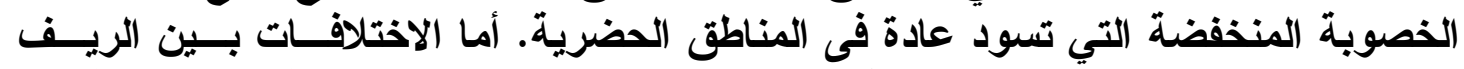

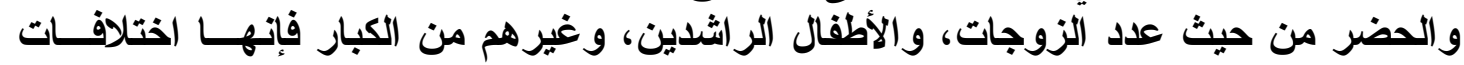
ضئيلة ولا تثنير إلى وجود نمط منتظم.

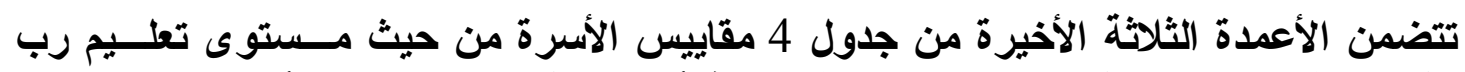

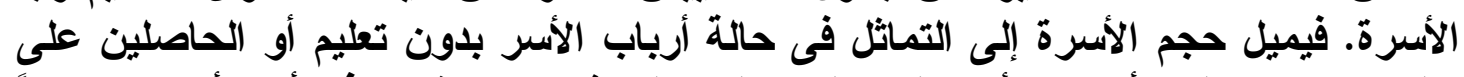

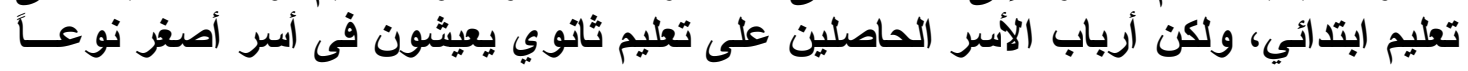




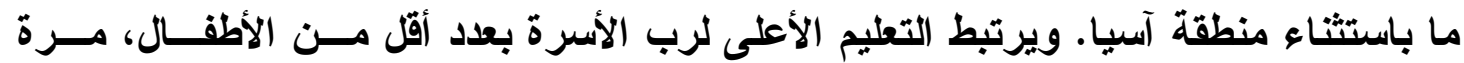

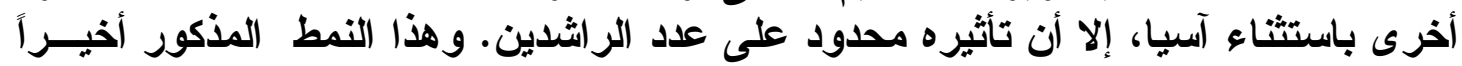

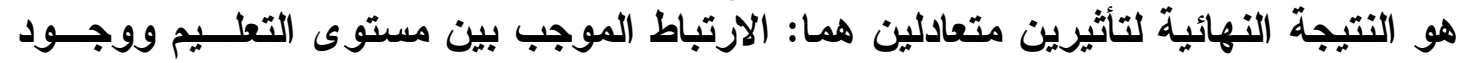

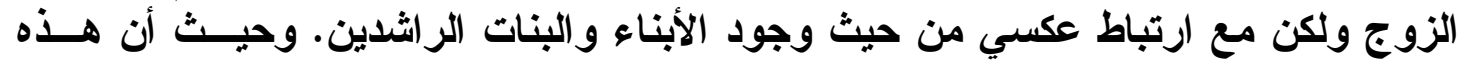

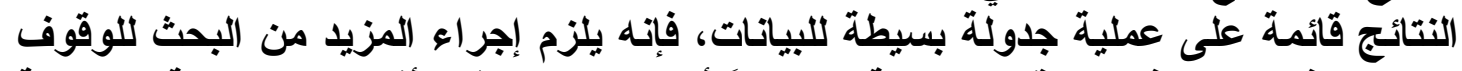

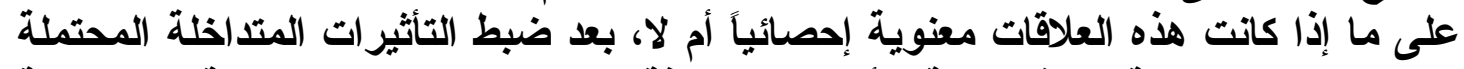

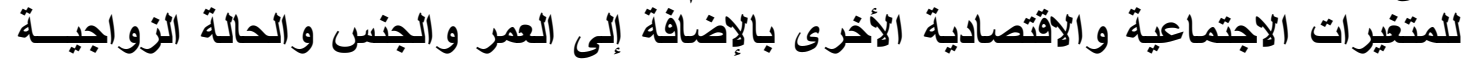

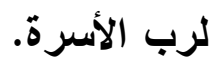

جدول 4 متوسط حجم مكونات الأسرة وفقاً لمكان الإقامة ومستوى تعليم رب الأسرة

\begin{tabular}{|c|c|c|c|c|c|c|}
\hline \multicolumn{3}{|c|}{ مستوى تعليم رب الأسرة } & \multicolumn{3}{|c|}{ مكان الإقامة } & \\
\hline ثُانوي & ابتدائي & لا يوجد & إجمالي & ريفي & حضري & \\
\hline & & & & & & حجم الأسرة \\
\hline 5.2 & 5.2 & 5.2 & 5.1 & 5.4 & 4.9 & آسيا \\
\hline 4.4 & 5.0 & 4.7 & 4.8 & 5.0 & 4.6 & أمريكا اللاتين \\
\hline 5.0 & 5.7 & 5.9 & 5.7 & 6.1 & 5.4 & الشرق الأدنح \\
\hline 5.0 & 5.3 & 5.2 & 5.3 & 5.3 & 5.1 & أفريقيا جنوب الصحراء \\
\hline & & & & & & عدد الأطفال \\
\hline 2.3 & 2.2 & 2.2 & 2.3 & 2.5 & 2.0 & آسيا \\
\hline 1.9 & 2.3 & 2.1 & 2.2 & 2.5 & 1.9 & أمريكا اللاتين \\
\hline 2.3 & 2.8 & 2.8 & 2.7 & 3.0 & 2.4 & الشرق الأدنح \\
\hline 2.5 & 2.8 & 2.7 & 2.8 & 2.9 & 2.5 & أفريقيا جنوب الصحراء \\
\hline & & & & & & عدد الراشدين \\
\hline 2.9 & 3.0 & 3.0 & 2.9 & 2.9 & 2.9 & آسيا \\
\hline 2.5 & 2.7 & 2.6 & 2.6 & 2.5 & 2.7 & أمريكا اللاتينب \\
\hline 2.7 & 2.9 & 3.1 & 2.9 & 3.0 & 3.0 & الثرق الأدنى/شمال أفريقيا \\
\hline 2.5 & 2.5 & 2.5 & 2.5 & 2.5 & 2.6 & أفريقيا جنوب الصحراء \\
\hline 0.8 & 0.7 & 0.6 & 0.8 & 0.8 & 0.8 & عدآ الأزواج \\
\hline 0.7 & 0.7 & 0.6 & 0.7 & 0.7 & 0.7 & أمريكا اللاتيني \\
\hline 0.9 & 0.9 & 0.8 & 0.8 & 0.8 & 0.8 & الثرق الأدنى"ثشمال أفريقيا \\
\hline 0.7 & 0.7 & 0.6 & 0.7 & 0.7 & 0.6 & أفريقيا جنوب الصحر اء \\
\hline 0.5 & 0.7 & 0.8 & 0.6 & 0.6 & 0.6 & عدد الأبناء/البنات الراشدين \\
\hline 0.3 & 0.6 & 0.7 & 0.5 & 0.5 & 0.6 & أميكا اللاد \\
\hline 0.3 & 0.5 & 0.9 & 0.7 & 0.7 & 0.8 & الثرة الأد \\
\hline 0.2 & 0.3 & 0.4 & 0.3 & 0.3 & 0.4 & أفريقيا جنوب الصحر اء \\
\hline
\end{tabular}




\begin{tabular}{|c|c|c|c|c|c|c|}
\hline & & & & & & عدد الراشدين الآخرين \\
\hline 0.6 & 0.6 & 0.6 & 0.5 & 0.5 & 0.5 & آسبيا \\
\hline 0.5 & 0.3 & 0.3 & 0.4 & 0.3 & 0.4 & أمريكا التلاتينية \\
\hline 0.5 & 0.5 & 0.5 & 0.4 & 0.5 & 0.4 & الشرق الأدنى/شمال أفريقيا \\
\hline 0.6 & 0.5 & 0.5 & 0.5 & 0.5 & 0.6 & أفريقيا جنوب الصحر اء \\
\hline
\end{tabular}

المصدر : تم حسابها من ملفات بيانات المسوح الديموجر افية و الصحية.

التفاوت بين الدول عند المستويات المختلفة للنمو

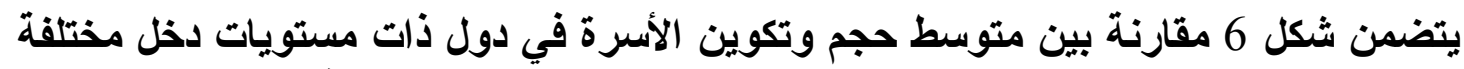

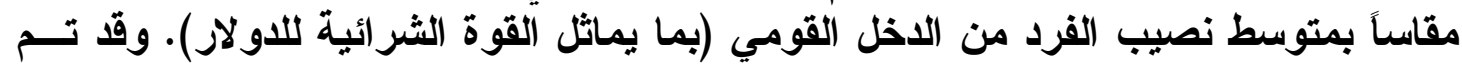

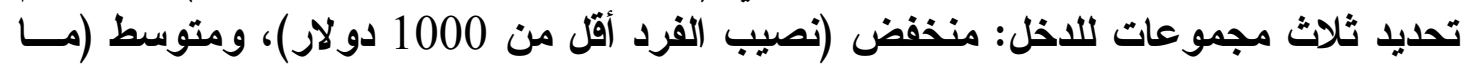

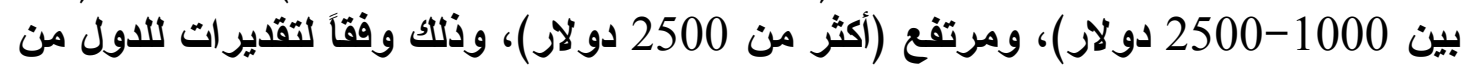

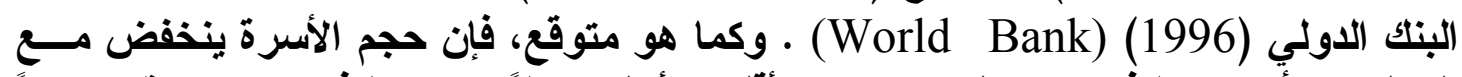

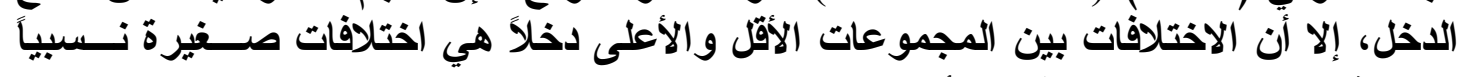

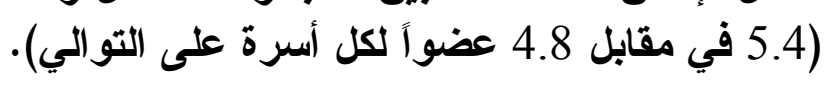

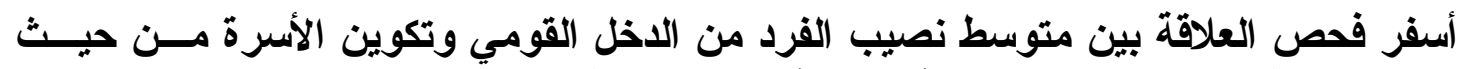

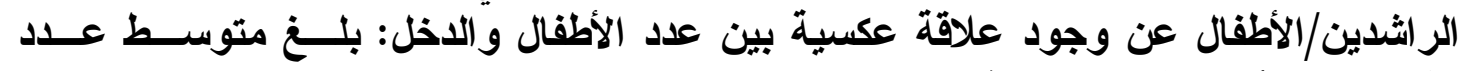

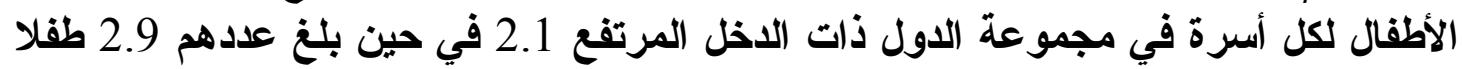

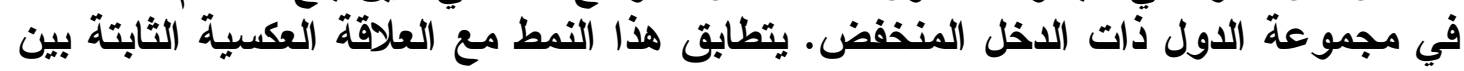

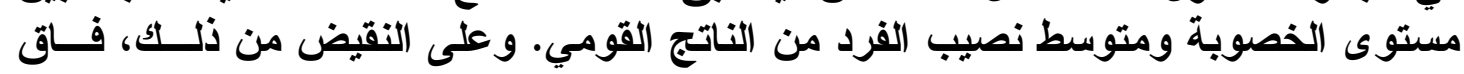

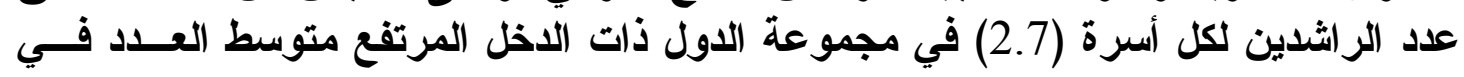

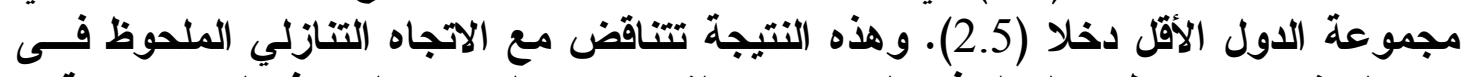

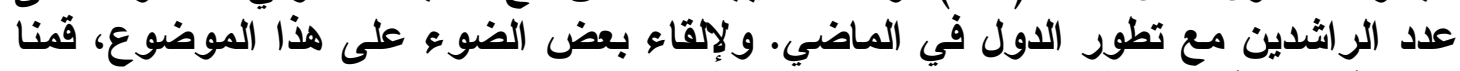

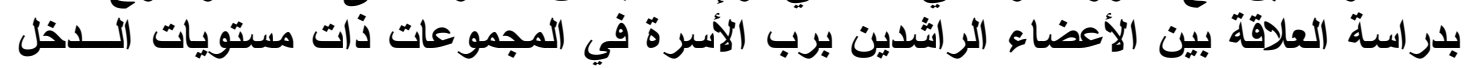

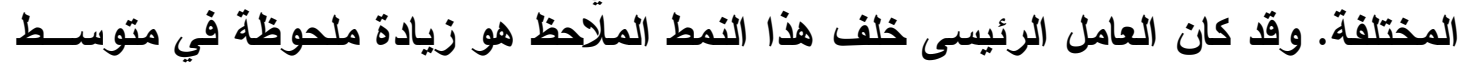

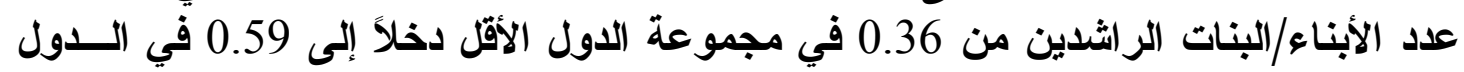

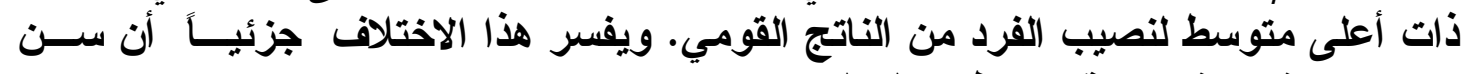
زواج الإناث يرتفع عادة مئو تطور الأول.

ارتفعت نسبة أعضاء الأسرة النووية (رب الأسرة، الزوج/الزوجة، الأطفال) قليلاً مــن 79

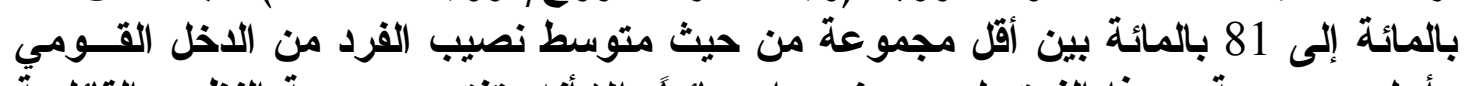

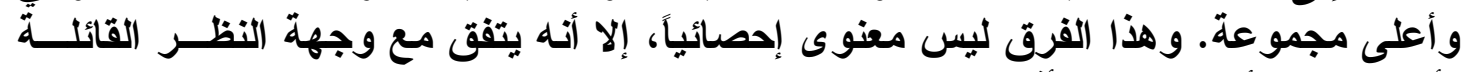
بأن تركيب الأسرة يصبح أقل تعقيدا كلما تطورت لئ المجتمعات.

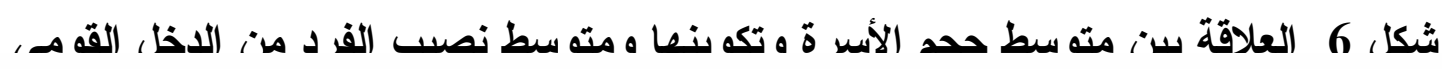
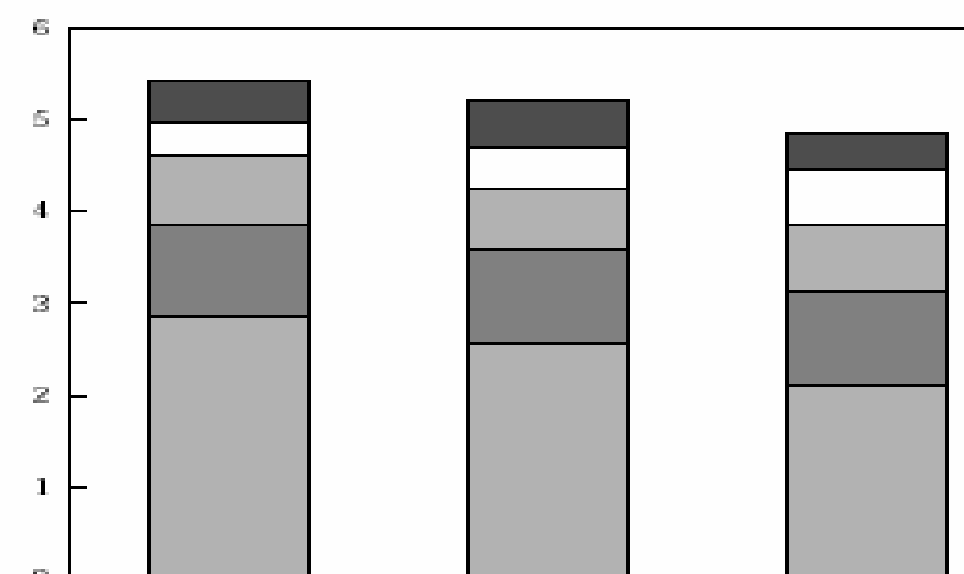


$$
\text { المصدر: بيانات المسح الديوجرافي والصحي، البنك الدولي (1996) }
$$

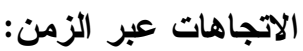

بالرغم من أن المسوح الديمجر افية والصحية لا توفر سلسلة من البيانات عن الأسرة عبر فترة ممتدة من

المصدر : ملفات بيانات المسوح الايموجر افية والصحية؛ البنك الدولى 1996.

$$
\text { الاتجاهات عبر الزمن }
$$

بالرغم من أن المسوح الايموجرافية الزية والصحية لا توفر سلسلة من البيانات عن الأسرة عبر

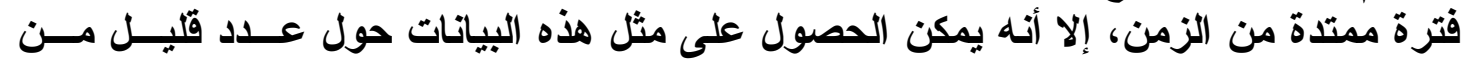

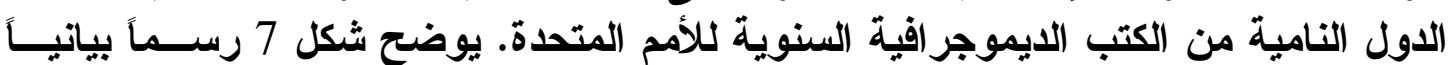

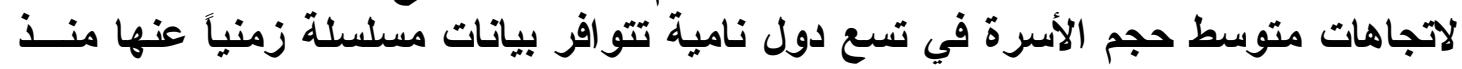

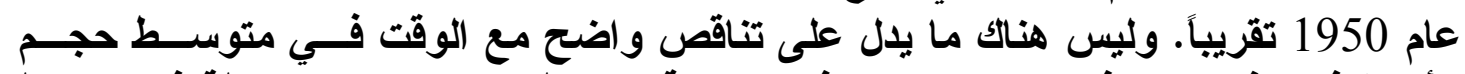

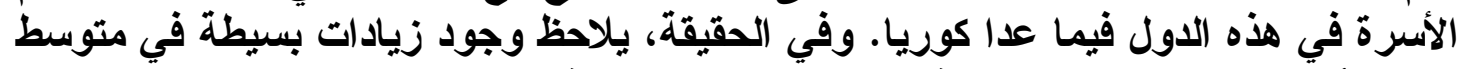

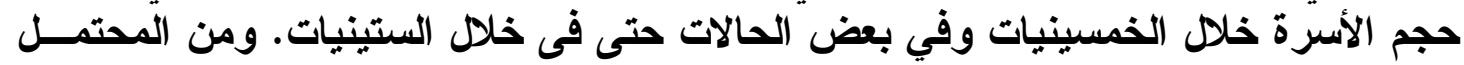

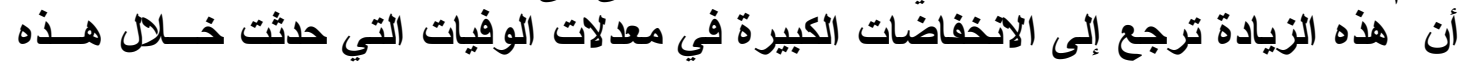

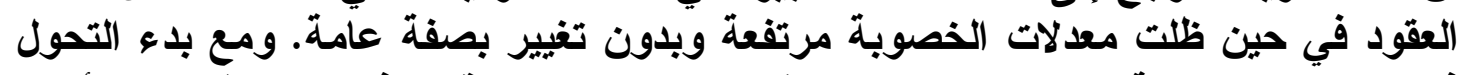

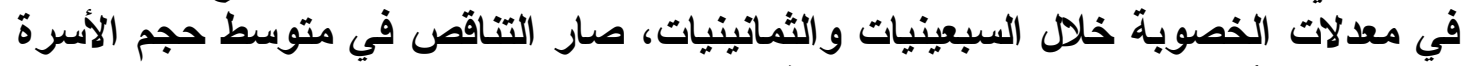

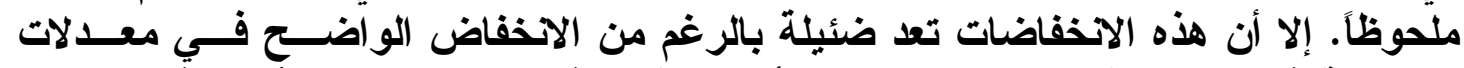

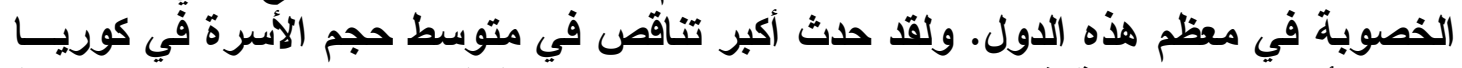

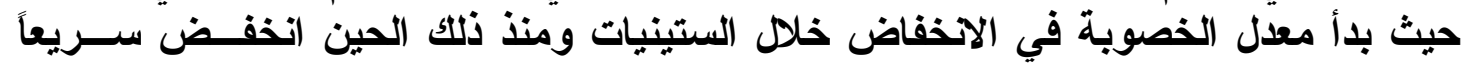
وبدرجة أكبر من الدول الأخرى المتضمنة في شكل فلاف 7.

شكل 7 اتجاهات متوسط حجم الأسرة في مجموعة مختارة من الدول النامية

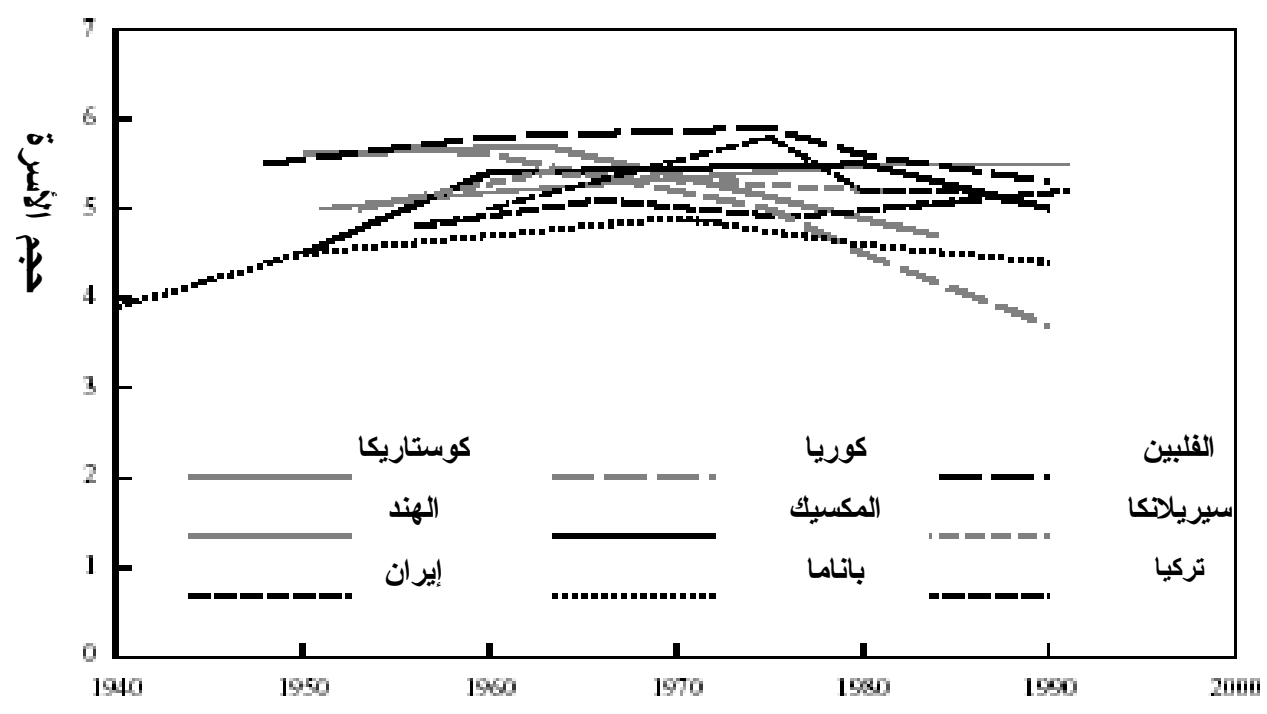


يمكن النظر بتعمق أكثر فى هذه الاتجاهات من خلال فحص تكوين الأسرة من حيث الراشدين

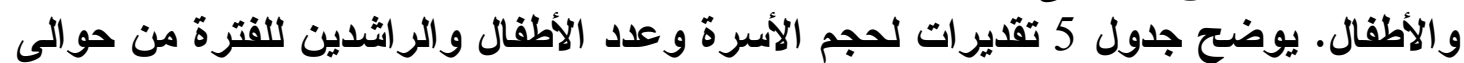

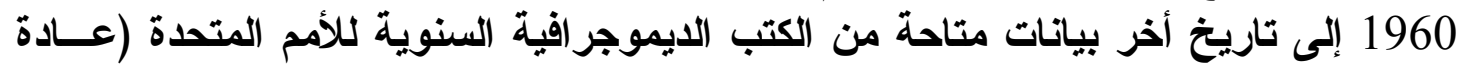

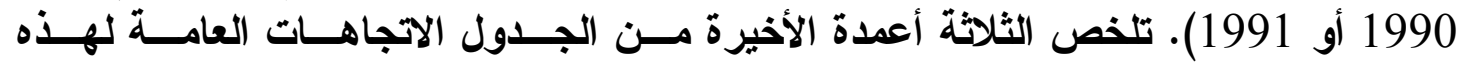

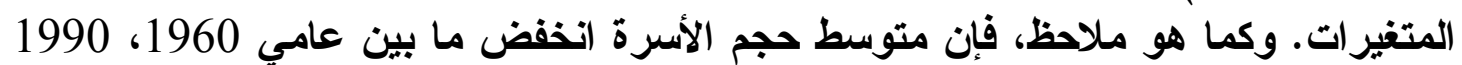

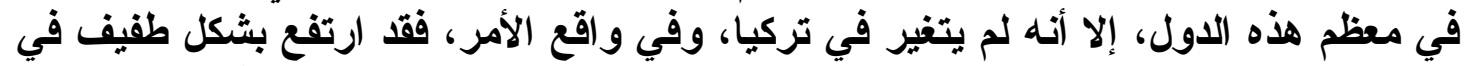

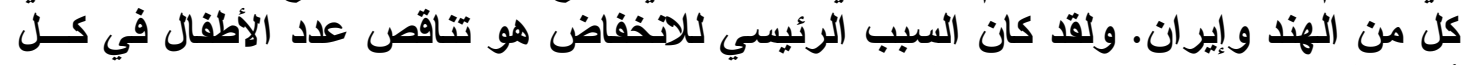

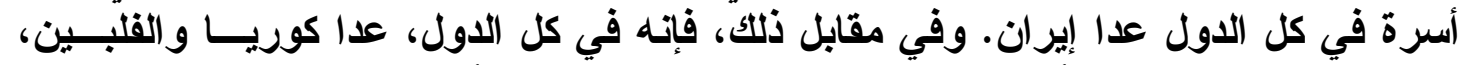

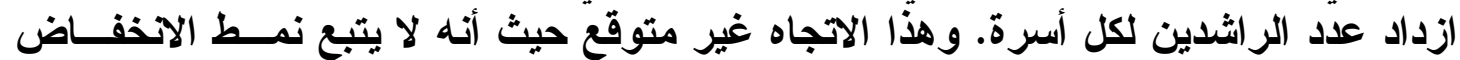

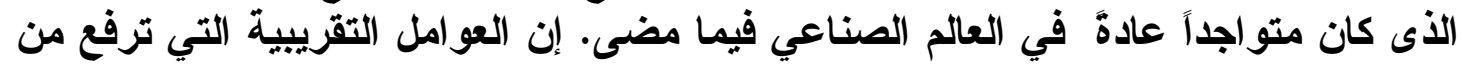

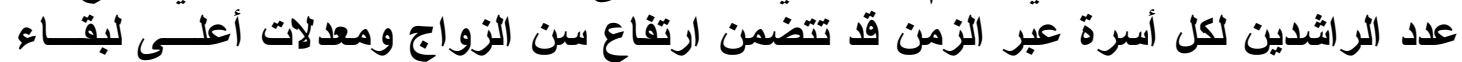

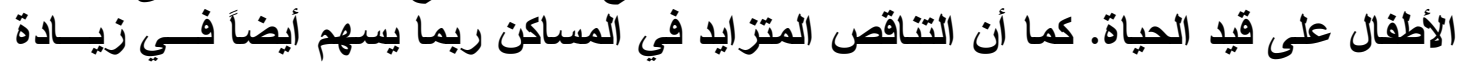
اتجاه الكبار للعيش معاً في هذه الدول.

جدول 5 اتجاهات متوسط حجم الأسرة وعدد الأطفال و الر اشثدين في مجموعة مختارة من الدول النامية

\begin{tabular}{|c|c|c|c|c|c|c|c|}
\hline \multicolumn{3}{|c|}{ الاتجاه في الفترة 1960- 1990} & \multicolumn{4}{|c|}{ عدد الأفر اد لكل أسرة } & \\
\hline الر اشدين & الأطفال & حجم الأسرة & إجمالي & الر الشدين & الأطفال & السنة & \\
\hline+ & - & $\begin{array}{ll}- \\
-\end{array}$ & 5.70 & 2.65 & 3.05 & 1963 & كوستاريكا \\
\hline & & & 4.70 & 2.66 & 2.04 & 1984 & \\
\hline+ & - & + & 5.20 & 2.83 & 2.37 & 1961 & الهند \\
\hline & & & 5.50 & 3.16 & 2.34 & 1991 & \\
\hline+ & + & + & 5.10 & 2.46 & 2.64 & 1966 & إيران \\
\hline & & & 5.20 & 2.52 & 2.68 & 1990 & \\
\hline- & - & - & 5.71 & 2.99 & 2.72 & 1960 & 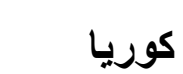 \\
\hline
\end{tabular}




\begin{tabular}{|c|c|c|c|c|c|c|c|}
\hline & & & 3.70 & 2.52 & 1.18 & 1990 & \\
\hline+ & - & - & $\begin{array}{l}5.40 \\
5.00\end{array}$ & $\begin{array}{l}2.65 \\
2.71\end{array}$ & $\begin{array}{l}2.75 \\
2.29\end{array}$ & $\begin{array}{l}1960 \\
1990\end{array}$ & المكسيك \\
\hline+ & - & - & $\begin{array}{l}4.70 \\
4.40\end{array}$ & $\begin{array}{l}2.40 \\
2.56\end{array}$ & $\begin{array}{l}2.30 \\
1.84\end{array}$ & $\begin{array}{l}1960 \\
1990\end{array}$ & باناما \\
\hline - & - & - & $\begin{array}{l}5.80 \\
5.30\end{array}$ & $\begin{array}{l}2.85 \\
2.83\end{array}$ & $\begin{array}{l}2.95 \\
2.47\end{array}$ & $\begin{array}{l}1960 \\
1990\end{array}$ & القلبين \\
\hline+ & - & - & $\begin{array}{l}5.40 \\
5.20\end{array}$ & $\begin{array}{l}2.83 \\
3.03\end{array}$ & $\begin{array}{l}2.57 \\
2.17\end{array}$ & $\begin{array}{l}1963 \\
1981\end{array}$ & سيريلانكا \\
\hline+ & - & & $\begin{array}{l}5.00 \\
5.00\end{array}$ & $\begin{array}{l}2.69 \\
2.92\end{array}$ & $\begin{array}{l}2.31 \\
2.08 \\
\end{array}$ & $\begin{array}{l}1960 \\
1990 \\
\end{array}$ & تركيا \\
\hline
\end{tabular}

المصدر : تم حسابها من ملفات بيانات المسوح الديموجرافية و الصحية.

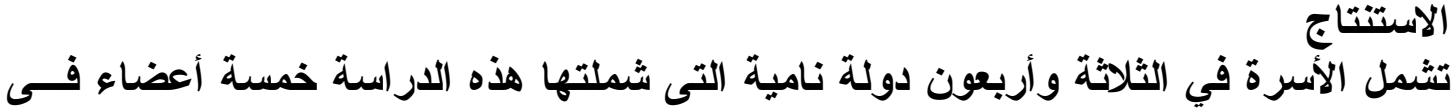

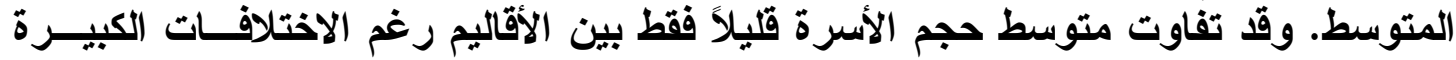

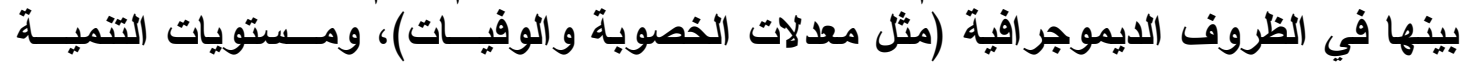

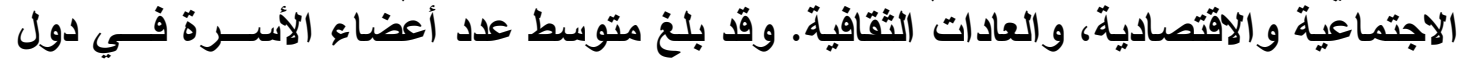

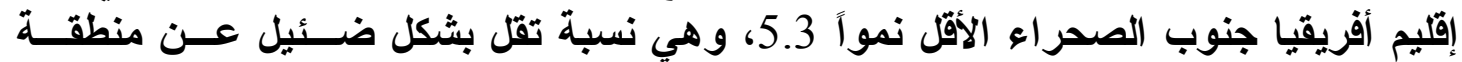

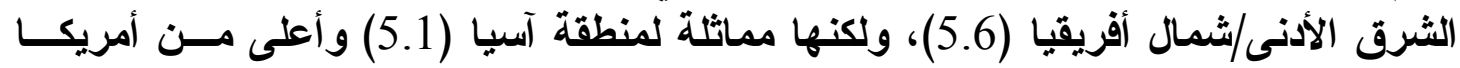

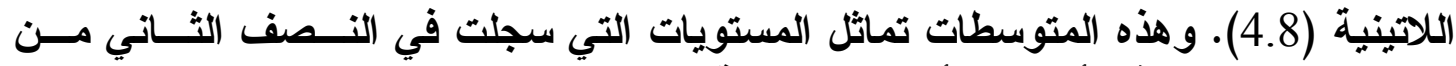
القرن التاسع عشر في أوروبا وأمريكا الشمالية.

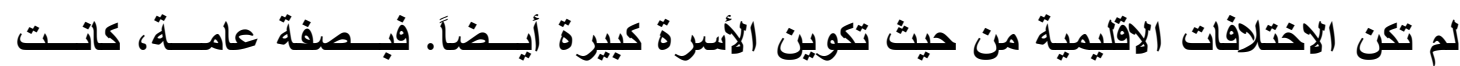

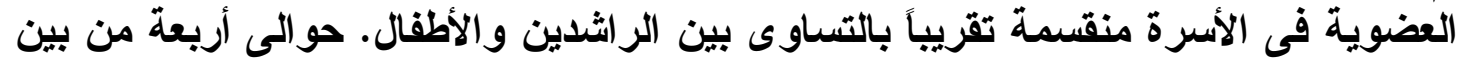

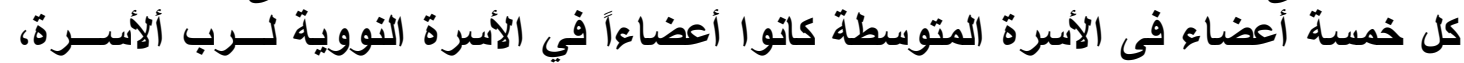

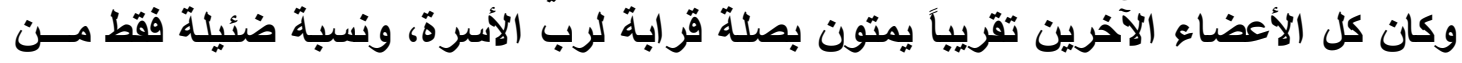

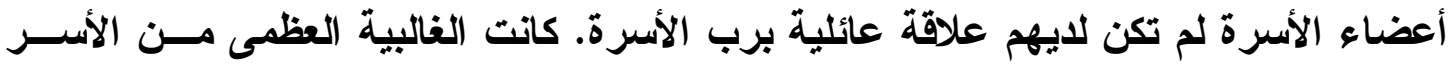

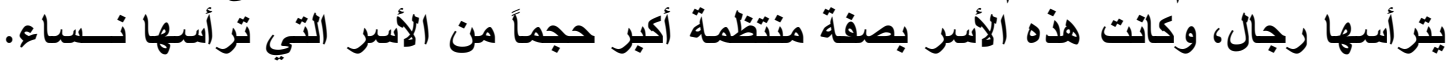

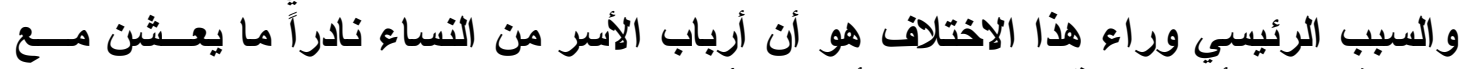
زوج في حين أن الغالبية العظمى من أرباب الأسر من الرجال يعيشون مع زوجاتهم.

وقد اتتهى فحص التفاوت الكبير في حجم الأسر وتركيبها على مستوى كل دولة إلى وجـــود

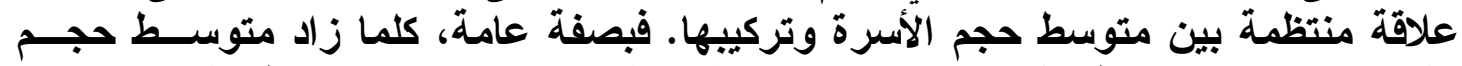

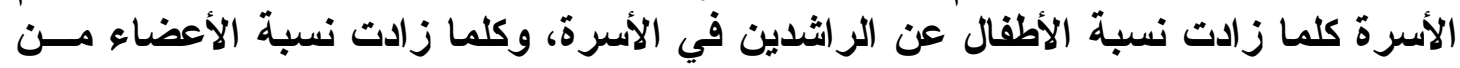

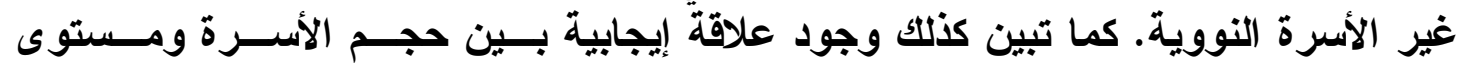


الخصوبة (المعدل تبعاً لنسبة بقاء الأطفال علي قيد الحياة) ومتوسط سن الزواجة مئه مع وجود

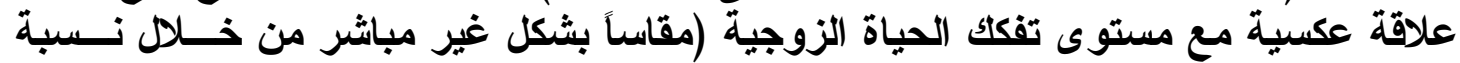

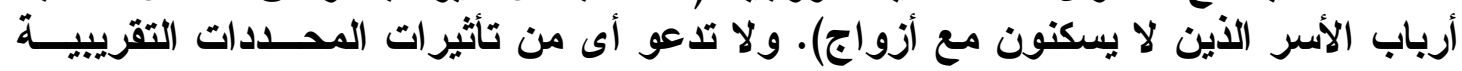

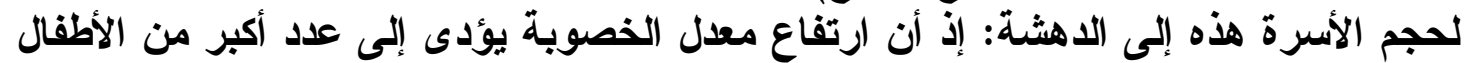

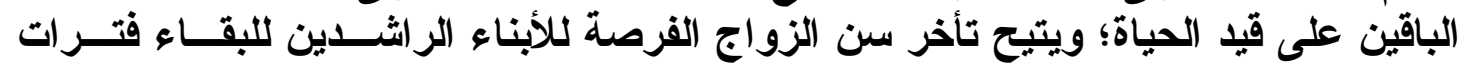

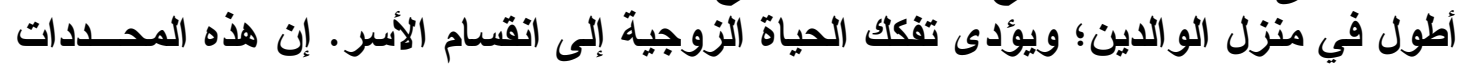

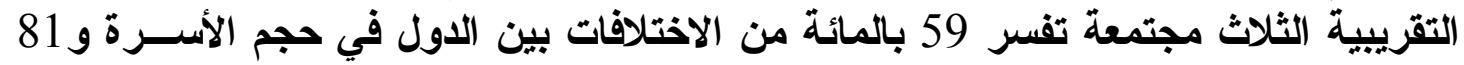

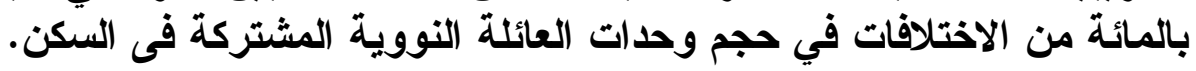

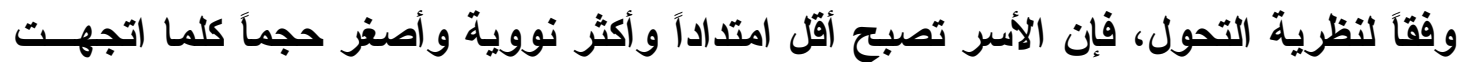

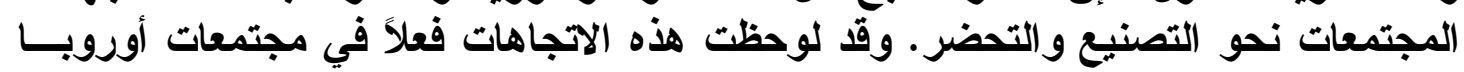

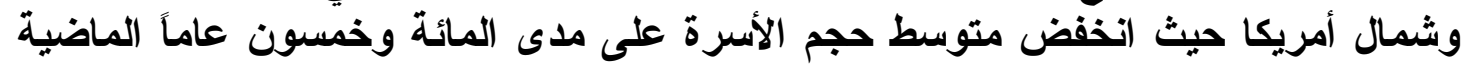

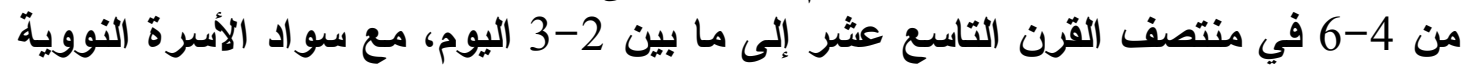

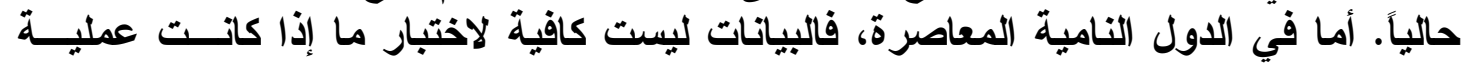

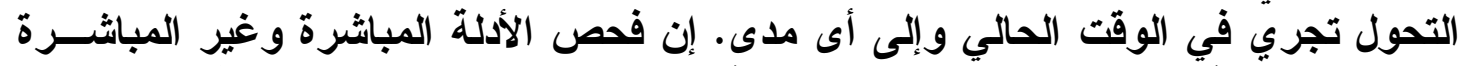

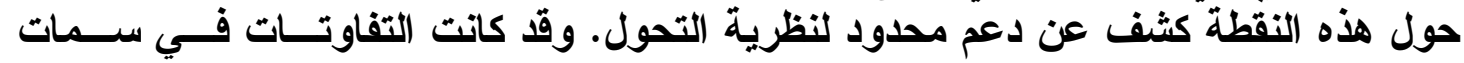

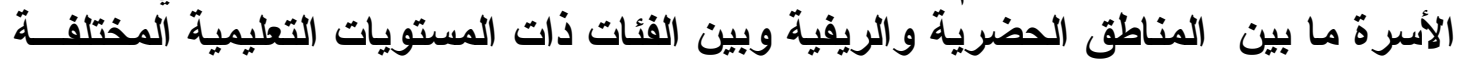

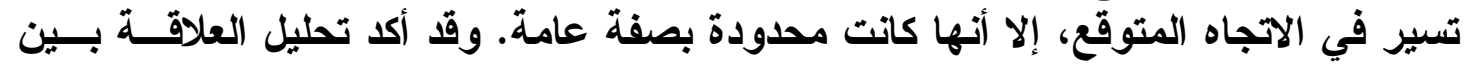

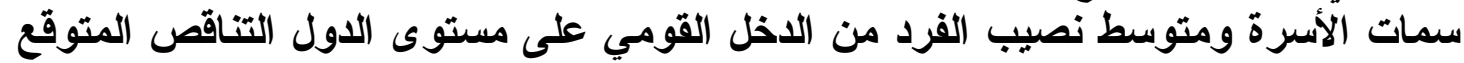

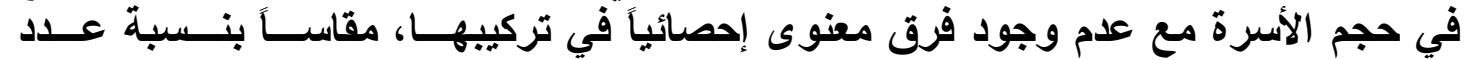

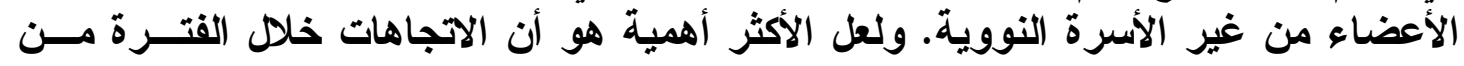

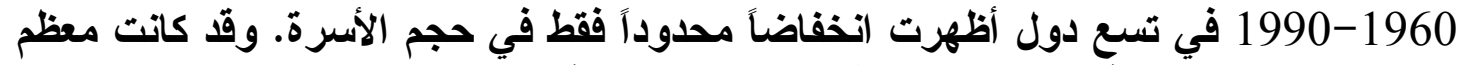

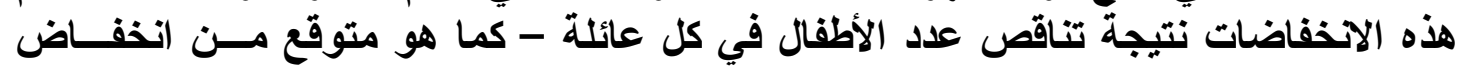

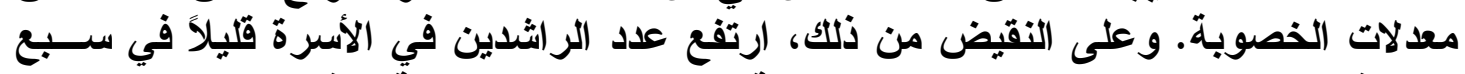

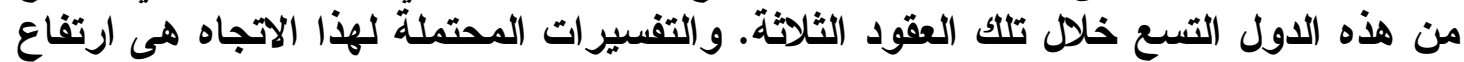

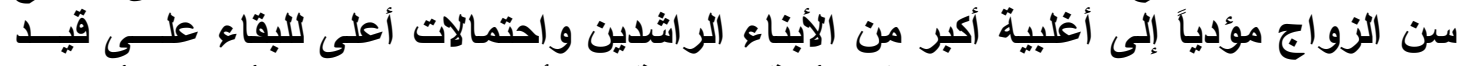

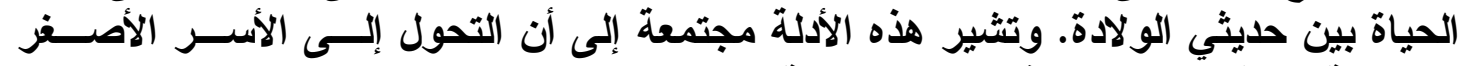
والنووية غالباً يتقّم ببطء في الدول وتئن النامية المعاصرة.

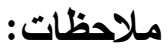

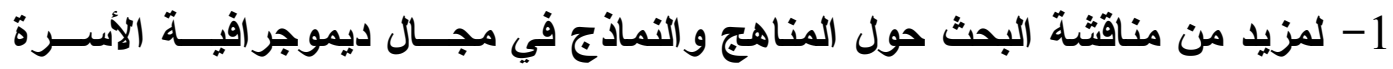

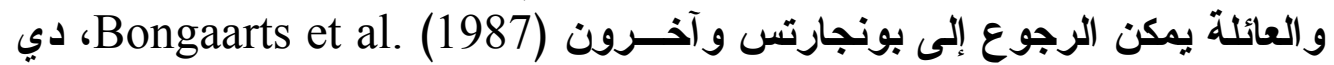

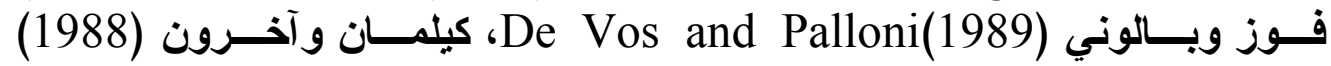
ونeilman et al.

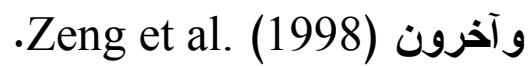
2- تم حساب تقدير 1998 للو لايات المتحدة الأمريكية بتطبيق قاعدة النسبة من إجمالي

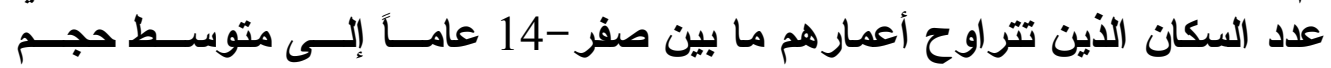
الأسرة. 
3- يعتبر كوزنتس Kuznets كل الأفراد فوق سن 14 عاماً من الراشدين. في تحليلتــا

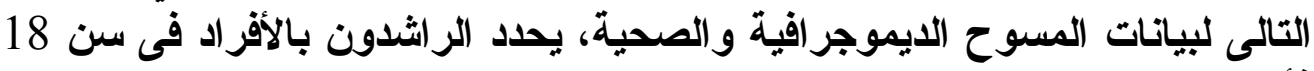

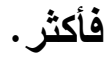

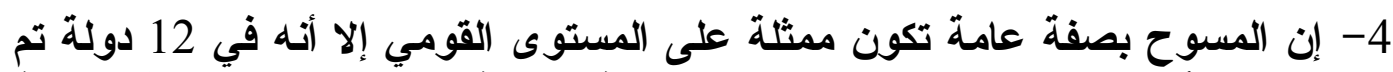

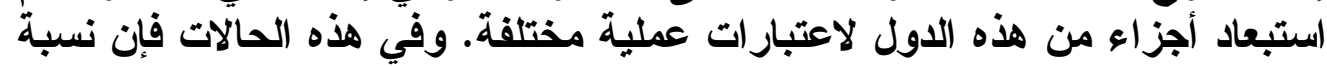

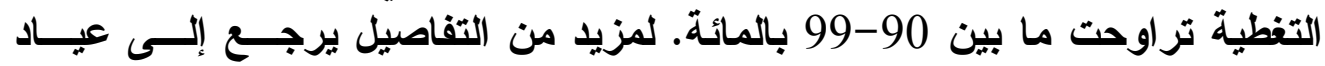

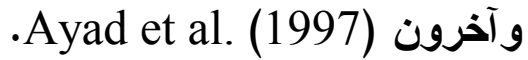

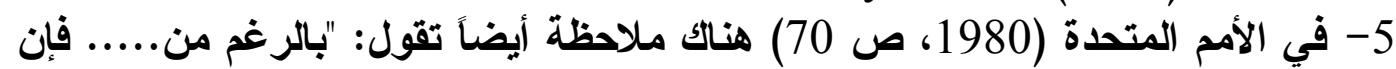

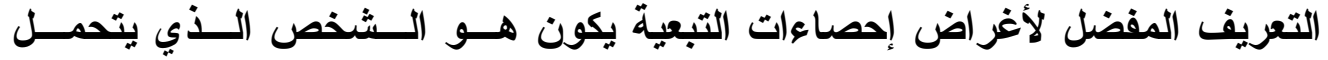

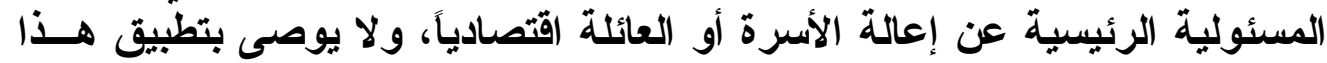

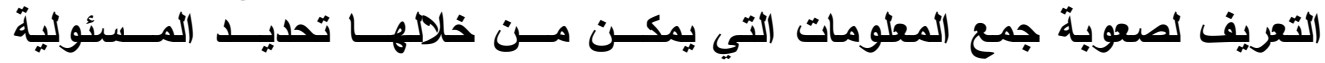
الاقتصنادية".

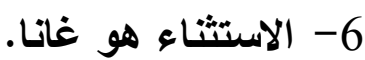
7- ت التضمن هذه الفئة الأفراد الذين يعيثون بمفردهم.

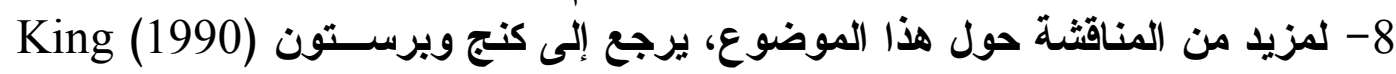
.and Preston 9- يشير مصطلح الهجرة إلى الحركة داخل وخارج الأسرة. و هذه الحركــة يمكـن أن تكون داخل المجتمع نفسه.

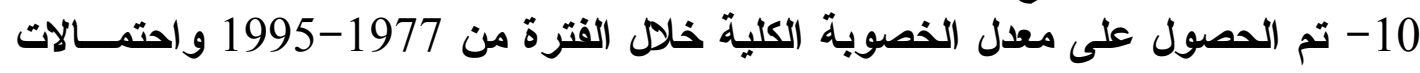

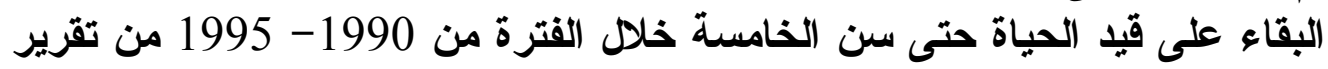

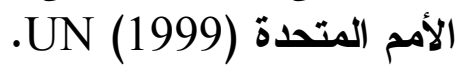
11- البيانات الخاصة بمتوسط سن زواج الئاج الذكور لم تكن متوفرة في عدد من الدول.

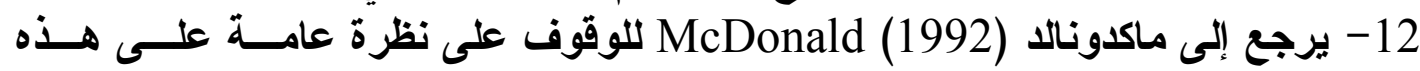

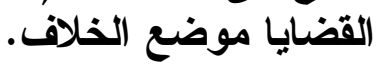

Armstrong, W.A. 1978. "The census enumerators' books: A commentary," in Richard Lawton (ed.), The Census and Social Structure: An Interpretative Guide to Nineteenth Century Censuses for England and Wales. London: Frank Cass.

Ayad, Mohamed, Bernard Barrere, and James Otto. 1997. Demographic and Socioeconomic Characteristics of Households. DHS Comparative Studies No. 26. 
Calverton, Maryland: Macro International Inc.

Becker, Gary S. 1991. A Treatise on the Family. Enlarged edition. Cambridge, MA: Harvard University Press.

Berquó, Elza and Peter Xenos. 1992. "Editors' introduction," in E. Berquó and P. Xenos (eds.), Family Systems and Cultural Change, pp. 812. New York: Oxford University Press.

Bongaarts, John. 1983. "The formal demography of families and households: An overview," IUSSP Newsletter no. 17 (January-April): $27-42$.

Bongaarts, John, Thomas K. Burch, and Kenneth W. Wachter (eds.). 1987. Family Demography: Methods and Their Application. Oxford: Clarendon Press.

Burch, Thomas K. 1967. "The size and structure of families: A comparative analysis of census data," American Sociological Review 32 (3): $347-363$.

Burch, Thomas K. 1972. "Some demographic determinants of average household size: An analytic approach," in P. Laslett, (ed.), Household and Family in Past Time, pp. 91-102. New York: Cambridge University Press.

Burch, Thomas K. 1979. "Household and family demography: A bibliographic essay," Population Index 45 (2): 173-195.

Burch, Thomas K. and Beverly J. Matthews. 1987. "Household formation in developed societies," Population and Development Review 13 (3): 495-511.

Demographic and Health Surveys. 1990. Interviewer's Manual for Use with Model "A" Questionnaire for High Contraceptive Prevalence Countries. DHS-II Basic Documentation Number 3. Institute for Resource Development/Macro International, Inc., Columbia Maryland.

De Vos, Susan. 1995. Household Composition in Latin America. New York: Plenum Press.

De Vos, Susan and Karen C. Holden. 1988. "On measuring living arrangements of older individuals in comparative studies," CDE Working 
Paper 88-09. University of Wisconsin-Madison, Center for Demography and Ecology.

De Vos, Susan and Alberto Palloni. 1989. "Formal models and methods for the analysis of kinship and household organization," Population Index 55 (2): 174-198.

Ermish, J.F. and Elizabeth Overton. 1985. "Minimal household units: A new approach to the analysis of household formation," Population Studies 39 (1): 33-54.

Goode, William J. 1963. World Revolution and Family Patterns. London: Free Press of Glencoe.

Keilman, Nico, Anton Kuijsten, and Ad Vossen (eds.). 1988. Modeling Household Formation and Dissolution. Oxford: Clarendon Press.

King, Miriam and Samuel H. Preston. 1990. "Who lives with whom? Individual versus household measures," Journal of Family History 15 (2): 117-132.

Kuznets, Simon. 1978. "Size and age structure of family households: Exploratory comparisons," Population and Development Review 4 (2): 187-223.

Laslett, Peter. 1972. "Introduction: The history of the family," in P. Laslett (ed.), Household and Family in Past Time. Cambridge: Cambridge University Press.

Le Bras, Hervé. 1979. Child and Family: Demographic Developments in the OECD Countries. Paris: OECD.

Levy, Marion. 1965. "Aspects of the analysis of family structure," in A.J. Coale and M. J. Levy (eds.), Aspects of the Analysis of Family Structure. Princeton: Princeton University Press.

Lloyd, Cynthia B. 1998. "Household structure and poverty: What are the connections?" in M. Livi-Bacci and G. De Santis (eds.), Population and Poverty in the Developing World, pp. 84-102. Oxford: Clarendon Press.

Lloyd, Cynthia B. and Niev Duffy. 1995. "Families in transition," in J. Bruce, C.B. Lloyd, and A. Leonard (eds.), Families in Focus: New 
Perspectives on Mothers, Fathers, and Children, pp. 5-23. New York: Population Council.

McDonald, Peter. 1992. "Convergence or compromise in historical change?" in E. Berquó and P. Xenos (eds.), Family Systems and Cultural Change, pp. 15-30. New York: Oxford University Press.

Ono-Osaki, Keiko. 1991. "Female headed households in developing countries: By choice or by circumstances?" in Demographic and Health Surveys World Conference, August 5-7, 1991, Proceedings, Vol. III. Columbia, Maryland: IRD/Macro International.

Ryder, Norman, B. 1977. "Models of family demography," Population Bulletin of the United Nations, No. 9, pp. 43-46.

Shryock, Henry S., Jacob S. Siegel, and Associates. 1973. The Methods and Materials of Demography. Washington, DC: US Department of Commerce, Bureau of the Census, vols. 1 and 2.

United Nations. 1956. Demographic Yearbook 1955. New York.

United Nations. 1964. Demographic Yearbook 1963. New York.

United Nations. 1973. The Determinants and Consequences of Population Trends: New Summary of Findings on Interaction of Demographic, Economic and Social Factors. New York.

United Nations. 1974. Demographic Yearbook 1973. New York.

United Nations. 1980. "Principles and recommendations for population and housing censuses," Statistical Papers, Series M. No. 67. New York.

United Nations. 1989. Demographic Yearbook 1987. New York.

United Nations. 1997. Demographic Yearbook 1995. New York.

United Nations. 1999. World Population Prospects: The 1998 Revision. Volume I: Comprehensive Tables. New York.

United Nations. 2000. World Marriage Patterns 2000. New York.

U.S. Census Bureau. 1999. Statistical Abstract of the United States: 1999. Washington, DC. 
van Imhoff, E. et al. (eds.). 1995. Household Demography and Household Modeling. New York: Plenum Press.

World Bank. 1996. From Plan to Market: World Development Report 1996. New York: Oxford University Press.

Zeng, Yi, James W. Vaupel, and Wang Zhenglian. 1998. "Household projection using conventional demographic data," in Frontiers of Population Forecasting, Supplement to Population and Development Review 24: 59-87. New York: Population Council.

POLICY RESEARCH DIVISION WORKING PAPERS

Recent Back Issues

1999

*120 John Bongaarts, "The fertility impact of changes in the timing of childbearing in the developing world." 
*121 James F. Phillips, Wendy L. Greene, and Elizabeth F. Jackson, "Lessons

from community-based distribution of family planning in Africa."

122 Mark R. Montgomery, "Mortality decline and the demographic response:

Toward a new agenda."

*123 Mark R. Montgomery, Mary Arends- Kuenning, and Cem Mete, "The quantity-quality transition in Asia."

124 Barbara S. Mensch, Wesley H. Clark, Cynthia B. Lloyd, and Annabel S.

Erulkar, "Premarital sex and school dropout in Kenya: Can schools make a difference?"

125 John Bongaarts and Rodolfo A. Bulatao, "Completing the demographic

transition."

126 Geoffrey McNicoll, "Population weights in the international order."

127 Cynthia B. Lloyd, Carol E. Kaufman, and Paul Hewett, "The spread of primary schooling in sub-Saharan Africa: Implications for fertility change."

128 John B. Casterline, "The onset and pace of fertility transition: National patterns in the second half of the twentieth century."

129 Mark R. Montgomery, Michele Gragnolati, Kathleen Burke, and Edmundo

Paredes, "Measuring living standards with proxy variables."

130 Bamikale Feyisetan and John B. Casterline, "Fertility preferences and contraceptive change in developing countries."

131 Martin Brockerhoff, "Urban growth in developing countries: A review of

projections and predictions."

132 Omaima El-Gibaly, Barbara Ibrahim, Barbara S. Mensch, and Wesley $\mathrm{H}$. 
Clark, "The decline of female circumcision in Egypt: Evidence and interpretation."

133 Mary Arends-Kuenning and Sajeda Amin, "The effects of schooling incentive programs on household resource allocation in Bangladesh."

134 John Bongaarts and Charles F. Westoff, "The potential role of contraception

in reducing abortion."

135 John B. Casterline and Steven W. Sinding, "Unmet need for family planning in developing countries and implications for population policy."

*136 Carol E. Kaufman, Thea de Wet, and Jonathan Stadler, "Adolescent pregnancy and parenthood in South Africa."

137 Valerie L. Durrant and Zeba A. Sathar, "Greater investments in children through women's empowerment: A key to demographic change in Pakistan?"

138 Sajeda Amin, Alaka Malwade Basu, and Rob Stephenson, "Spatial variation in contraceptive use in Bangladesh: Looking beyond the borders."

139 Geoffrey McNicoll, "Managing population- environment systems: Problems of institutional design."

140 Barbara S. Mensch, Barbara L. Ibrahim, Susan M. Lee, and Omaima El-

Gibaly, "Socialization to gender roles and marriage among Egyptian adolescents."

141 John Bongaarts and Elof Johansson, "Future trends in contraception in the developing world: Prevalence and method mix."

142 Alaka Malwade Basu and Sajeda Amin, "Some preconditions for fertility decline in Bengal: History, language identity, and an openness to innovations." 
143 Zeba Sathar, Cynthia B. Lloyd, Cem Mete, and Minhaj ul Haque, "Schooling opportunities for girls as a stimulus for fertility change in rural Pakistan."

2001

144 John Bongaarts, "Household size and composition in the developing world."

* No longer available 